\title{
Global Equity MARKet Volatility SPIllovers: A Broader Role For the United States*
}

\author{
DANIEL BUNCIC" \\ Institute of Mathematics $\mathcal{E}$ Statistics \\ University of St. Gallen \\ Switzerland
}

\author{
KATJA I. M. GISLER \\ School of Economics \& Political Science \\ University of St. Gallen \\ Switzerland
}

First Version: March 5, 2015

This Version (rv.int.3b): March 18, 2015

\begin{abstract}
Rapach et al. (2013) have recently shown that U.S. equity market returns carry valuable information to improve return forecasts in a large cross-section of international equity markets. In this study, we extend the work of Rapach et al. (2013) and examine if U.S. based equity market information can be used to improve realized volatility forecasts in international equity markets. For that purpose, we obtain volatility data for the U.S. and 17 international equity markets from the Oxford Man Institute's realized library and augment for each foreign equity market the benchmark HAR model with lagged U.S. equity market volatility information. In-sample as well as out-of-sample evaluation results suggest a strong role for U.S. based volatility information. More specifically, apart from standard in-sample tests, which find U.S. volatility information to be highly significant, we show that this information can be used to substantially improve out-of-sample forecasts of realized volatility. Using large out-of-sample evaluation periods containing at least 2500 observations, we find that forecast improvements, as measured by the out-of-sample $R^{2}$ (relative to a model that does not include U.S. based volatility information), can be as high as $12.83,10.43$ and 9.41 percent for the All Ordinaries, the Euro STOXX 50 and the CAC 40 at the one-step-ahead horizon. Moreover, forecast improvements are highly significant at the one-step-ahead horizon for all 17 equity markets that we consider, yielding Clark-West adjusted $t$-statistics of over 7 . We show further that the improvements from including U.S. based volatility information are consistently experienced over the entire out-of-sample period that we consider, and hold for forecast horizons of up to 22 days ahead.
\end{abstract}

Keywords: Realized Volatility, HAR modelling and forecasting, augmented HAR model, U.S. volatility information, VIX, international volatility spillovers.

JEL Classification: C22, C52, C53, E17, F31, G17.

\footnotetext{
${ }^{\star}$ We are grateful to Francesco Audrino and Matthias Fengler for helpful comments and discussions on an earlier version of the paper.

"Corresponding Author: Institute of Mathematics and Statistics, Bodanstrasse 6, 9000 St. Gallen, Switzerland. Tel: +41 (71) 224 2604. Email: daniel.buncic@unisg.ch. Web: http:/ / www.danielbuncic.com.

上Email: katja.gisler@unisg.ch.
} 


\section{Table of Contents}

1 Introduction $\quad 3$

2 Modelling volatility 6

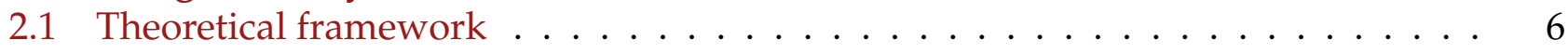

2.2 Empirical volatility model . . . . . . . . . . . . . . . . 7

3 Data $r$

4 Assessing the value of U.S. volatility 12

4.1 In-sample evaluation . . . . . . . . . . . . . . . . . . . . . . . . 13

4.2 Out-of-sample forecast evaluation . . . . . . . . . . . . . . . . . . . . . . . . . . . . . . . .

4.2 .1 Prediction setting . . . . . . . . . . . . . . . . . 14

4.2 .2 Evaluation criteria $\ldots \ldots \ldots \ldots$

4.2 .3 Forecast evaluation results . . . . . . . . . . . . . 18

5 Robustness checks $\quad 22$

5.1 Varying the size of the in-sample period . . . . . . . . . . . . . . . . 22

5.2 Using the DJIA as the headline U.S. index . . . . . . . . . . . . . . . . . . . . . . . . . . . . . . . .

5.3 Is the VIX driving all the forecast improvement results? . . . . . . . . . . . . . . 24

6 Conclusion $r$

$\begin{array}{lr}\text { References } & 27\end{array}$

$\begin{array}{lr}\text { Figures and Tables } & 31\end{array}$

$\begin{array}{lr}\text { Appendix } & \text { A-1 }\end{array}$

A.1. Robustness checks . . . . . . . . . . . . . . . . . . A A-1 
'... since the U.S. equity market is the world's largest, investors likely focus more intently on this market, so that information on macroeconomic fundamentals relevant for equity markets worldwide diffuses gradually from the U.S. market to other countries' markets.' (Rapach et al., 2013, page 1635)

\section{Introduction}

In a recent influential paper, Rapach et al. (2013) have shown that equity market returns of the United States (U.S.) have significant predictive power to forecast equity returns in a large crosssection of international equity markets. This predictive power is attributed to the leading role that the U.S. plays in generating (relevant) macroeconomic as well as financial information to both U.S. and non-U.S. investors. Rapach et al. (2013) argue that, due to information frictions, information diffuses only gradually from the U.S. to other equity markets around the world, thereby generating predictive content in lagged U.S. returns. The U.S. is the world's largest economy, is an important and large trading partner to many countries, and has the world's largest equity market in terms of market capitalization. When forming investment decisions, investors with a global investment perspective in mind are therefore intently focused not only on developments in macroeconomic and financial fundamentals in the U.S., but also on the formation of expectations and risk premia that come out of this process. ${ }^{1}$

The objective of this study is to provide a first comprehensive analysis of the predictive content of U.S. based equity market volatility information on realized volatility forecasts in a large cross-section of 17 international (non-U.S.) equity markets. For this purpose, we use daily realized volatility data from the Oxford Man Institute's realized library and augment the well known and widely used Heterogeneous Autoregressive (HAR) model of Corsi (2009) with (lagged) daily, weekly and monthly U.S. HAR components as well as log VIX data. We use the HAR model of Corsi (2009) as our benchmark realized volatility model to measure the contribution of U.S. based volatility information on realized volatility forecasts in non-U.S. equity markets, considering standard in-sample as well as out-of-sample evaluation criteria. In this context, our study can be viewed as a natural extension of the work by Rapach et al. (2013), nevertheless, with the focus of our analysis being on what role the U.S. plays as a source of volatility information. We find an overwhelmingly strong role for U.S. based volatility information for all 17 international equity markets that we consider.

Our study is related to a growing realized volatility spillover literature. Contributions to this literature typically differ in their definition of the interdependence measure adopted and include recent studies by Bonato et al. (2013), Diebold and Yilmaz (2014a,b), Fengler and Gisler (2015) among others. Diebold and Yilmaz $(2014 a, b)$ model realized volatility as a vec-

\footnotetext{
${ }^{1}$ The dominant role of the U.S. market as a source of both return and volatility transmission in international equity markets has been documented in numerous multi-country studies (see, for example, Engle (1990), Hamao et al. (1990), King and Wadhwani (1990), Lin et al. (1994), Becker et al. (1995) and others).
} 
tor autoregressive (VAR) process and define volatility spillovers based on a multiple-stepsahead forecast-error variance decomposition. Their results suggests strong realized volatility spillovers across banks, particularly during crises periods. Using a similar approach, Fengler and Gisler (2015) extend the results from Diebold and Yilmaz (2012, 2014a) by including realized covariances in the spillover transmission mechanism. They show that realized covariance spillovers are substantial and allow for an earlier detection of the recent financial and debtceiling crises attributable to a flight-to-quality phenomenon. Bonato et al. (2013), on the other hand, define spillovers as the dependence of realized covariance on past realized covariance. They model realized covariance as a Wishart autoregressive process and find that sector- and currency covariance spillovers improve the forecasting performance. Similarly, Dimpfl and Jung (2012) model realized volatility spillovers around the globe in a structural VAR framework and find substantial improvements in return and realized volatility forecasts. ${ }^{2}$

Although our study is related to the volatility spillover literature, we intentionally avoid the use of (structural) VAR or multivariate GARCH type of approaches to model the information flow from the U.S. to international (non-U.S.) equity markets. The reasons for this are as follows. First, multivariate GARCH models are difficult to estimate for large cross-sections of volatility. Second, standard structural VAR models require an assumption on the causal ordering if impulse responses or forecast error variance decompositions are used as measures of spillovers. This may not be problematic for smaller VARs where the causal ordering is known from an underlying assumption regarding which equity market generates the most important information, ie., the U.S., for instance. Nevertheless, since we consider realized volatility data for 17 international equity markets, it becomes much more difficult to justify the ordering of the countries in the VAR. Third, estimating (unrestricted) VARs on realized volatility for a large number of variables is highly inefficient and makes out-of-sample predictions inaccurate. We thus prefer to examine the role of the U.S. as a source of volatility information within the simple augmented HAR model framework.

Using daily realized volatility data for the U.S. and 17 international equity markets, covering a period from January 3, 2000 to January 23, 2015, we find a strong role for the U.S. equity market as a source of volatility information. Considering three in-sample fitting periods, ie., full sample, and pre and post Lehman Brothers collapse, our in-sample results show that U.S. based volatility information is (jointly) highly significant, resulting in $p$-values that are virtually 0 . The log VIX as well as the daily and monthly U.S. HAR components are the most important sources of volatility information from the U.S. equity market. For some equity markets such as the All Ordinaries and the EURO STOXX 50, the parameter estimate of the daily U.S. HAR component has a larger magnitude than its own daily HAR component, suggesting that the

\footnotetext{
${ }^{2}$ Modelling spillover effects has also a much broader role in the financial stability literature. For instance, given the role of U.S. volatility and an interconnected world, it may be important to account for U.S. based information when designing macro-prudential stress tests, in particular for Eastern European countries. See, for instance, Buncic and Melecky (2013) for a recent study on how this could be implemented.
} 
previous day's high frequency volatility information from the U.S. is more important than its own lagged volatility. One interesting finding of our in-sample analysis is a negative feedback effect from the low frequency volatility component from the U.S. to realized volatility in nonU.S. equity markets. This finding is consistent across all of the 17 international equity markets that we consider.

Our results show further that the important role of U.S. based volatility information for international equity markets holds also out-of-sample. Using a standard expanding (recursive) estimation window of 500 in-sample observations (leaving at least 2500 out-of-sample data points), together with commonly used out-of-sample forecast evaluation criteria that are suitable for (pairwise) nested model forecast comparisons, we show that one-step-ahead forecasts from the augmented HAR model are (statistically) superior to forecasts from the benchmark HAR model which does not include U.S. equity market volatility information. That is, the Clark and West (2007) adjusted $t$-statistic at the one-step-ahead horizon is at least 7.4 and as high as 15.6, indicating rather strong rejections of the null hypothesis of no forecast improvement. Outof-sample $R^{2}$ values are as high as 12.83, 10.43 and 9.41 percent for the All Ordinaries, the Euro STOXX 50 and the CAC 40 equity indices. Moreover, from a visual inspection of the cumulative difference of the squared forecast errors from the augmented HAR model (relative to the benchmark) it is evident that the forecast improvements in the augmented HAR model are experienced consistently over the entire out-of-sample period, which is indicated by the (nearly) monotonically increasing value in this sequence.

At the multiple-steps-ahead horizon, forecast improvements relative to the benchmark HAR model stay highly significant (at the $1 \%$ level) for all 17 international equity markets at the 5 day ( 1 week) ahead horizon. For forecast horizons of 10 and 22 days ( 1 month) ahead, improvements in the forecasts relative to the benchmark HAR model start to deteriorate gradually for some of the international equity markets, nevertheless, they remain significant at the $1 \%$ level for 14 and 12 equity markets, respectively. Overall, our results show that U.S. based equity market volatility data is most informative for forecasts of realized volatility of the All Ordinaries index and also all of the European equity markets.

The remainder of the paper is organised as follows. In Section 2 we outline how realized volatility is modelled and how we extend the standard HAR model of Corsi (2009) by augmenting it with U.S. based information about equity market volatility. The data that we use in the study is described in detail in Section 3. In Section 4, we evaluate the importance of U.S. based volatility information for the determination of volatility in 17 international (non-U.S.) equity markets by means of an in-sample and out-of-sample evaluation. In Section 5, we provide a robustness analysis of our findings. Lastly, we conclude the study. 


\section{Modelling volatility}

This section outlines the modelling approach that we use to assess the contributing role that U.S. equity market volatility information plays in improving realized volatility forecasts in a large cross-section of international equity markets. Before we describe the empirical model that we employ to model and forecast realized volatility in international equity markets, we first briefly describe the background that links empirical realized volatility to its theoretical counterpart, integrated volatility.

\subsection{Theoretical framework}

Let $p_{t}$ denote the logarithm $(\log )$ of an asset price at time $t$. The log asset price is assumed to be a continuous-time diffusion process driven by a Brownian motion, with dynamics described by the following stochastic differential equation:

$$
d p_{t}=\mu_{t} d t+\sigma_{t} d W_{t}
$$

where $\mu_{t}$ is a predictable and locally bounded drift term, $\sigma_{t}$ is a càdlàg volatility process bounded away from zero and $W_{t}$ is a standard Brownian motion. The quadratic variation $(\mathrm{QV})$ process of $p_{t}$ is given by: ${ }^{3}$

$$
\mathrm{QV}_{t}=\int_{0}^{t} \sigma_{s}^{2} d s
$$

In the absence of jumps, as is the case in our setting in (1), the term $\int_{0}^{t} \sigma_{s}^{2} d s$ in (2) is known as the integrated variance (IV) of the process $p_{t}$.

The simplest consistent estimator of QV in (2) is, by definition, realized variance (RV), which is computed as the sum of discretely observed squared intraday log returns. More formally, let $r_{t, i}$ be the $\log$ return observed at time $t$ in the $i^{t h}$ interval of an equidistant grid with a total of $m$ intervals. Then, the classical RV estimator of QV in (2) is defined as:

$$
\mathrm{RV}_{t}=\sum_{i=1}^{m} r_{t, i}^{2}
$$

and its square root $\sqrt{\mathrm{RV}_{t}}$ is known as realized volatility. The general properties of the estimator in (3) are summarised in Andersen et al. (2003). ${ }^{4}$

\footnotetext{
${ }^{3}$ The quadratic variation process of $p_{t}$ is defined as $\left[p_{t}\right]=\operatorname{plim}_{m \rightarrow \infty} \sum_{k=1}^{m}\left(p\left(t_{k}\right)-p\left(t_{k-1}\right)\right)^{2}$, where plim denotes convergence in probability, and $0=t_{0} \leq t_{1}<\ldots<t_{m}=t$ is a partition such that $\sup _{k}\left\{t_{k+1}-t_{k}\right\} \rightarrow 0$ as $m \rightarrow \infty$ (Jacod and Shiryaev, 1987).

${ }^{4}$ Note that we will use the terms realized variance and realized volatility interchangeably to denote the variability or variation in an asset price, although strictly speaking, it is an abuse of the terminology that we have just defined.
} 


\subsection{Empirical volatility model}

There exist three broad classes of empirical models for RV. The first belongs to the traditional ARMA and also fractionally integrated ARMA (ARFIMA) class of long-memory time series models for RV (see Baillie (1996), Baillie et al. (1996), Comte and Renault (1996), Comte and Renault (1998), and Andersen et al. (2003) among many others). The second class considers nonlinear time series models, where long-memory patterns in RV are generated spuriously from nonlinear short-memory models with structural breaks or regime switches (see, for instance, the papers by McAleer and Medeiros (2008), Chen et al. (2010), Fengler et al. (2013) and others). The third belongs to the class of Heterogeneous Autoregressive (HAR) models for RV, as initially introduced by Corsi (2009) into the realized variance modelling literature.

We use the HAR model of Corsi (2009) as our benchmark RV model for each of the foreign equity markets that we consider. The HAR model has a cascade type structure, where volatility at any point in time is constructed as a linear combination of a daily, weekly and monthly volatility component. This temporal cascade structure is motivated by the so-called Heterogeneous Market Hypothesis (HMH) of Müller et al. (1993), where it is assumed that financial markets are populated by heterogeneous agents, each having different endowments, risk profiles, institutional constraints, information processing capabilities, as well as various other characteristics (see Corsi (2009) for a more detailed discussion). The defining feature of the HAR model is that each agent has a different time horizon for trading. The intuition is that short-term volatility does not matter for a long-term investor, whereas long-term volatility is of importance to short-term investors because of its impact on the investment opportunity set.

To formalise the structure of the HAR model for RV, let $\log R V_{t}^{(d)}=\log R V_{t}, \log R V_{t}^{(w)}=$ $\frac{1}{5} \sum_{i=1}^{5} \log \mathrm{RV}_{t+1-i}$ and $\log \mathrm{RV}_{t}^{(m)}=\frac{1}{22} \sum_{i=1}^{22} \log \mathrm{RV}_{t+1-i}$ be the daily, weekly, and monthly HAR components. The HAR model is then defined as: ${ }^{5}$

$$
\log \mathrm{RV}_{t+1}=b_{0}+b^{(d)} \log \mathrm{RV}_{t}^{(d)}+b^{(w)} \log \mathrm{RV}_{t}^{(w)}+b^{(m)} \log \mathrm{RV}_{t}^{(m)}+\epsilon_{t+1}
$$

where $\epsilon_{t+1}$ is an innovation term. One of the main attractions of the HAR model in (4) is its simplicity. Once the daily, weekly, and monthly volatility components are constructed, the HAR model can be estimated by ordinary least squares (OLS) regression. Moreover, due to its parsimonious setup, the HAR model is an extremely difficult to beat benchmark model in out-of-sample forecast evaluations (see Corsi et al. (2012) for a recent survey of differen types of models for RV that have been evaluated against the HAR model). Since we are primarily inter-

\footnotetext{
${ }^{5}$ Note here that the original formulation of the HAR model of Corsi (2009) used RV instead of log RV in the HAR specification in (4). Nevertheless, there has been a shift toward modelling the log RV series. In the words of Andersen et al. (2007, page 704): 'from a modeling perspective, the logarithmic realized volatilities are more amenable to the use of standard time series procedures'. Moreover, log transformed RV data are much closer to being normally distributed, and there is further no need to impose any non-negativity restrictions on the fitted and forecasted volatilities. We will thus follow Corsi et al. (2010), Corsi and Renó (2012) and many others in the empirical RV literature and use log RV in the HAR model.
} 
ested in a real time out-of-sample comparison of the predictive content of U.S. equity market volatility information on volatility in other global equity markets, it is necessary to recursively update the model parameters of interest when constructing the forecasts. Unlike AR(FI)MA and other more general nonlinear time series models, which require numerical optimisation of the likelihood function and are thus time consuming to estimate and also frequently numerically unstable, the HAR model in (4) can be estimated efficiently and accurately by standard OLS procedures.

We should also highlight at this point that, since its introduction, the HAR model of Corsi (2009) has undergone numerous refinements. For instance, there exists some recent evidence to suggest that separating the quadratic variation process in (2) into a continuous and a jump component part leads to better out-of-sample forecasts (see, for instance, Andersen et al. (2007), Corsi et al. (2010) and Corsi and Renó (2012)). Moreover, allowing for nonlinear and asymmetric effects in the HAR model, such as the leverage effect, can also be beneficial for out-of-sample forecasting (see Bollerslev et al. (2006), Chen and Ghysels (2011), Corsi and Renó (2012), and Patton and Sheppard (2013) amongst others). Nevertheless, despite these findings, we want to abstract from including such refinements of the HAR model in this study and instead want to focus our attention solely on the role the U.S. plays as a source of information related to international asset price volatility, and most importantly, if this information can be exploited to improve forecasts of realized volatility in other global equity markets. ${ }^{6}$

To assess the value of U.S. equity market volatility data on forecasts of $\log$ RV in other equity markets around the world, we augment each individual foreign equity market's benchmark HAR model with U.S. volatility information. This is achieved by adding the log RV HAR components from the U.S. and also log VIX data to the (foreign) benchmark HAR models. More specially, for each of the 17 international equity markets that we consider, we specify the following augmented HAR model:

$$
\begin{aligned}
\log \mathrm{RV}_{t+1} & =\overbrace{\beta_{0}+\beta^{(d)} \log \mathrm{RV}_{t}^{(d)}+\beta^{(w)} \log \mathrm{RV}_{t}^{(w)}+\beta^{(m)} \log \mathrm{RV}_{t}^{(m)}}^{\text {benchmark (local) HAR components of each foreign equity market }} \\
& +\underbrace{\beta_{\mathrm{VIX}} \log \mathrm{VIX}_{t}+\beta_{\mathrm{US}}^{(d)} \log \mathrm{RV}_{t, \mathrm{US}}^{(d)}+\beta_{\mathrm{US}}^{(w)} \log \mathrm{RV}_{t, \mathrm{US}}^{(w)}+\beta_{\mathrm{US}}^{(m)} \log \mathrm{RV}_{t, \mathrm{US}}^{(m)}}_{\text {U.S. volatility information: } \log \text { VIX and U.S. HAR components }}+\epsilon_{t+1}^{\mathrm{US}},
\end{aligned}
$$

where the daily, weekly, and monthly HAR components for the U.S., denoted by $\log \mathrm{RV}_{t, \mathrm{US}}^{(\cdot)}$, are analogously defined as above for (4), the $\log \mathrm{VIX}_{t}$ series is the log of the Chicago Board Options Exchange (CBOE) Volatility Index (henceforth, VIX for short), and $\epsilon_{t+1}^{\mathrm{US}}$ is again an innovation term.

\footnotetext{
${ }^{6}$ Evidently, with a growing number of regressors, one could also make the modelling of the HAR more flexible, by using a time varying parameter model as recently used in Grassi et al. (2014), Buncic and Piras (2014) and Buncic and Moretto (2015), or by using a shrinkage estimator such as the Lasso for variable selection as used in Buncic and Melecky (2014) in a cross-sectional setting.
} 
Our motivation for including the log VIX as an additional regressor in the augmented HAR model in (5) is as follows. Recall that the VIX measures the volatility implied by option prices on the S\&P 500 and thereby reflects investors' expectations about stock market volatility over the next month. ${ }^{7}$ The VIX is thus meant to not only provide a forward looking view on expected U.S. equity market volatility, but to also provide us with a general sense of risk aversion in the market. A higher value in the VIX is generally taken as an indication of market participants anticipating an overall negative economic or financial outlook, and hence an increased aversion to risk (see Brunnermeier et al. (2009) for a discussion). This increased aversion to risk is likely to spill over to other international equity markets, given the dominant role of the U.S. as a source of economic and financial information in the world economy. Moreover, in a recent study, Grassi et al. (2014) have documented some predictive power of the VIX for S\&P 500 realized volatility forecasts. We therefore expect the VIX also to contain predictive information that can be exploited to improve realized volatility forecasts in other international equity markets.

\section{Data}

We obtain daily 'volatility' data from the publicly available Oxford-Man Institute's Quantitative Finance Realized Library of Heber et al. (2009). ${ }^{8}$ The Oxford-Man Realized Library uses high frequency tick data from Reuters DataScope Tick History to construct a whole suit of daily 'realized measures' of asset price variability, providing further also the number of transactions, the time span between the first and last observation, the close-to-open return, the local opening time, the high-low range, the high-open range, as well as the opening and closing prices for each series. ${ }^{9}$ The library contains realized measures for 4 U.S. and 17 foreign (non-U.S.) equity price indices from January 3, 2000 to the present. Our sample ends on January 23, 2015.

As our preferred estimator of asset price variation, we use realized variance sampled at equally spaced 5 minute intervals (simply 5 minute RV henceforth). This is the estimator under the heading ' $* . r v$ ' in the Oxford-Man Realized Library under each equity market data block. The choice for 5 minute RV is driven partly by simplicity and partly by robustness. In a recent and extensive study of realized measures, Liu et al. (2014) have highlighted that there exists

\footnotetext{
${ }^{7}$ The VIX is computed as the weighted average of the implied volatilities of options on the S\&P 500 index for a wide range of strikes and mainly first and second month expirations. Note here that Chow et al. (2014) have recently shown that the VIX is a biased measure of market expectations about future volatility. Nevertheless, our intention with including the VIX as a regressor in the HAR is to account for the potential predictive information that it may have for volatility in other global equity markets, rather than trying to gauge whether it is an appropriate measure of volatility expectations in the U.S.

${ }^{8}$ Our data are from Library Version 0.2. The url link to the data source is http:/ / realized.oxford-man.ox.ac.uk/ media/1366/oxfordmanrealizedvolatilityindices.zip.

${ }^{9}$ The term 'realized measures' was coined by Liu et al. (2014). The various types of realized measures that are included in the library are listed at http:/ / realized.oxford-man.ox.ac.uk/documentation/estimators. With regards to the 'quality 'of the tick data, Heber et al. (2009) point out that the raw data from Reuters DataScope Tick History is already of high quality. Nevertheless, Heber et al. (2009) still employ a high frequency data 'cleaning procedure' described in detail at http:/ / realized.oxford-man.ox.ac.uk/documentation/data-cleaning and references therein, to make the data 'suitable' for econometric analysis.
} 
little evidence to suggest that 5 minute RV is significantly 'outperformed' by any of the other realized measures that are considered in the benchmark comparison. In particular, when working with international equity market data, Liu et al. (2014, page 4) point out that "more sophisticated realized measures generally perform significantly worse" than 5 minute RV. We therefore use the 5 minute RV estimator of Heber et al. (2009) - henceforth, simply RV to avoid cumbersome and repetitive language - throughout this study.

In total, we have access to realized measures data for 17 international equity markets that are included in the Oxford-Man Realized Library. These are the FTSE 100 (United Kingdom), the Nikkei 225 (Japan), the DAX (Germany), the All Ordinaries (Australia), the CAC 40 (France), the Hang Seng (Hong Kong), the KOSPI (South Korea), the AEX (The Netherlands), the Swiss Market Index (Switzerland), the IBEX 35 (Spain), the S\&P CNX Nifty (China), the IPC Mexico (Mexico), the Bovespa (Brazil), the S\&P TSX (Canada), the Euro STOXX 50 (Euro area), the FT Straits Times (Singapore), and the FTSE MIB (Italy).

For the U.S., the library contains realized measures for four different equity market indices. These are the Dow Jones Industrial Average (DJIA), the Russel 2000, the Nasdaq 100 and the S\&P 500. We use the S\&P 500 as our key headline U.S. equity market index. The Nasdaq 100 is a specialized technology industry index and is thus too narrowly defined to be considered as a valid headline U.S. equity market index. The Russel 2000 on the other hand is likely to be too sensitive to volatility movements induced by the small cap nature of the index. From our point of view, only the DJIA qualifies as a viable alternative to the S\&P 500, as it is an index that is widely focused on by the financial media, thereby providing broad headline information about the performance of U.S. equities. Nevertheless, an evident shortcoming of the DJIA is that it is composed of only 30 blue chip stocks. We find it therefore also too narrowly focused. Our preference is thus to use the S\&P 500 as our key equity market index for the U.S. ${ }^{10}$ The VIX data that we include in the augmented HAR model in (5) is obtained from the St. Louis Fed FRED2 database. ${ }^{11}$ In Table 1 we provide standard summary statistics on all (log transformed) RV and VIX data that are used in our study. In addition to the summary statistics in Table 1, we also show time series, as well as autocorrelation function (ACF) and partial ACF (PACF) plots in Figure 1 and Figure 2 to provide further information about the data series that we use.

In the first to fifth columns of Table 1, the equity index, the corresponding country, the full sample period, the number of observations $T$, as well as the number of missing entries (Miss.) are shown. In columns six to twelve, we list standard sample statistics such as the mean, median (Med), standard deviation (Std.dev), skewness (Skew), kurtosis (Kurt), as well as the minimum (Min) and maximum (Max) of the series. In the last six columns (grouped into three), the first to

\footnotetext{
${ }^{10}$ We would like to stress here though that despite our choice for the S\&P 500, there is very little difference in the results that we obtain if we use instead the DJIA as the U.S. index. We provide additional details regarding the robustness of our results in Section 5.

${ }^{11}$ The url to the database is http:/ / research.stlouisfed.org/fred2/. The FRED mnemonic for the VIX is VIXCLS and contains daily closing prices (16:15 EST) of the Chicago Board Options Exchanges (CBOEs) Volatility Index (VIX for short).
} 
third order ACF and PACF are provided $\operatorname{ACF}(1-3)$ and $\operatorname{PACF}(1-3)$, respectively). From the third column of Table 1 we can see that there are some differences with respect to the actual first available data points across the various equities that are used. For all but two series, the first available data point is either on the $3^{r d}$ or the $4^{\text {th }}$ of January 2000. For the S\&P TSX (Canada) the sample starts in May 2, 2002, and for the S\&P CNX Nifty (China) it starts in July 8, 2002.

A few additional comments on the data are in order here. For the S\&P CNX Nifty, the availability of realized measures data was extremely sparse before July 8,2002 . That is, for the 653 entries before July 8, 2002, only 100 data entries were available (553 missing entries). Due to this, we decided to delete all entries before July 8, 2002 and start the effective sample for the S\&P CNX Nifty from July 8,2002 . There are three other equity markets with unusual missing data patterns that deserve mentioning. The first is the All Ordinaries (Australia), where data is missing for 15 consecutive days from July 4, 2014 to July 25, 2014, the second is the FT Straits Times (Singapore), where from January 2, 2008 to March 3, 2008, 43 consecutive entries are missing, and the third is the Hang Seng (Hong Kong), which between September 5, 2008 to November 3, 2009 had 168 out of 300 entries missing. All missing entries were deleted from the final data set used in the analysis. Deleting entries in time series data evidently creates some difficulties with regards to interpreting $h$-step ahead forecasts over these time periods, as it is not clear what the next trading day is that is being predicted. Nevertheless, the alternative would have been to fill the missing values with the next previously available data point, which has the drawback of artificially amplifying the persistence in the series. We thus preferred to exclude these missing values and continued the sequence with the next available non-missing data entry. The total number of missing entries, including 'regular' missing entries due to public holiday closings, are given in column 4 of Table $1 .^{12}$

Looking over the summary statistics in Table 1 , one sees that the log RV data are fairly symmetrically distributed with means and medians lining up reasonably closely, skewness being between 0 and 1, and kurtosis largely around 3. Two notable exceptions are the log RV series of Bovespa (Brazil) and Euro STOXX 50, which are closer to 5, showing thus somewhat heavier tails than a Gaussian random variable. Interestingly, Bovespa and FT Straits Times have the lowest variation, with the standard deviation of log RV being only around 0.75, while the remaining series are closer to 1 . The ACF and PACF entries in Table 1 highlight the well known 'long-memory' property of log RV data. The most 'persistent' log RV series are the KOSPI (South Korea), the AEX (The Netherlands) and the Swiss Market Index with first order ACFs of around 0.86 , while the least persistent ones are the All Ordinaries and the Bovespa with $\mathrm{ACF}(1)$ values of around 0.68 and 0.69 , respectively. The long-memory property of the log RV data is also clearly visible from the ACF and PACF plots in Figure 2. From these plots we see that the log RV series of Bovespa seems to have the shortest 'memory', while the Nikkei 225 has the most hyperbolic looking ACF decay pattern. Finally, from the time series plots of the log RV and log

\footnotetext{
${ }^{12}$ The Oxford-Man Realized Library uses (largely) a five day calender week format, which also includes standard public holidays such as New Year, Christmas etc.
} 
VIX series in Figure 1, we can notice that for major events such as the Lehman Brothers collapse in September 2008, there appears to be a fairly homogenous movement in volatility across all equity markets.

One last important point that we would like to stress here is that the Oxford-Man Realized Library only uses intraday data collected over the official (local) trading hours of the respective equity markets of interest. That is, no variation due to overnight price changes are considered in the construction of the realized measures. ${ }^{13}$ Since we are using information at time $t$ from the U.S. to forecast $(\log )$ realized volatility in all other foreign equity markets at time $t+1$ (and further ahead), there is no overlap in the official trading hours between the U.S. market's previous day closing and the foreign market's current day opening. The official trading hours of the New York Stock Exchange (NYSE) are from 9:30 to 16:00 Eastern Standard Time (EST), which is 14:30 to 21:00 Coordinated Universal Time (UTC) in (northern hemisphere) winter. From the foreign equity markets that we include, the first one to open the next day is the Australian Securities Exchange (ASX) in Sydney at 10:00 Australian Eastern Standard Time (AEST), which is 00:00 UTC. During (northern hemisphere) summer, the UTC closing time for the U.S. market is 20:00 UTC, while the ASX in Sydney opens at 23:00 UTC. Hence there is a gap of 3 hours between New York closing and Sydney opening. ${ }^{14}$

\section{Assessing the value of U.S. volatility}

We assess the importance of U.S. equity market volatility data from the previous trading day and how it can be used to improve the modelling and forecasting of 'realized volatility' in other international equity markets by first looking at the in-sample contribution of U.S. based volatility information to the model. We then extend the analysis by using standard forecast evaluation techniques to see if these in-sample gains carry over to the out-of-sample forecast environment.

Before we evaluate the in-sample fit of the augmented HAR model in (5), it will be convenient to condense the representation of the model somewhat. For this purpose, let us define $\boldsymbol{x}_{t}=\left[1 \log \mathrm{RV}_{t}^{(d)} \log \mathrm{RV}_{t}^{(w)} \log \mathrm{RV}_{t}^{(m)}\right]$ to be the $(1 \times 4)$ vector of HAR components (including an intercept term) of the foreign equity market of interest and let the $(1 \times 4)$ vector contain-

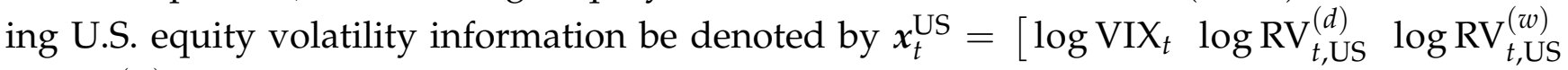
$\left.\log \mathrm{RV}_{t, \mathrm{US}}^{(m)}\right]$. We further define $y_{t+1}=\log \mathrm{RV}_{t+1}$. Then, we can express the augmented HAR

\footnotetext{
${ }^{13}$ The official opening hours (in local time) are recorded in column 15 of the respective equity market's realized measures data block in the Oxford-Man Realized Library, with the time span (time passed in seconds) between the first and the last observation captured in column 13.

${ }^{14}$ The switch from and to Daylight Saving Time (DST) is not co-ordinated, so it does not occur on the same days. For the U.S., DST is 'on' from March to November, while for Australia, DST is 'off' from April to October. This is, nevertheless, immaterial for our discussion as it does not induce any trading hour overlap.
} 
model in (5) in the following compact form:

$$
y_{t+1}=\overbrace{\boldsymbol{x}_{t} \boldsymbol{\beta}}^{\text {local volatility info }}+\underbrace{\boldsymbol{x}_{t}^{\mathrm{US}} \boldsymbol{\beta}_{\mathrm{US}}}_{\text {U.S. volatility info }}+\epsilon_{t+1}^{\mathrm{US}}
$$

where $\boldsymbol{\beta}=\left[\begin{array}{llll}\beta_{0} & \beta^{(d)} & \beta^{(w)} & \beta^{(m)}\end{array}\right]^{\prime}$ and $\beta_{\mathrm{US}}=\left[\begin{array}{lll}\beta_{\mathrm{VIX}} & \beta_{\mathrm{US}}^{(d)} & \beta_{\mathrm{US}}^{(w)} \\ \beta_{\mathrm{US}}^{(m)}\end{array}\right]^{\prime}$ are the corresponding $(4 \times 1)$ dimensional foreign and U.S. parameter vectors, respectively.

\subsection{In-sample evaluation}

We fit the HAR model in (6) to three sample periods to gauge the magnitude and significance of the estimated parameters of the relation in (6). We first estimate the model over the full available data set, and then also consider the two subperiods leading up to and following the Lehman Brothers collapse on September 15, 2008. Estimation results for the full period and the two subperiods are shown in Table 2 and Table 3, respectively. In each table we show in the first column the equity index of interest, the time period over which the model in (6) was fitted, followed by the set of 8 point estimates of the augmented HAR model parameters, and a $\chi^{2}-$ test statistic of joint significance of the U.S. regressors (capturing the importance of U.S. equity market volatility) being different from zero. In square brackets below the parameter estimates and the $\chi^{2}$-test statistic, we show 2 -sided (one sided for the $\chi^{2}$-test statistic) $p$-values computed with a Heteroskedasticity and Autocorrelation Consistent (HAC) variance/covariance matrix estimator. ${ }^{15}$ Additionally, since the information provided in Tables 2 and 3 may be too detailed and potentially too cumbersome to read, we also provide graphical plots of the $\beta$ estimates (excluding the intercept) in Figure 3. In each plot in Figure 3, we show point estimates (very thin blue line) together with corresponding 95\% confidence intervals (light blue shading) for the full sample period. We then further superimpose the point estimates from the pre and post Lehman Brothers collapse periods (thick red and thin black lines, respectively) to provide a visual comparison of the estimates over these subperiods.

From the evidence in Tables 2 and 3 and Figure 3, we can summarise the most notable insample fitting results as follows. First, U.S. equity market volatility data from the previous trading day is highly informative. A formal test of joint significance is strongly rejected by the data for all equity markets of interest and for all three sample periods. The range of values of the $\chi^{2}$-test statistic that we obtain are between 32.16 (lowest) for the Hang Seng in the post Lehman Brothers collapse period and 333.06 (highest) for the All Ordinaries in the full sample period. Note here that we are imposing 4 restrictions. With the $1 \%$ upper tail critical value of a $\chi^{2}$ random variable with 4 degrees of freedom being 13.28, we can see that even at the lowest $\chi^{2}$-test statistic, these are fairly strong rejections.

\footnotetext{
${ }^{15}$ We use a standard Bartlett Kernel and a Newey and West (1994) rule of thumb bandwidth set equal to $4(T / 100)^{2 / 9}$.
} 
Second, from the plots in Figure 3 it is evident that the estimates are rather stable over the three sample periods, remaining most of the time inside (or at least close to) the $95 \%$ confidence interval (CI) of the full sample period estimates. ${ }^{16}$ Third, the parameter estimates on the daily and monthly U.S. HAR components (ie., $\hat{\beta}_{U S}^{(d)}$ and $\hat{\beta}_{\text {US }}^{(m)}$ ), as well as the $\log$ VIX $\mathrm{X}_{t}$ are significantly different from zero (at the 5\% and 1\% levels, respectively). Moreover, from the plots in Figure 3 we see further that the overall magnitude of the $\hat{\beta}_{\mathrm{US}}^{(d)}$ is similar to that of $\hat{\beta}^{(d)}$, suggesting that they are about equally important in determining the next day's log RV of the foreign equity market under consideration. It is interesting to see that the absolute size of the coefficient on the monthly U.S. HAR component is relatively large when compared to the other non-U.S. $\beta$ estimates, having a cross-sectional average (over the 17 equity markets) of about -0.3 . The negative sign on the $\hat{\beta}_{\mathrm{US}}^{(m)}$ coefficient is somewhat surprising, as it suggest that there is a negative feedback from the 'low frequency' (monthly) U.S. volatility component to the 'high frequency' daily volatility component of the foreign equity market of interest. ${ }^{17}$ The $\hat{\beta}_{\mathrm{VIX}}$ coefficients are also of a sizeable magnitude, with the broad range being between 0.4 to 1 , and with a mean of around 0.7 .

\subsection{Out-of-sample forecast evaluation}

Given the strong in-sample evidence of the importance of lagged U.S. based equity market volatility information for the determination of international equity market volatility, we now assess the value of this information within an out-of-sample forecast environment. Below, we initially outline the general prediction setting and the evaluation criteria that we use and then proceed by presenting the forecast evaluation results.

\subsubsection{Prediction setting}

We follow a standard one-step-ahead out-of-sample prediction setting, where we produce forecasts of $y_{t+1}=\log R V_{t+1}$ from the augmented and benchmark HAR models by first obtaining OLS estimates of $\boldsymbol{\beta}, \boldsymbol{\beta}_{\mathrm{US}}$ and $\boldsymbol{b}$ from the two regressions:

$$
\begin{aligned}
& y_{t}=\boldsymbol{x}_{t-1} \boldsymbol{\beta}+\boldsymbol{x}_{t-1}^{\mathrm{US}} \boldsymbol{\beta}_{\mathrm{US}}+\epsilon_{t}^{\mathrm{US}} \\
& y_{t}=x_{t-1} \boldsymbol{b}+\epsilon_{t}
\end{aligned}
$$

\footnotetext{
${ }^{16}$ Note here, that we have plotted the confidence interval for the full sample period, which, due to the larger number of observations and in the absence of any severe structural breaks, will contain much tighter intervals than the smaller pre and post Lehman Brothers collapse periods. Thus, if these intervals include the point estimates of the two subperiods most of the time, we can take this as an indication of no substantial structural breaks having influenced the parameter estimates.

${ }^{17}$ It should be clear here that the two monthly components are considerably correlated, which is due to the cumulative construction of the monthly series. The pairwise correlation is around 0.90 for most of the foreign countries that we consider. Although it may seem that the negative sign is attributable to this correlation, one would also expect to see highly inflated standard errors with multi-collinearity issues, resulting in largely insignificant point estimates. This is, nonetheless, not the case here. We thus do not believe that the opposite sign structure is purely driven by the 'correlatedness' of the low frequency monthly components.
} 


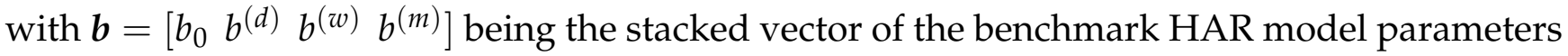
in (4). One-step-ahead out-of-sample forecasts for each foreign equity market's log RV series from the augmented and benchmark HAR models are then computed as:

$$
\begin{aligned}
& \hat{y}_{t+1 \mid t}^{\mathrm{US}}=\boldsymbol{x}_{t} \hat{\boldsymbol{\beta}}+\boldsymbol{x}_{t}^{\mathrm{US}} \hat{\boldsymbol{\beta}}_{\mathrm{US}} \\
& \hat{y}_{t+1 \mid t}=\boldsymbol{x}_{t} \hat{\boldsymbol{b}}
\end{aligned}
$$

where $\hat{\boldsymbol{\beta}}, \hat{\boldsymbol{\beta}}^{\mathrm{US}}$ and $\hat{\boldsymbol{b}}$ are the (time $t$ ) estimates of the parameters in (7) and (8). One-step ahead out-of-sample forecast errors are, respectively:

$$
\begin{aligned}
& \hat{e}_{t+1 \mid t}^{\mathrm{US}}=\left(y_{t+1}-\hat{y}_{t+1 \mid t}^{\mathrm{US}}\right) \\
& \hat{e}_{t+1 \mid t}=\left(y_{t+1}-\hat{y}_{t+1 \mid t}\right) .
\end{aligned}
$$

To construct multiple-steps-ahead forecasts, we follow Andersen et al. (2007), Corsi and Renó (2012) and others by implementing the so-called 'direct' forecasting approach. ${ }^{18}$ That is, we define the (normalised) multi-period log RV series as:

$$
y_{t}^{(h)}=\frac{1}{h} \sum_{j=1}^{h} y_{t-j+1}=\frac{1}{h} \sum_{j=1}^{h} \log \mathrm{RV}_{t-j+1}
$$

and re-formulate the regression relations in (7) and (8) for the general $h$-steps-ahead log RV series as:

$$
\begin{aligned}
& y_{t}^{(h)}=x_{t-h} \boldsymbol{\beta}^{(h)}+\boldsymbol{x}_{t-h}^{\mathrm{US}} \boldsymbol{\beta}_{\mathrm{US}}^{(h)}+\epsilon_{t}^{\mathrm{US}} \\
& y_{t}^{(h)}=\boldsymbol{x}_{t-h} \boldsymbol{b}^{(h)}+\epsilon_{t}
\end{aligned}
$$

and compute $h$-step-ahead forecasts as

$$
\begin{aligned}
\hat{y}_{t+h \mid t}^{\mathrm{US}(h)} & =\boldsymbol{x}_{t} \hat{\boldsymbol{\beta}}^{(h)}+\boldsymbol{x}_{t}^{\mathrm{US}} \hat{\boldsymbol{\beta}}_{\mathrm{US}}^{(h)} \\
\hat{y}_{t+h \mid t}^{(h)} & =\boldsymbol{x}_{t} \hat{\boldsymbol{b}}^{(h)} .
\end{aligned}
$$

The $h$ superscripts on the $\boldsymbol{\beta}^{(h)}, \boldsymbol{\beta}_{\mathrm{US}}^{(h)}$ and $\boldsymbol{b}^{(h)}$ terms (as well as their estimates) indicate that these are from the $h$-periods off-set (or multi-period) regressions in (14) and (15). The $h$-steps-ahead forecast errors corresponding to the predictions in (16) and (17) are

$$
\hat{e}_{t+h \mid t}^{\mathrm{US}(h)}=\left(y_{t+h}^{(h)}-\hat{y}_{t+h \mid t}^{\mathrm{US}(h)}\right)
$$

\footnotetext{
${ }^{18}$ See Clements and Hendry (1996), Chevillon and Hendry (2005), Marcellino et al. (2006), Chevillon (2007), and Pesaran et al. (2011), among others, for a motivation, evaluation and comparison of the direct forecasting approach to iterated forecasts.
} 


$$
\hat{e}_{t+h \mid t}=\left(y_{t+h}^{(h)}-\hat{y}_{t+h \mid t}^{(h)}\right)
$$

Corresponding Mean Squared Forecast Errors (MSFEs) are constructed as:

$$
\operatorname{MSFE}=\frac{1}{T_{o s}} \sum_{t=T_{i s}}^{T}\left(\hat{e}_{t+h \mid t}\right)^{2} \text { and } \operatorname{MSFE}_{(\mathrm{US})}=\frac{1}{T_{o s}} \sum_{t=T_{i s}}^{T}\left(\hat{e}_{t+h \mid t}^{\mathrm{US}}\right)^{2},
$$

where the terms $T_{o s}$ and $T_{i s}$ denote, respectively, the number of out-of-sample and in-sample observations, with $T_{o s}=T-T_{i s}-h+1$, and $T$ being the full sample size.

We use the first 500 observations from the full available data set as the in-sample fitting period. We judge 500 observations to be large enough to obtain reasonably precise estimates of the $\beta$ and $\beta_{\text {US }}$ parameters to initialise the out-of-sample forecasts. Following Corsi and Renó (2012), Rapach et al. (2013), Neely et al. (2014) and others, we then use an expanding window (or recursive) forecasting scheme, where we add one extra observation to the 500 in-sample data points and then re-estimate the models to produce recursively updated parameter estimates as well as forecasts. Overall, this gives us, at the minimum, around 2500 data points that can be used to conduct a statistically meaningful out-of-sample forecast evaluation. Since the 'selection' of the in-sample fitting period may seem rather ad hoc, we provide a robustness check with a larger in-sample fitting period of $T_{i s}=1000$ to corroborate our general findings in Section 5 . Overall we should stress here again that we use rather large in-sample fitting as well as out-ofsample evaluation periods, so that our overall conclusions regarding the improvements in the forecasts that we obtain are not sensitive to the choice of these two windows.

\subsubsection{Evaluation criteria}

To assess the out-of-sample forecast performance of the augmented HAR model in (6), we follow the approaches in Corsi and Renó (2012) and the recent literature on forecasting the equity premium (see Campbell and Thompson (2008), Rapach et al. (2013), Neely et al. (2014) and many others) and evaluate the forecasts in terms of the Clark and West (2007) Mean Squared Forecast Error (MSFE) adjusted $t$-statistic (denote by $\mathrm{CW}$ - statistic) and the Campbell and Thompson (2008) out-of-sample $R^{2}$ (denoted by $R_{o s}^{2}$ henceforth). Note here that we are performing a simple pairwise forecast comparison between the augmented and benchmark HAR models for each foreign equity market's log RV series, and are not comparing forecasts from many models. A Diebold and Mariano (1995) (DM) type test of unconditional predictive ability is thus sufficient for our purpose of assessing the contribution of U.S. based volatility information to each foreign equity market's volatility forecasts. Since the augmented HAR model in (6) nests the standard HAR model in (4), we utilize the Clark and West (2007) MSFE adjusted $t$-statistic, which corrects for the bias that arises with the DM test when nested models are being compared.

Following the suggestion in Clark and West (2007, page 294), the simplest way to compute 
the MSFE adjusted $t$-statistic is to form the sequence

$$
\mathrm{CW}_{t+h}=\mathrm{DM}_{t+h}+\operatorname{adj}_{t+h}
$$

where

$$
\mathrm{DM}_{t+h}=\left(\hat{e}_{t+h \mid t}\right)^{2}-\left(\hat{e}_{t+h \mid t}^{\mathrm{US}}\right)^{2}
$$

and

$$
\operatorname{adj}_{t+h}=\left(\hat{y}_{t+h \mid t}-\hat{y}_{t+h \mid t}^{\mathrm{US}}\right)^{2}
$$

The $\mathrm{DM}_{t+1}$ term is the standard Diebold and Mariano (1995) sequence that is computed to test for (unconditional) superior predictive ability. The adjustment term $\operatorname{adj}_{t+1}$ arises due to the nested nature of the models being compared and performs a bias correction (see Clark and West (2007) for more details). The CW - statistic is then computed as

$$
\mathrm{CW}-\text { statistic }=\frac{\overline{\mathrm{CW}}}{\sqrt{\operatorname{Var}(\overline{\mathrm{CW}})}}
$$

where $\overline{\mathrm{CW}}=T_{o s}^{-1} \sum_{t=T_{i s}}^{T} \mathrm{CW}_{t+1}$ and $\operatorname{Var}(\overline{\mathrm{CW}})$ is the variance of the sample mean, which can simply be obtained as the HAC robust $t$-statistic on the intercept term from a regression of $\mathrm{CW}_{t+1}$ on a constant. ${ }^{19}$

The CW - statistic implements a test of the null hypothesis that the MSFE of the benchmark HAR model, which does not include U.S. equity market volatility information, is equal to the MSFE of the augmented HAR model's forecast in (6), against the one sided alternative hypothesis that the benchmark's MSFE is greater than that of the augmented HAR model. A rejection of the null hypothesis hence suggests that forecasts from the augmented HAR model are (on average) significantly smaller than from the benchmark HAR model forecasts. It should be highlighted here again that the $\mathrm{CW}$ - statistic is particularly suitable in the given context, as it is designed for a comparison of nested (forecasting) models. Our benchmark model is the standard HAR model, which can be obtained from the augmented HAR model by restricting $\boldsymbol{\beta}_{\mathrm{US}}$ in (6) to $\mathbf{0}_{4 \times 1}$.

The Campbell and Thompson (2008) $R_{o s}^{2}$ is computed as follows. Let $\mathrm{MSFE}_{(\mathrm{US})}$ be the MSFE from the augmented HAR model including U.S. volatility information and let MSFE denote the mean squared forecast error from the benchmark HAR model. Then, the $R_{o s}^{2}$ comparing the performance of the two forecasts is defined as:

$$
R_{o S}^{2}=1-\frac{\operatorname{MSFE}_{(\mathrm{US})}}{\mathrm{MSFE}}
$$

\footnotetext{
${ }^{19}$ See also the discussion in Section 2.1 in Diebold (2015) for more background on this in the context of the traditional Diebold-Mariano (DM) statistic.
} 
Intuitively, the $R_{o s}^{2}$ statistic in (25) measures the reduction in MSFE of the proposed model relative to the benchmark model. When $R_{o s}^{2}>0$, then this is an indication that the proposed model performs better than the benchmark model, while $R_{o s}^{2}<0$ suggests that the benchmark model performs better.

In addition to the CW - statistic of Clark and West (2007) and the out-of-sample $R^{2}$ of Campbell and Thompson (2008), we also compute the cumulative difference of the squared forecast errors from the two HAR models over the out-of-sample period. This cumulative difference (denoted by cumSFE $E_{t+1}$ ) is commonly used in the equity premium forecasting literature as a tool to highlight the predictive performance of the proposed model relative to the benchmark model over time (see Goyal and Welch (2008) and Rapach et al. (2013), among many others). In our setting, this difference is defined as:

$$
\operatorname{cumSFE}_{t+1}=\sum_{t=T_{i s}}^{T_{o s}}\left(\left(\hat{e}_{t+1 \mid t}\right)^{2}-\left(\hat{e}_{t+1 \mid t}^{\mathrm{US}}\right)^{2}\right) .
$$

The cumSFE $E_{t+1}$ sequence allows us to analyse how the forecast performance of the two models has changed over time. A value of the cumSFE $E_{t+1}$ series above zero indicates that the cumulative sum of the squared forecast errors of the benchmark model are larger than those of the proposed augmented HAR forecasts, indicating that the benchmark's forecasts are less accurate. Moreover, an upward sloping cumSFE t $_{t+1}$ sequence means that the proposed augmented HAR model produces 'consistently' better predictions than the benchmark HAR model (i.e. without U.S. volatility information).

\subsubsection{Forecast evaluation results}

In Table 4 we present the one-step-ahead out-of-sample forecast evaluation results for all 17 international equity markets that we consider, using an expanding (recursive) estimation window of $T_{i s}=500$ data points. The first four columns in Table 4 show the foreign equity index of interest, the corresponding country, the actual out-of-sample evaluation period and the effective number of out-of-sample observations $T_{o s}$ that are used. In columns five to seven, the MSFE of the benchmark HAR model, the relative MSFE (denoted by Rel-MSFE and computed as $\operatorname{MSFE}_{(\mathrm{US})} / \mathrm{MSFE}$ ) and the Campbell and Thompson (2008) $R_{o s}^{2}$ are shown. In the last two columns, we show the Clark and West (2007) MSFE adjusted $t$-statistic (CW - statistic) and the corresponding one-sided $p$-value. We also include the results of a 'standard' DM-test with corresponding $p$-value in columns 8 and 9 in Table 4. Although it is known that the 'standard' DM-statistic is downward biased, due to the nested nature of the HAR models that are being compared, we include it here as a 'reference' value to show that our out-of-sample evaluation results are 'strong', resulting in $p$-values of less than $1 \%$ even if one does not adjust for the bias that arises from the nested model structure.

From the evaluation results in Table 4, we can see the solid positive effect that information 
about U.S. equity market volatility has on improving out-of-sample forecasts of log RV in global equity markets. For all 17 international equity markets that we consider, the $\mathrm{CW}$-statistic is in excess of 7 , resulting in $p$-values that are effectively 0 . The out-of-sample $R^{2}$ values of Campbell and Thompson (2008) are as high as 12.83,10.43 and 9.41 percent for the All Ordinaries, the Euro STOXX 50 and the CAC 40, with the lowest value of 1.81 percent being recorded for the Bovespa index. Note here that these $R_{o s}^{2}$ magnitudes are considerable. In the equity premium forecasting literature, Campbell and Thompson (2008) and more recently Neely et al. (2014) have shown with monthly data that $R_{o s}^{2}$ values as low as $0.5 \%$ (per month) produce sizable predictive results in the sense that 'large' gains in portfolio performance can be obtained. ${ }^{20}$ It is difficult to meaningfully gauge our $R_{o s}^{2}$ magnitudes here in the context of realized volatility forecasting, but it should be clear, nonetheless, that the improvements in the log RV forecasts can be substantial if one augments the benchmark HAR model with U.S. based equity market volatility information. Recall here also from the out-of-sample evaluation periods, that we are using sample sizes of at least 2500 observations, being as high as about 3200 observations. Our test results should thus not be sensitive to 'small sample issues'.

To provide some further intuition about the strong positive (statistical) out-of-sample forecast evaluation results that we obtain, we examine the evolution of the cumulative difference of the squared forecast errors from the augmented HAR model relative to the benchmark HAR model over time. This cumSFE ${ }_{t+1}$ series, as defined in (26), is plotted as the thin blue line in Figure 4 for the 17 international equity markets of interest. As a reminder, the cumSFE $E_{t+1}$ series is defined such that an increasing value indicates an improvement in the augmented HAR model's predictive performance relative to the benchmark HAR model (i.e., the benchmark HAR model produces larger one-step-ahead out-of-sample forecast errors). ${ }^{21}$ In addition to the expanding (recursive) window based cumSFE ${ }_{t+1}$ series shown in Figure 4, we also compute the cumSFE $E_{t+1}$ series based on a rolling window scheme, i.e., one that uses 500 observations to construct the forecasts and then rolls through the out-of-sample data, keeping the estimation window fixed at $T_{i s}=500$. This series is plotted as the thick orange line in Figure 4. Our intention here is to give a visual confirmation that our expanding (recursive) window based out-of-sample forecast evaluation results are 'broadly similar' to those obtained from a rolling window based set-up, and are thus not sensitive to this choice. ${ }^{22}$

Examining the cumSFE $t_{t+1}$ series shown in Figure 4, we can summarise the most interesting results from these plots as follows. First, the cumSFE $t$ is (nearly) uniformly above zero for the entire out-of-sample evaluation period and for all 17 foreign equity markets that we consider. The single main exception is the Bovespa index for Brazil, which does not appear to be con-

\footnotetext{
${ }^{20}$ What large is here depends on the setting. See the papers by Campbell and Thompson (2008) and Neely et al. (2014) for more details on how this is assessed.

${ }^{21}$ Note the difference in the $y$-axis scale in the plots. The $y$-axis scale for the All Ordinaries and the Euro STOXX 50 is from -20 to 160 and -20 to 120 , respectively, while for the remaining equity indices it is from -20 to 80 .

${ }^{22} \mathrm{We}$ provide further robustness results with respect to the in-sample estimation period in Section 5.
} 
sistently above zero until about October 2007, but is increasing steadily thereafter. Second, the cumSFE $_{t+1}$ series is (nearly) monotonically increasing for all series over the full out-of-sample period. There are some instances of 'flattening off' for some of the 17 equity markets, occurring largely around the September 2008 to June 2010 time period. Nonetheless, if one was to draw a hypothetical straight line from the beginning of the out-of-sample period until the end in January 23, 2015, one would find a fairly close lining-up of the cumSFE $E_{t+1}$ series to such a straight line. This highlights the steady improvement over time that the inclusion of U.S. volatility information offers when forecasting volatility in other international equity markets.

Third, it is interesting to observe that the cumulative improvement in the squared forecast errors of the augmented HAR model over the benchmark HAR is strongest for the All Ordinaries, the Euro STOXX 50, the CAC 40 and the AEX, and weakest for the Bovespa, KOSPI, Hang Seng and FT Straits Times equity indices. Overall, one can notice that, apart from the All Ordinaries, the European equity indices benefit the most from the inclusion of U.S. based equity market volatility information. The strong improvement in the log RV forecasts of the All Ordinaries seems intuitive, due to the narrow time gap between NYSE closing in the U.S. and ASX opening in Australia. Nevertheless, it is somewhat surprising to see here that for the other five Asian equity indices, that is, the Nikkei 225, the Hang Seng, the FT Straits Times, the S\&P CNX Nifty and the KOSPI, where the trading gap is also only a few hours as for the All Ordinaries, the spillover effect is much weaker. ${ }^{23}$ From these five equity indices, the Nikkei 225 and the S\&P CNX Nifty show the largest forecast improvements when U.S. volatility information is included, nevertheless, with the improvements being much softer than for the All Ordinaries index.

From the one-step-ahead out-of-sample forecast evaluation results, we can see further that for the European equity markets the response pattern is fairly consistent across the eight indices that we include. The improvement in the out-of-sample $R^{2}$ of Campbell and Thompson (2008) is in the range of 6.43 and 10.43 percent. For the three North and South American equity indices, the improvement is smaller overall than for the European equity markets, with the Brazilian Bovespa showing the weakest gain. Our conjecture for this result is that, due to the general trading hour overlap between these markets and the NYSE, most of the U.S. based equity market volatility information is transferred on the same trading day. The NYSE is open from 14:30 to 21:00 UTC (during winter). The IPC Mexico and S\&P TSX trade over the same hours as the NYSE, while the Bovespa is open from 13:00 to 20:00 UTC. We expect therefore the HAR components of the respective foreign equity markets to absorb and carry most of the relevant volatility information on the same trading day, thereby reducing the impact lagged U.S. volatility information has on the forecasts. In a different context, Nikkinen et al. (2006) have found that Latin American countries are not affected by U.S. news announcements, highlight-

\footnotetext{
${ }^{23}$ Both, the Nikkei 225 and the KOSPI open at 00:00 UTC time during summer, same as the All Ordinaries, while the FT Straits Times, Hang Seng and S\&P CNX Nifty open at 01:00, 01:20, and 01:30, respectively.
} 
ing the fact that they are less integrated with the U.S. ${ }^{24}$

Multiple-steps-ahead out-of-sample forecast evaluation results are presented in Table 5. The column entries in Table 5 contain the same information as the one-step-ahead evaluation results reported in Table 4, with the only exception that the two columns related to the (invalid) DM-statistic and its $p$-value have been removed. We follow Corsi and Renó (2012) and construct (normalised) multi-period log RV forecasts for horizons $h=5,10$ and 22 steps-ahead as in (13). Table 5 is split in three parts, with the top, middle and lower part, each corresponding to one of the three forecast horizons that we consider.

Before we discuss the multiple-steps-ahead forecast evaluation results, we would like to stress here that we take particular care when computing the HAC standard errors needed to construct the $p$-values of the CW - statistic. It is well known that $h$-step-ahead forecast errors follow at least an $\mathrm{MA}(h-1)$ process. When computing differences of the squared forecast errors from the two competing models to construct the $\mathrm{CW}-$ statistic, the $\mathrm{CW}_{t+h}$ sequence itself will be autocorrelated for $h>1$. This autocorrelation can be sizable for large $h$. We employ a pre-whitening step, using an $\operatorname{ARMA}(1,1)$ as the approximating model for the $\mathrm{CW}_{t+h}$ sequence to reduce the initial autocorrelation in the series, and then apply a Quadratic Spectral (QS) kernel based non-parametric HAC estimator on the residuals from the ARMA $(1,1)$ model. Following Andrews and Monahan (1992), we choose the bandwidth optimally with an AR(1) as the approximating model for the $\operatorname{ARMA}(1,1)$ (pre-whitened) residuals, and then re-colour to obtain the required HAC standard errors. ${ }^{25}$

To provide some intuition about the autocorrelation structure in the original $\mathrm{CW}_{t+h}$ series, we show plots of the ACF and PACF of the (22 day-ahead) $\mathrm{CW}_{t+22}$ sequence for the All Ordinaries in Panel (a) in Figure 5. A fairly slow decay pattern in the ACF is clearly visible, with some significant PACFs, typical of such a sequence. In Panel (b) in Figure 5, we plot the ACF and PACF of the pre-whitened residuals, using an $\operatorname{ARMA}(1,1)$ model for $\mathrm{CW}_{t+22}$ to remove most of the autocorrelation. It is clear from Panel (b) in Figure 5 that the autocorrelation structure is much weaker, making the choice of the bandwidth parameter for the non-parametric HAC estimator less dramatic. Note here also that we have at the minimum around 2500 outof-sample observations. Our $\operatorname{ARMA}(1,1)$ coefficients needed for the pre-whitening and recolouring steps should therefore be estimated rather precisely.

From the multiple-steps-ahead forecast results in Table 5 we can see that the forecast improvements relative to the benchmark HAR model stay highly significant for all 17 interna-

\footnotetext{
${ }^{24}$ In a different context, in the news effect and announcement literature, Brand et al. (2010) have shown that European equity and bond markets react less to news form the U.S. such as initial unemployment claims, once conditioning on ECB announcements.

${ }^{25}$ That is, using the notation in Andrews and Monahan (1992), the bandwidth parameter is set to $1.3221\left[\hat{\alpha}(2) T_{o s}\right]^{1 / 5}$, where the constant $\hat{\alpha}(2)=4 \hat{\rho}^{2} /(1-\hat{\rho})^{4}$ and $\hat{\rho}$ is the $\operatorname{AR}(1)$ parameter estimate obtained from an AR(1) regression of the (pre-whitened) residual series obtained from the ARMA $(1,1)$ model fitted to the $\mathrm{CW}_{t+h}$ sequence. To obtained the HAC variance, we then 're-colour' again with the ratio of the square of the ARMA lag polynomials (see Andrews and Monahan, 1992 for more details on the exact computations).
} 
tional equity markets at the 5 day ( 1 week) ahead horizon. At the 10 day ( 2 week) ahead horizon, the improvements remain substantial, nevertheless, now with some of them, for instance, the KOSPI, the S\&P CNX Nifty and Bovespa being significant at the lower 5\% level. For 11 out of the 17 equity markets, the $\mathrm{CW}$ - statistic is above 4, indicating a fairly strong rejection of the null that there is no forecast improvement when U.S. equity market volatility information is included. Moreover, for these 11 equity markets, the $R_{o s}^{2}$ values are in the sizeable 4.12 to 9.48 percent range. Looking over the 22 day-ahead forecast evaluation results, we see that even at the 1 month ahead horizon, there still exist noticeable improvements in predictive performance for most of the foreign equity markets that we include. That is, for 10 out of the 17 equity markets, the $\mathrm{CW}$ - statistic remains solidly above 3, with the $R_{o s}^{2}$ for these 10 markets being between 2.78 and 7.37 percent.

In summary of the out-of-sample forecast evaluating results that we have presented in this section, it is clear that including information about U.S. equity market volatility from the previous trading day leads to substantial improvements in out-of-sample predictions of log RV in all 17 international equity markets that we consider. Moreover, this improvement has a lasting impact and effects forecasts as far as 1 month ahead. The equity markets whose forecasts are most improved by including U.S. volatility information are the All Ordinaries index, followed by all the European equity indices that we analyse. The weakest results are obtained for the forecasts of the South American, as well as some of the Asian equity markets that we examine.

\section{Robustness checks}

In this section, we address some pertinent questions related to the robustness of our out-ofsample forecast evaluation results that we presented in Section 4. In particular, we address concerns related to questions about $a$ ) varying the size of the in-sample period, $b$ ) the choice of the headline U.S. equity market index used and $c$ ) whether most of the out-of-sample forecasting power comes from the log VIX series alone. We address each one of these concerns separately, taking the results we obtained in Table 4, Figure 4 and Table 5 as the status quo. All tables and figures supporting our discussion below are provided in the Appendix. Here we summarize the main findings of the robustness checks.

\subsection{Varying the size of the in-sample period}

A well known issue when performing sample splitting for out-of-sample forecast evaluation analysis is that the in- and out-of-sample periods can be chosen so as to 'maximize' the out-ofsample forecast performance of the model. ${ }^{26}$ To provide some evidence that this is not the case

\footnotetext{
${ }^{26}$ See, for instance, the discussion in Rossi and Inoue (2012) and references therein. Note here that Rossi and Inoue (2012) focus on the effect of sample splitting in rather small samples, which are common when dealing with monthly or quarterly data. Moreover, they focus on finding a good mix that ensures that out-of-sample predictability results are not adversely affected by doing a poor in- versus out-of-sample split, and provide guidelines for the
} 
here, we report out-of-sample forecast evaluation results for $T_{\text {in }}=1000$ in Table A.1, Figure A.1 and Table A.2. As can be seen from Table A.1 and in line with the findings based on $T_{\text {in }}=500$ in-sample observations, the $\mathrm{CW}$ - statistic of all 17 equity markets remains above 7 , resulting in $p$-values that are effectively zero. The range of out-of-sample $R^{2}$ values in Table A.1 is between 2.58 to 13.48 percent. This range is somewhat higher than for $T_{i n}=500$, which is between 1.81 and 12.83 percent.

Assessing visually the differences in forecast performance between a rolling and expanding (recursive) estimation scheme in the cumSFE $t_{t+1}$ series, we can see from Figure A.1 that the general strong upward trend remains. Overall, the two cumSFE ${ }_{t+1}$ series based on a rolling and expanding (recursive) window line up rather closely, as was the case with 500 in-sample observations. One noticeable difference is for the IPC Mexico index, where the rolling window based cumSFE $t_{t+1}$ series starts to diverge slightly from approximately the end of 2008 to the end of 2011. This divergence is less pronounced when using 500 in-sample observations. In general, nonetheless, the expanding window based results are very similar to what we have seen in Figure 4.

From the multiple-steps-ahead forecast evaluation results in Table A.2 we can see that for $h=5$, all CW - statistics remain significant at the $1 \%$ level. At the 10 day ahead forecast horizon, 14 out of 17 forecasts remain significant at the $1 \%$ level, with the other three having $p$-values between 0.0104 and 0.0183 . At the 22 day ahead horizon, forecast improvements start to deteriorate for some of the international equity markets, nevertheless, in the same manner as was observed in Table 5 with $T_{i s}=500$. There are still 11 out of 17 of the 22 day ahead forecasts that are significant at the $1 \%$ level, with out-of-sample $R^{2}$ values in the sizeable 2.35 to 9.09 percent range.

\subsection{Using the DJIA as the headline U.S. index}

Our analysis so far has relied on using log RV data from the S\&P500 index. We now assess the robustness of our findings with respect to this choice, by using log RV data from intraday returns of the Dow Jones Industrial Average (DJIA) index instead. These results are reported in Table A.3, Figure A.2 and Table A.4. From the one-step-ahead results in Table A.3 we can see that the results are highly consistent with those from the S\&P500. The CW - statistic remains above 7 for all but one of the 17 international equity markets (for Bovespa it is 6.77), indicating a very strong rejection of the null hypothesis that U.S. equity market volatility information does not improve one-step-ahead out-of-sample forecasts. The range of $R_{o s}^{2}$ values is between 1.26 and 12.86 percent, and hence also largely in line with the S\&P500 based findings.

Examining the cumSFE $t_{t+1}$ series in Figure A.2, we see overall the same pattern as with the S\&P500. There is still a general strong upward trend in the series, indicating that the outof-sample forecast improvement is consistent over the whole time period that we analyze. A splitting. 
closer investigation of the cumSFE $E_{t+1}$ series shows that for most of the international equity markets, the overall improvement is somewhat weaker than when the S\&P500 is used as the headline index, as is evident from the marginally flatter slopes in the cumSFE $\mathrm{t}_{t+1}$ series. As an example, looking at the expanding window based cumSFE $E_{t+1}$ series, we can see that at the end of the sample in January 23, 2015 it reaches a value of around 40 for the DAX when the DJIA is used, while it is closer to 50 with the S\&P500 as the headline index. Nonetheless, the overall differences in the cumSFE $t_{t+1}$ series are rather small.

At the multiple step horizon shown in Table A.4 the forecast evaluation results are again very similar. At the 5 step-ahead horizon, the $\mathrm{CW}$ - statistic remains significant at the $1 \%$ level for all 17 international equity markets. For forecast horizons of 10 and 22 steps-ahead, respectively, 15 and 12 forecast improvements are significant at the $1 \%$ level. The magnitudes of the $R_{o s}^{2}$ are further inline with the ranges obtained with the S\&P500 index.

\subsection{Is the VIX driving all the forecast improvement results?}

As a final check, we assess the impact of the (lagged) log VIX series on the forecast evaluation results. We have seen earlier in Table 2 from the in-sample estimates, that the coefficient on the $\log$ VIX series can be quite large, i.e., it is between 0.6440 to 0.8975 for 10 out of our 17 international equity markets. To determine how much of the forecast improvements are driven by the VIX, we remove the $\log \mathrm{VIX}_{t}$ series from $x_{t}^{\mathrm{US}}$ in (6) and repeat our out-of-sample forecast evaluation assessment against the benchmark HAR model as before. These evaluation results are reported in Table A.5, Figure A.3 and Table A.6.

From these results it is evident that the importance of the VIX on the predictive performance is mixed, and depends on the forecast horizon and the foreign equity market that is analysed. At the one-step-ahead horizon, we can see from Table A.5 that the improvements remain significant for all 17 international equity markets at the $1 \%$ level. Nevertheless, the lowest CW - statistic recorded drops now to around 4 (S\&P TSX), while the largest one is still over 15 (All Ordinaries). The out-of-sample $R^{2}$ is as low as 0.64 and 0.71 percent for the Bovespa and S\&P TSX one-step-ahead forecasts, but remains high for the All Ordinaries at 12.15 percent. When comparing the cumSFE $t_{t+1}$ series in Figure A.3 to the one including the log VIX as a regressor in $x_{t}^{\mathrm{US}}$, we see that, apart from the All Ordinaries, the FT Straits Times, the Nikkei 225 and also the Hang Seng, the slopes of the cumSFE $t_{t+1}$ series are considerably subdued, with the Bovespa and S\&P TSX ones remaining rather flat over the entire out-of-sample period. For the DAX, the CAC40, FTSE MIB and Swiss Market Index it is evident that the improvements in out-of-sample forecast performance did not materialise until about the end of 2006.

Looking over the evaluation results at longer forecast horizons, one can see that the performance of the augmented HAR model which excludes the log VIX data diminishes quickly. At the 5 day ahead horizon, the $\mathrm{CW}$ - statistic remains significant at the $1 \%$ level for 15 out the 17 equity markets. Nevertheless, with the exception of the All Ordinaries series, the overall 
improvement in the forecasts is noticeably weaker, resulting in much smaller $R_{o s}^{2}$ values. The improvements deteriorate even further for 10 and 22 day-ahead prediction horizons. At the 10 day-ahead horizon, only 12 out of 17 forecast improvements stay significant at the 1\% level, while at the 22 day-ahead horizon, only the results for the All Ordinaries are significant at the $1 \%$ level. In summary, it is clear that the improvements in forecasts up to one week ahead are significant, sizeable and not entirely driven by the VIX. The predictive content in the VIX is most informative for longer horizon forecasts, particulary for predictions 1 month ahead.

\section{Conclusion}

In this study, we extend the work of Rapach et al. (2013) and examine what role the U.S. plays as a source of information relevant for volatility in international equity markets. For that purpose, we augment the benchmark HAR model of Corsi (2009) with daily, weekly and monthly U.S. HAR components and log VIX data and evaluate the in-sample as well as out-of-sample contribution of U.S. equity market volatility information on realized volatility in international (non-U.S.) equity markets. Our results show that there is a strong role for the U.S. as a source of volatility information, being particularly important for the Australian and all European equity markets that we consider.

Using daily realized volatility data for the U.S. and 17 international (non-U.S.) equity markets from the Oxford Man Institutes realized library and covering a period from January 3, 2000 to January 23, 2015, our in-sample analysis shows that U.S. equity volatility information is highly informative and statistically significant. For some equity markets such as the All Ordinaries and the EURO STOXX 50, the parameter estimate of the daily U.S. HAR component has a larger magnitude than its own daily HAR component, suggesting that the previous day's high frequency volatility information from the U.S. is more important than its own lagged volatility. One interesting finding of our in-sample analysis is a negative feedback effect from the low frequency volatility component from the U.S. to realized volatility in non-U.S. equity markets. This finding is consistent across all of the 17 international equity markets that we consider.

From our out-of-sample forecast evaluation we find (at the one-step ahead horizon) a highly significant (at the 1\% level) improvement for all 17 equity markets when U.S. equity volatility information is included. The daily Campbell and Thompson (2008) out-of-sample $R^{2}$ ranges between $1.18 \%$ to $12.83 \%$ and is the highest for All Ordinaries (12.83\%), the EURO STOXX 50 $(10.43 \%)$ and the CAC 40 (9.41\%), while it is the lowest for the Brazilian Bovespa Index (1.18\%). This improvement is also reflected in the cumulative difference of the squared forecast errors from the augmented HAR model relative to the benchmark HAR model. That is, we find a (nearly) uniformly above zero and monotonically increasing sequence for the entire out-ofsample evaluation period and for (nearly) all 17 foreign equity markets (the exception being the Bovespa Brazilian equity market index). Moreover, our results show that particularly the 
Australian and the European equity markets benefit the most from including U.S. based equity market volatility information in forecasting realized volatility, while the South American as well as some Asian equity markets benefit the least. For longer forecast horizons, we find similarly strong results for the one week ahead horizon, and somewhat weaker results for two week and one month ahead horizons. More specifically, at the 10 day-ahead forecast horizon, the improvements are still statistically significant at the $1 \%$ level for all 14 equity markets and for 12 equity markets at the 1 month-ahead horizon. At the 10 day-ahead horizon, sizeable $R_{o s}^{2}$ values of between $4.12 \%$ to $9.48 \%$ are obtained for forecasts that are significant at the $1 \%$ level. Although the results deteriorate for the one month forecast horizon, out-of-sample $R^{2}$ values remain in the $2.78 \%$ to $7.37 \%$ range for 10 of the most significant equity markets.

In summary, our analysis confirms the important role the U.S. plays as a source of equity market information. This role is not only important for international equity return forecasts as documented in Rapach et al. (2013), but also for forecasts of realized volatility in international equity markets. 


\section{References}

Andersen, Torben G., Tim Bollerslev and Francis X. Diebold (2007): “Roughing It Up: Including Jump Components in the Measurement, Modeling and Forecasting of Return Volatility," Review of Economics and Statistics, 89(4), 701-720.

Andersen, Torben G., Tim Bollerslev, Francis X. Diebold and Paul Labys (2003): "Modeling and Forecasting Realized Volatility," Econometrica, 71(2), 579-625.

Andrews, Donald W. K. and J. Christopher Monahan (1992): "An Improved Heteroskedasticity and Autocorrelation Consistent Covariance Matrix Estimator," Econometrica, 60(4), 953-966.

Baillie, Richard T. (1996): "Long memory processes and fractional integration in econometrics," Journal of Financial Econometrics, 73(1), 5-59.

Baillie, Richard T., Tim Bollerslev and Hans O. Mikkelsen (1996): “Fractionally integrated generalized autoregressive conditional heteroskedasticity," Journal of Econometrics, 74, 3-30.

Becker, K. K., J. E. Finnerty and J. E. Friedman (1995): “Economic news and equity market linkages between the US and UK," Journal of Banking and Finance, 19, 1191-1210.

Bollerslev, Tim, Julia Litvinova and George Tauchen (2006): "Leverage and volatility feedback effect in high-frequency data," Journal of Financial Econometrics, 4(3), 353-384.

Bonato, Matteo, Massimiliano Caporin and Angelo Ranaldo (2013): “Risk spillovers in international equity portfolios," Journal of Empirical Finance, 24, 121-137.

Brand, Claus, Daniel Buncic and Jarkko Turunen (2010): “The Impact of ECB Monetary Policy Decisions and Communication on the Yield Curve," Journal of the European Economic Association, 8(6), 1266-1298.

Brunnermeier, Markus K., Stefan Nagel and Lasse H. Pedersen (2009): “Carry Trades and Currency Crashes," in NBER Macroeconomics Annual 2008, edited by Daron Acemoglu, Kenneth Rogoff and Michael Woodford, University of Chicago Press, Volume 23, 313-347s.

Buncic, Daniel and Martin Melecky (2013): "Macroprudential stress testing of credit risk: A practical approach for policy makers," Journal of Financial Stability, 9(3), 347-370.

(2014): “Equilibrium credit: The reference point for macroprudential supervisors," Journal of Banking and Finance, 41(April), 135-154.

Buncic, Daniel and Carlo Moretto (2015): "Forecasting Copper Prices with Dynamic Averaging and Selection Models," North American Journal of Economics and Finance, forthcoming.

Buncic, Daniel and Gion Donat Piras (2014): "Heterogenous Agents, the Financial Crisis and Exchange Rate Predictability," Discussion Paper No. 2014-36, School of Economics and Political Sciences, University of St. Gallen. Available from: https:/ /ideas.repec.org/p/usg/econwp/201436.html.

Campbell, John Y. and Samuel B. Thompson (2008): "Predicting Excess Stock Returns Out of Sample: Can Anything Beat the Historical Average?" Review of Financial Studies, 21(4), 1509-1531.

Chen, Xilong and Eric Ghysels (2011): "News - good or bad - and its impact on volatility predictions over multiple horizons," Review of Financial Studies, 24(1), 46-81. 
Chen, Ying, Wolfgang K. Härdle and Uta Pigorsch (2010): "Localized realized volatility modelling," Journal of the American Statistical Association, 105(492), 1376-1393.

Chevillon, Guillaume (2007): "Direct multi-step Estimation and Forecasting," Journal of Economic Surveys, 21(4), 746-785.

Chevillon, Guillaume and David F. Hendry (2005): “Non-parametric direct multi-step estimation for forecasting economic processes," International Journal of Forecasting, 21(2), 201-218.

Chow, Victor, Wanjun Jiang and Jingrui Li (2014): “Does VIX Truly Measure Return Volatility?” SSRN Working Paper No. 2489345. Available from: http:/ / ssrn.com/abstract=2489345.

Clark, Todd E. and Kenneth D. West (2007): “Approximately normal tests for equal predictive accuracy in nested models," Journal of Econometrics, 138(1), 291-311.

Clements, Michael P. and David F. Hendry (1996): "Multi-step Estimation for Forecasting," Oxford Bulletin of Economics and Statistics, 58(4), 657-84.

Comte, Fabienne and Eric Renault (1996): “Long-memory continuous time models," Journal of Econometrics, 73(1), 101-149.

(1998): "Long memory in continuous-time stochastic volatility models," Mathematical Finance, 8(4), 291-323.

Corsi, Fulvio (2009): “A Simple Approximate Long-Memory Model of Realized Volatility," Journal of Financial Econometrics, 7(2), 174-196.

Corsi, Fulvio, Francesco Audrino and Roberto Renó (2012): "HAR Modeling for Realized Volatility Forecasting," in Handbook of Volatility Models and their Applications, edited by Luc Bauwens, Christian Hafner and Sebastien Laurent, John Wiley and Sons, Inc., 363-382.

Corsi, Fulvio, Davide Pirino and Roberto Renó (2010): “Threshold bipower variation and the impact of jumps on volatility forecasting," Journal of Econometrics, 159(2), 276-288.

Corsi, Fulvio and Roberto Renó (2012): “Discrete-time volatility forecasting with persistent leverage effect and the link with continuous-time volatility modeling," Journal of Business and Economic Statistics, 30(3), 368-380.

Diebold, Francis X. (2015): “Comparing Predictive Accuracy, Twenty Years Later: A Personal Perspective on the Use and Abuse of Diebold-Mariano Tests," Journal of Business and Economic Statistics, 33(1), 1-9.

Diebold, Francis X. and Roberto S. Mariano (1995): “Comparing Predictive Accuracy," Journal of Business and Economic Statistics, 13(1), 253-263.

Diebold, Francis X. and Kamil Yilmaz (2012): "Better to give than to receive: Predictive directional measurement of volatility spillovers," International Journal of Forecasting, 28, 57-66.

- (2014a): “On the network topology of variance decompositions: Measuring the connectedness of financial firms," Journal of Econometrics, 182(1), 119-134.

(2014b): “Trans-Atlantic Volatility Connectedness Among Financial Institutions," Manuscript, University of Pennsylvania and Koc University. Available from: http://www.ssc.upenn.edu/ $\sim$ fdiebold/papers/paper120/euusbanks.pdf. 
Dimpfl, Thomas and Robert C. Jung (2012): "Financial market spillovers around the globe," Applied Financial Economics, 22, 45-57.

Engle, Robert F. (1990): "Stock volatility and the crash of '87: Discussion," The Review of Financial Studies, 3(1), 103-106.

Fengler, Matthias R. and Katja I. M. Gisler (2015): “A variance spillover analysis without covariances: What do we miss?" Journal of International Money and Finance, 51, 174-195.

Fengler, Matthias R., Enno Mammen and Michael Vogt (2013): "Additive Modeling of Realized Variance: Tests for Parametric Specifications and Structural Breaks," SSRN Working Paper No. 2348600. Available from: http:/ / ssrn.com/abstract=2348600.

Goyal, Amit and Ivo Welch (2008): "A Comprehensive Look at The Empirical Performance of Equity Premium Prediction," Review of Financial Studies, 21(4), 1455-1508.

Grassi, Stefano, Nima Nonejad and Paolo Santucci de Magistritis (2014): "Forecasting with the standardized self-perturbed Kalman filter," CREATES Research Paper 2014-12, Aahrhus University.

Hamao, Yasushi, Ronald Masulis and Victor Ng (1990): "Correlations in price changes and volatility across international stock markets," The Review of Financial Studies, 3, 281-307.

Heber, Gerd, Asger Lunde, Neil Shephard and Kevin Sheppard (2009): “Oxford-Man Institute's realized library," Oxford-Man Institute, University of Oxford. Available from: http://realized.oxford-man.ox. ac.uk/.

Jacod, Jean and Albert N. Shiryaev (1987): Limit Theorems for Stochastic Processes, Springer.

King, Mervyn A. and Sushil Wadhwani (1990): "Transmission of volatility between stock markets," The Review of Financial Studies, 3, 5-33.

Lin, Wen-Ling, Robert F. Engle and Takatoshi Ito (1994): “Do bulls and bears move across borders? International transmission of stock returns and volatility," The Review of Financial Studies, 7(3), 507-538.

Liu, Lily, Andrew J. Patton and Kevin Sheppard (2014): “Does Anything Beat 5-Minute RV? A Comparison of Realized Measures Across Multiple Asset Classes," Discussion Paper 645, University of Oxford.

Marcellino, Massimiliano, James H. Stock and Mark W. Watson (2006): “A comparison of direct and iterated multistep AR methods for forecasting macroeconomic time series," Journal of Econometrics, 135(12), 499-526.

McAleer, Michael and Marcelo C. Medeiros (2008): “Realized volatility: a review," Econometric Reviews, 27(1), 10-45.

Müller, Ulrich A., Michel M. Dacorogna, Rakhal D. Davé, Richard B. Olsen, Olivier V. Pictet and John R. Ward (1993): "Fractals and Intrinsic Time - A Challenge to Econometricians," Invited presentation at the 39th International AEA Conference on Real Time Econometrics, 14 - 15 October 1993, Luxembourg.

Neely, Christopher J., David E. Rapach, Jun Tu and Guofu Zhou (2014): "Forecasting the Equity Risk Premium: The Role of Technical Indicators," Management Science, 60(7), 1772-1791. 
Newey, Whitney K and Kenneth D West (1994): “Automatic Lag Selection in Covariance Matrix Estimation," Review of Economic Studies, 61(4), 631-53.

Nikkinen, Jussi, Mohammed Omran, Petri Sahlström and Janne Äjiö (2006): “Global stock market reactions to schedulded U.S. macroeconomic news announcements," Global Finance Journal, 17, 92-104.

Patton, Andrew J. and Kevin Sheppard (2013): “Good Volatility, Bad Volatility: Signed Jumps and the Persistence of Volatility," Review of Economics and Statistics.

Pesaran, M. Hashem, Andreas Pick and Allan Timmermann (2011): "Variable selection, estimation and inference for multi-period forecasting problems," Journal of Econometrics, 164(1), 173-187.

Rapach, David E., Jack K. Strauss and Guofu Zhou (2013): "International Stock Return Predictability: What Is the Role of the United States?" The Journal of Finance, 68(4), 1633-1662.

Rossi, Barbara and Atsushi Inoue (2012): “Out-of-Sample Forecast Tests Robust to the Choice of Window Size," Journal of Business and Economic Statistics, 30(3), 432-453. 
Figures and Tables 


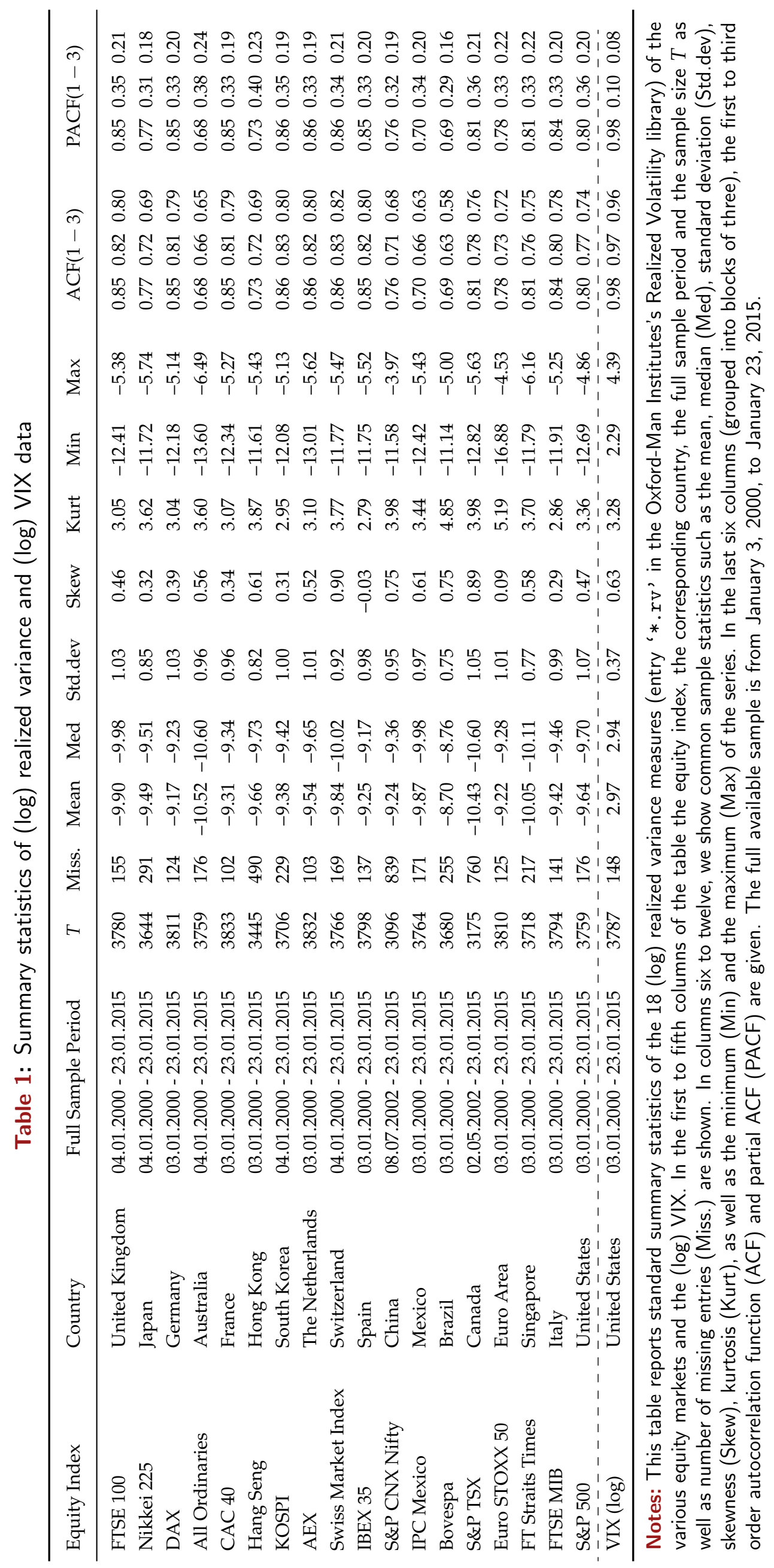



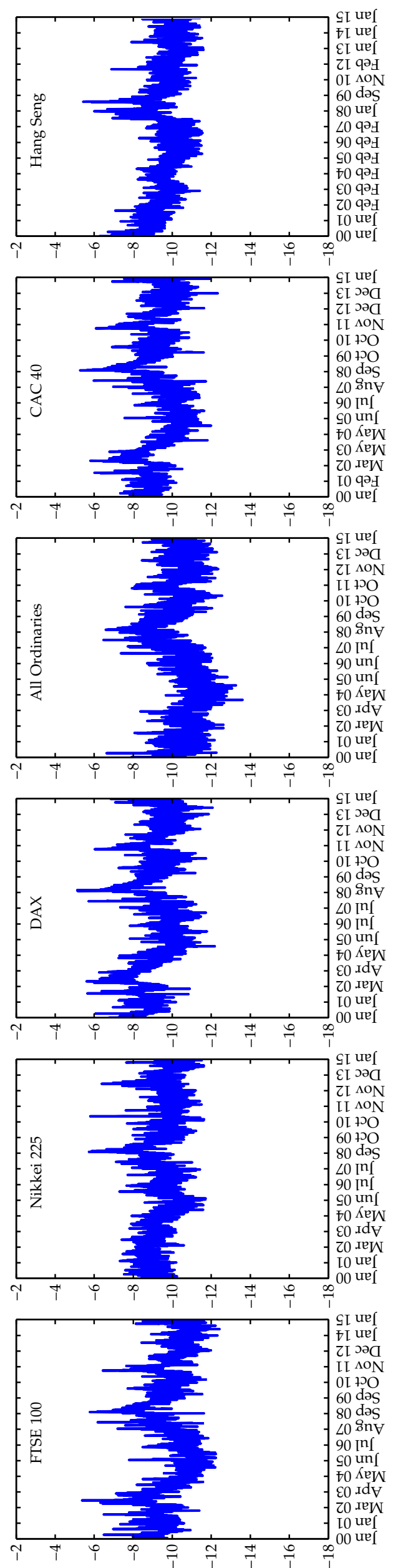
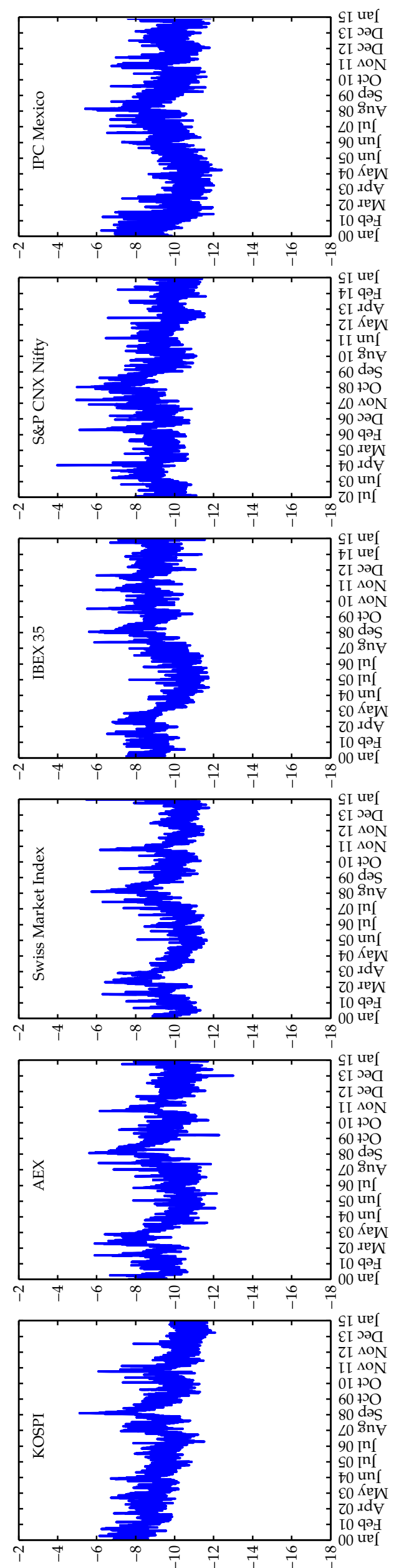
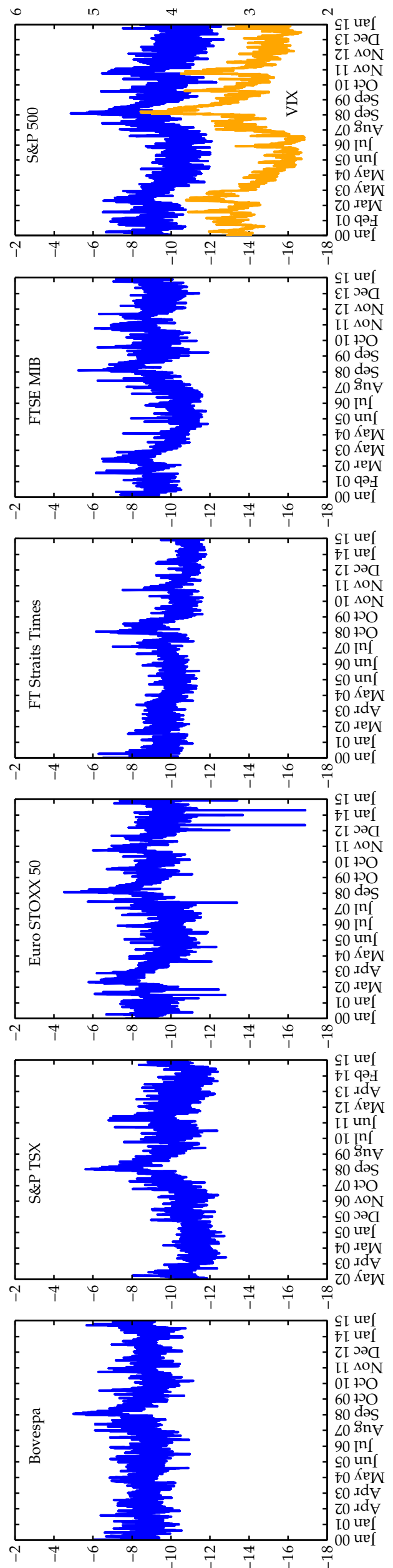

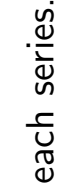

흐

응

$\frac{0}{2}$

हี

$\frac{0}{0}$

$\frac{\pi}{\frac{\pi}{0}}$

$\frac{\pi}{\pi}$

$\overline{5}$

$\stackrel{\Phi}{\amalg}$

$\bar{\nu}$

ว

$\stackrel{x}{>}$

0

을

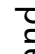

ษ్

- $\frac{\pi}{2}$

$>$

$\stackrel{\stackrel{N}{\sigma}}{\mathbb{V}}$

$\stackrel{1}{2}$

每

4

흠

ำ

ㅇำ

है

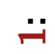

壱

证 
FTSE 100

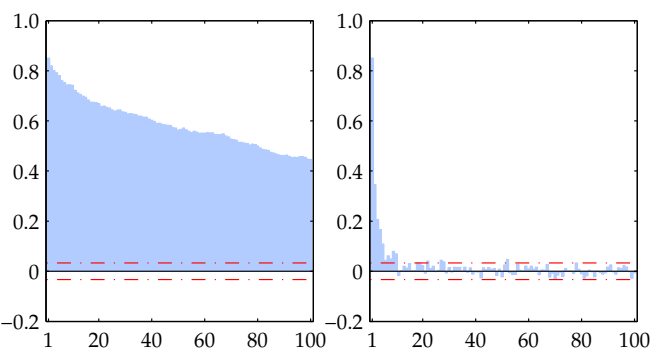

All Ordinaries

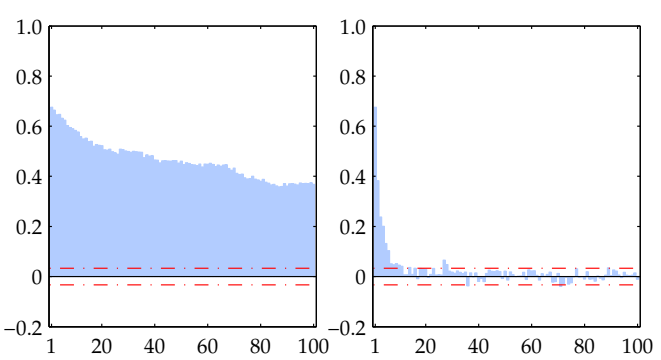

KOSPI

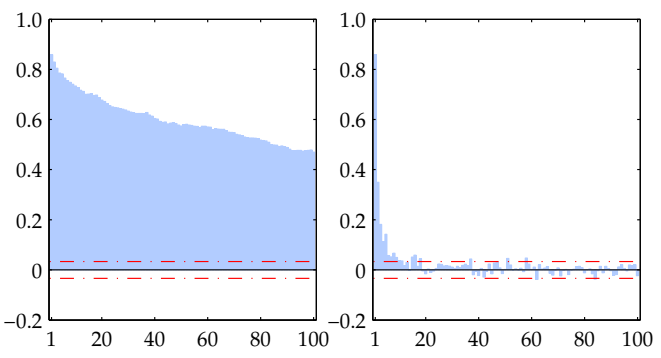

IBEX 35

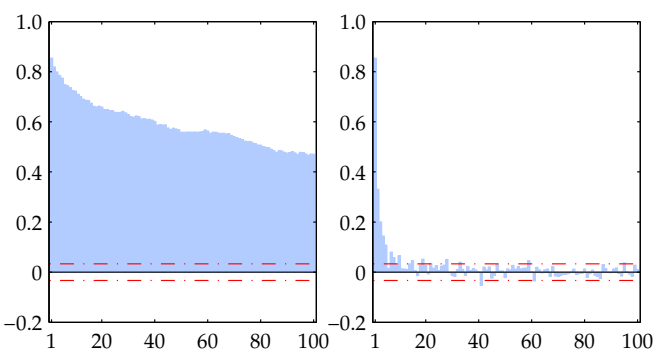

Bovespa

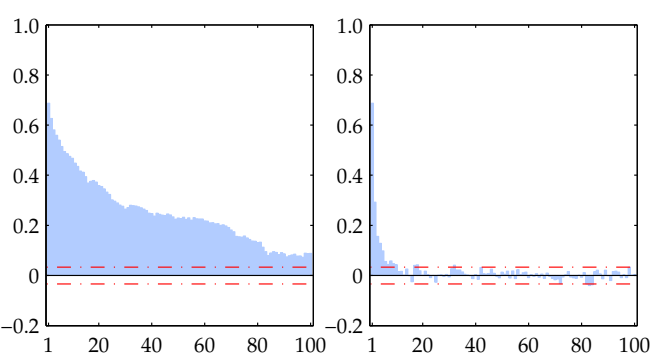

FT Straits Times

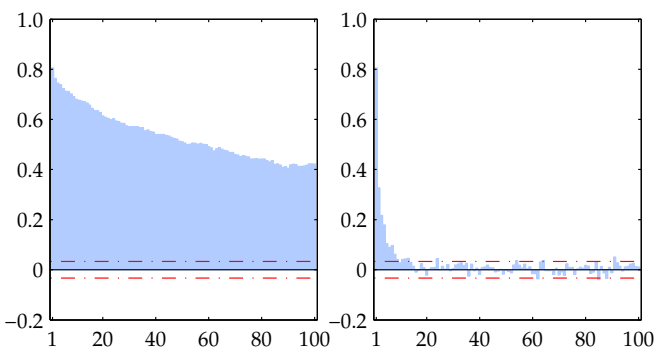

Nikkei 225

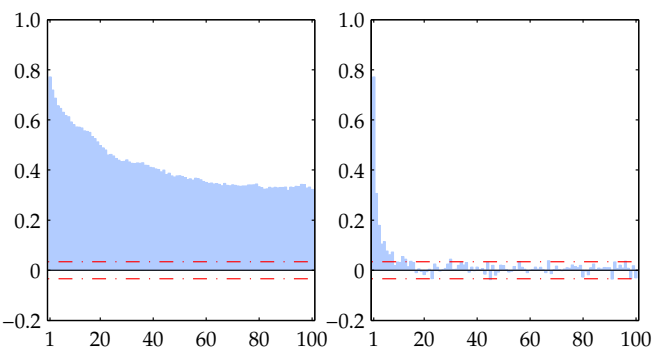

CAC 40

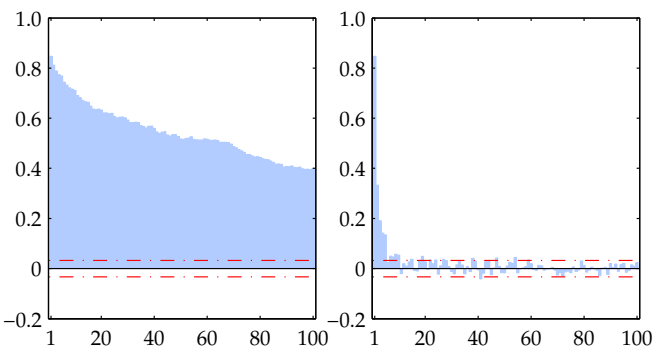

AEX

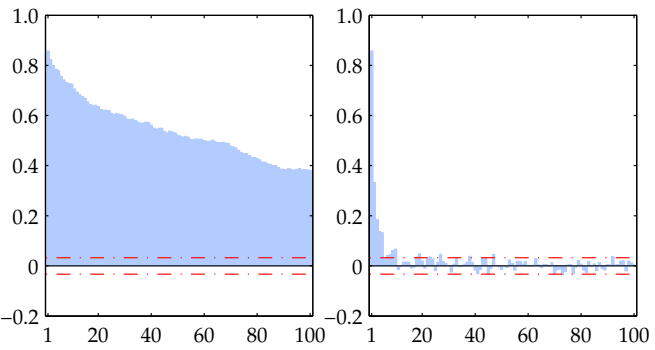

S\&P CNX Nifty

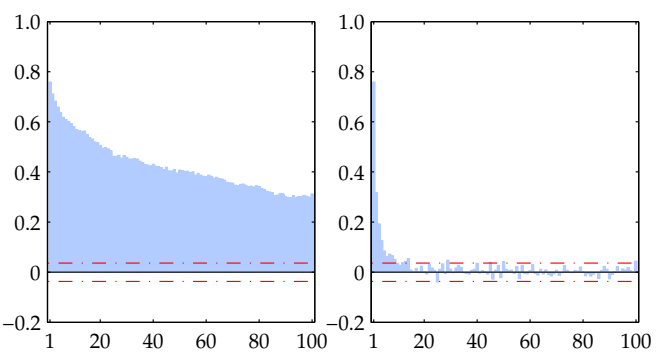

S\&P TSX

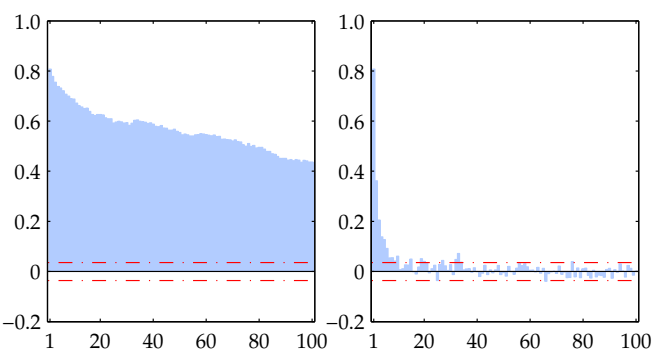

FTSE MIB

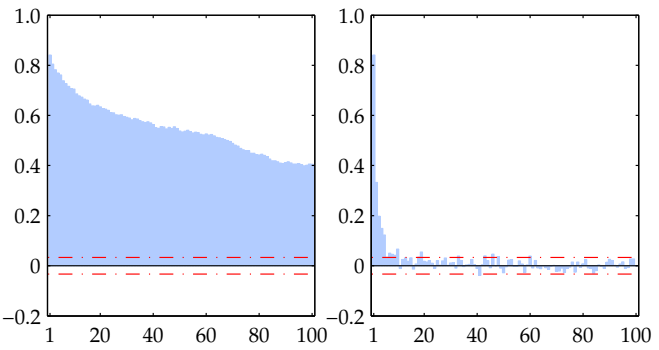

DAX

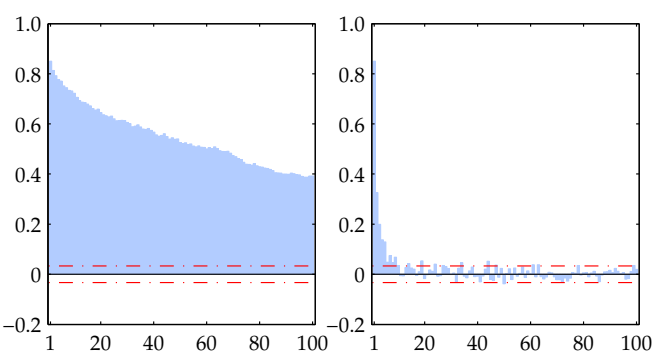

Hang Seng

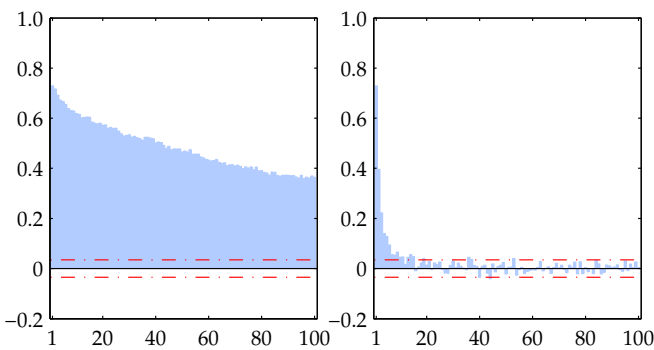

Swiss Market Index

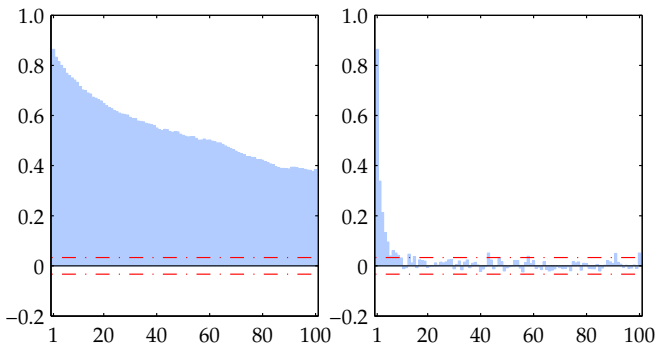

IPC Mexico

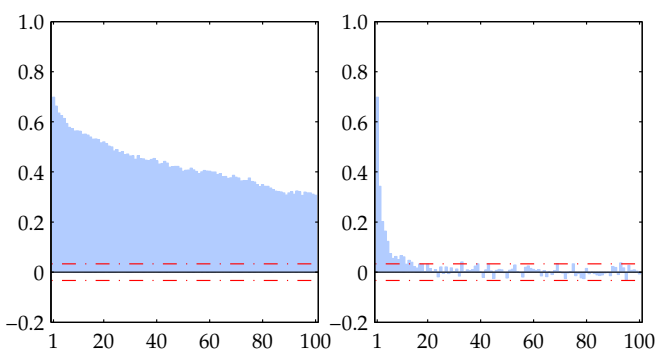

Euro STOXX 50

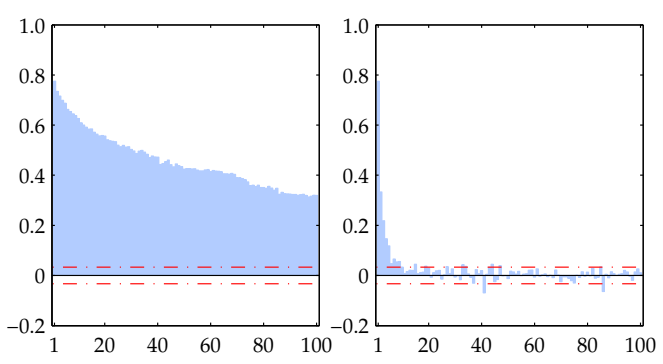

S\&P 500

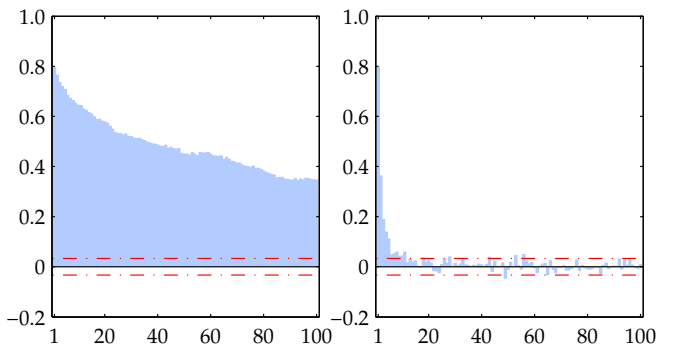

Figure 2: Autocorrelation function (ACF) and partial ACF (PACF) plots of all (log) realized variance series. 
Table 2: Augmented HAR model parameter estimates over the full sample period

\begin{tabular}{|c|c|c|c|c|c|c|c|c|c|c|}
\hline Equity Index & Sample Period & $\hat{\beta}_{0}$ & $\hat{\beta}^{(d)}$ & $\hat{\beta}^{(w)}$ & $\hat{\beta}^{(m)}$ & $\hat{\beta}_{\mathrm{VIX}}$ & $\hat{\beta}_{\mathrm{US}}^{(d)}$ & $\hat{\beta}_{\mathrm{US}}^{(w)}$ & $\hat{\beta}_{\mathrm{US}}^{(m)}$ & $\chi^{2}-$ test \\
\hline FTSE 100 & $04.02 .2000-23.01 .2015$ & $\begin{array}{r}-6.24 \\
{[0.00]}\end{array}$ & $\begin{array}{l}0.1807 \\
{[0.0000]}\end{array}$ & $\begin{array}{l}0.3716 \\
{[0.0000]}\end{array}$ & $\begin{array}{l}0.2529 \\
{[0.0000]}\end{array}$ & $\begin{array}{l}0.8691 \\
{[0.0000]}\end{array}$ & $\begin{array}{l}0.1431 \\
{[0.0000]}\end{array}$ & $\begin{array}{c}-0.0442 \\
{[0.2719]}\end{array}$ & $\begin{array}{r}-0.2790 \\
{[0.0000]}\end{array}$ & $\begin{array}{r}253.15 \\
{[0.00]}\end{array}$ \\
\hline Nikkei 225 & 07.02.2000 - 23.01.2015 & $\begin{array}{c}-2.85 \\
{[0.00]}\end{array}$ & $\begin{array}{l}0.3120 \\
{[0.0000]}\end{array}$ & $\begin{array}{l}0.3403 \\
{[0.0000]}\end{array}$ & $\begin{array}{l}0.2544 \\
{[0.0000]}\end{array}$ & $\begin{array}{l}0.3584 \\
{[0.0000]}\end{array}$ & $\begin{array}{l}0.1691 \\
{[0.0000]}\end{array}$ & $\begin{array}{r}-0.0990 \\
{[0.0014]}\end{array}$ & $\begin{array}{r}-0.1631 \\
{[0.0000]}\end{array}$ & $\begin{array}{r}160.81 \\
{[0.00]}\end{array}$ \\
\hline DAX & 03.02.2000 - 23.01.2015 & $\begin{array}{r}-5.30 \\
{[0.00]}\end{array}$ & $\begin{array}{l}0.2115 \\
{[0.0000]}\end{array}$ & $\begin{array}{l}0.3868 \\
{[0.0000]}\end{array}$ & $\begin{array}{l}0.2795 \\
{[0.0000]}\end{array}$ & $\begin{array}{l}0.7515 \\
{[0.0000]}\end{array}$ & $\begin{array}{l}0.1689 \\
{[0.0000]}\end{array}$ & $\begin{array}{r}-0.0845 \\
{[0.0351]}\end{array}$ & $\begin{array}{r}-0.2867 \\
{[0.0000]}\end{array}$ & $\begin{array}{r}247.84 \\
{[0.00]}\end{array}$ \\
\hline All Ordinaries & $07.02 .2000-23.01 .2015$ & $\begin{array}{c}-3.11 \\
{[0.00]}\end{array}$ & $\begin{array}{l}0.0421 \\
{[0.0340]}\end{array}$ & $\begin{array}{l}0.4109 \\
{[0.0000]}\end{array}$ & $\begin{array}{l}0.4639 \\
{[0.0000]}\end{array}$ & $\begin{array}{l}0.3846 \\
{[0.0000]}\end{array}$ & $\begin{array}{l}0.3261 \\
{[0.0000]}\end{array}$ & $\begin{array}{r}-0.0639 \\
{[0.0861]}\end{array}$ & $\begin{array}{r}-0.3758 \\
{[0.0000]}\end{array}$ & $\begin{array}{r}333.06 \\
{[0.00]}\end{array}$ \\
\hline CAC 40 & $03.02 .2000-23.01 .2015$ & $\begin{array}{c}-6.34 \\
{[0.00]}\end{array}$ & $\begin{array}{l}0.1864 \\
{[0.0000]}\end{array}$ & $\begin{array}{l}0.4083 \\
{[0.0000]}\end{array}$ & $\begin{array}{l}0.1959 \\
{[0.0000]}\end{array}$ & $\begin{array}{l}0.8802 \\
{[0.0000]}\end{array}$ & $\begin{array}{l}0.1587 \\
{[0.0000]}\end{array}$ & $\begin{array}{r}-0.0776 \\
{[0.0418]}\end{array}$ & $\begin{array}{r}-0.2660 \\
{[0.0000]}\end{array}$ & $\begin{array}{r}249.84 \\
{[0.00]}\end{array}$ \\
\hline Hang Seng & 03.02.2000 - 23.01.2015 & $\begin{array}{c}-2.43 \\
{[0.00]}\end{array}$ & $\begin{array}{l}0.1263 \\
{[0.0000]}\end{array}$ & $\begin{array}{l}0.4132 \\
{[0.0000]}\end{array}$ & $\begin{array}{l}0.3780 \\
{[0.0000]}\end{array}$ & $\begin{array}{l}0.2957 \\
{[0.0000]}\end{array}$ & $\begin{array}{l}0.0971 \\
{[0.0000]}\end{array}$ & $\begin{array}{r}-0.0051 \\
{[0.8694]}\end{array}$ & $\begin{array}{r}-0.1706 \\
{[0.0000]}\end{array}$ & $\begin{array}{l}58.68 \\
{[0.00]}\end{array}$ \\
\hline KOSPI & 07.02.2000 - 23.01.2015 & $\begin{array}{r}-2.60 \\
{[0.00]}\end{array}$ & $\begin{array}{l}0.3254 \\
{[0.0000]}\end{array}$ & $\begin{array}{l}0.3825 \\
{[0.0000]}\end{array}$ & $\begin{array}{l}0.2535 \\
{[0.0000]}\end{array}$ & $\begin{array}{l}0.3579 \\
{[0.0000]}\end{array}$ & $\begin{array}{l}0.0746 \\
{[0.0000]}\end{array}$ & $\begin{array}{r}-0.0449 \\
{[0.0949]}\end{array}$ & $\begin{array}{r}-0.1515 \\
{[0.0000]}\end{array}$ & $\begin{array}{l}66.77 \\
{[0.00]}\end{array}$ \\
\hline AEX & $03.02 .2000-23.01 .2015$ & $\begin{array}{c}-5.83 \\
{[0.00]}\end{array}$ & $\begin{array}{l}0.1993 \\
{[0.0000]}\end{array}$ & $\begin{array}{l}0.4152 \\
{[0.0000]}\end{array}$ & $\begin{array}{l}0.2146 \\
{[0.0000]}\end{array}$ & $\begin{array}{l}0.8173 \\
{[0.0000]}\end{array}$ & $\begin{array}{l}0.1792 \\
{[0.0000]}\end{array}$ & $\begin{array}{r}-0.0774 \\
{[0.0410]}\end{array}$ & $\begin{array}{r}-0.2859 \\
{[0.0000]}\end{array}$ & $\begin{array}{r}271.55 \\
{[0.00]}\end{array}$ \\
\hline Swiss Market Index & $04.02 .2000-23.01 .2015$ & $\begin{array}{r}-4.75 \\
{[0.00]}\end{array}$ & $\begin{array}{l}0.2329 \\
{[0.0000]}\end{array}$ & $\begin{array}{l}0.4238 \\
{[0.0000]}\end{array}$ & $\begin{array}{l}0.2440 \\
{[0.0000]}\end{array}$ & $\begin{array}{l}0.6440 \\
{[0.0000]}\end{array}$ & $\begin{array}{l}0.1187 \\
{[0.0000]}\end{array}$ & $\begin{array}{r}-0.0305 \\
{[0.3284]}\end{array}$ & $\begin{array}{r}-0.2818 \\
{[0.0000]}\end{array}$ & $\begin{array}{r}225.34 \\
{[0.00]}\end{array}$ \\
\hline IBEX 35 & $04.02 .2000-23.01 .2015$ & $\begin{array}{r}-5.65 \\
{[0.00]}\end{array}$ & $\begin{array}{l}0.2346 \\
{[0.0000]}\end{array}$ & $\begin{array}{l}0.4276 \\
{[0.0000]}\end{array}$ & $\begin{array}{l}0.2324 \\
{[0.0000]}\end{array}$ & $\begin{array}{l}0.7710 \\
{[0.0000]}\end{array}$ & $\begin{array}{l}0.1318 \\
{[0.0000]}\end{array}$ & $\begin{array}{r}-0.0987 \\
{[0.0038]}\end{array}$ & $\begin{array}{r}-0.2806 \\
{[0.0000]}\end{array}$ & $\begin{array}{r}183.77 \\
{[0.00]}\end{array}$ \\
\hline S\&P CNX Nifty & 07.08.2002 - 23.01.2015 & $\begin{array}{r}-1.87 \\
{[0.00]}\end{array}$ & $\begin{array}{l}0.2934 \\
{[0.0000]}\end{array}$ & $\begin{array}{l}0.3578 \\
{[0.0000]}\end{array}$ & $\begin{array}{l}0.2848 \\
{[0.0000]}\end{array}$ & $\begin{array}{l}0.2137 \\
{[0.0069]}\end{array}$ & $\begin{array}{l}0.1995 \\
{[0.0000]}\end{array}$ & $\begin{array}{r}-0.0829 \\
{[0.0241]}\end{array}$ & $\begin{array}{r}-0.1839 \\
{[0.0000]}\end{array}$ & $\begin{array}{r}140.94 \\
{[0.00]}\end{array}$ \\
\hline IPC Mexico & $03.02 .2000-23.01 .2015$ & $\begin{array}{r}-5.20 \\
{[0.00]}\end{array}$ & $\begin{array}{l}0.1494 \\
{[0.0000]}\end{array}$ & $\begin{array}{l}0.2419 \\
{[0.0000]}\end{array}$ & $\begin{array}{l}0.5647 \\
{[0.0000]}\end{array}$ & $\begin{array}{l}0.6928 \\
{[0.0000]}\end{array}$ & $\begin{array}{l}0.0782 \\
{[0.0061]}\end{array}$ & $\begin{array}{l}0.0933 \\
{[0.0327]}\end{array}$ & $\begin{array}{r}-0.4525 \\
{[0.0000]}\end{array}$ & $\begin{array}{r}162.77 \\
{[0.00]}\end{array}$ \\
\hline Bovespa & $04.02 .2000-23.01 .2015$ & $\begin{array}{r}-3.87 \\
{[0.00]}\end{array}$ & $\begin{array}{l}0.2659 \\
{[0.0000]}\end{array}$ & $\begin{array}{l}0.3793 \\
{[0.0000]}\end{array}$ & $\begin{array}{l}0.2477 \\
{[0.0000]}\end{array}$ & $\begin{array}{l}0.4701 \\
{[0.0000]}\end{array}$ & $\begin{array}{l}0.0602 \\
{[0.0030]}\end{array}$ & $\begin{array}{r}-0.0222 \\
{[0.5203]}\end{array}$ & $\begin{array}{r}-0.1984 \\
{[0.0000]}\end{array}$ & $\begin{array}{l}86.67 \\
{[0.00]}\end{array}$ \\
\hline S\&P TSX & 05.06.2002 - 23.01.2015 & $\begin{array}{r}-6.28 \\
{[0.00]}\end{array}$ & $\begin{array}{l}0.1969 \\
{[0.0000]}\end{array}$ & $\begin{array}{l}0.3674 \\
{[0.0000]}\end{array}$ & $\begin{array}{l}0.3644 \\
{[0.0000]}\end{array}$ & $\begin{array}{l}0.8447 \\
{[0.0000]}\end{array}$ & $\begin{array}{l}0.0615 \\
{[0.0120]}\end{array}$ & $\begin{array}{r}-0.0351 \\
{[0.4390]}\end{array}$ & $\begin{array}{r}-0.3414 \\
{[0.0000]}\end{array}$ & $\begin{array}{r}153.96 \\
{[0.00]}\end{array}$ \\
\hline Euro STOXX 50 & $03.02 .2000-23.01 .2015$ & $\begin{array}{r}-6.48 \\
{[0.00]}\end{array}$ & $\begin{array}{l}0.1008 \\
{[0.0013]}\end{array}$ & $\begin{array}{l}0.3941 \\
{[0.0000]}\end{array}$ & $\begin{array}{l}0.3007 \\
{[0.0000]}\end{array}$ & $\begin{array}{l}0.8975 \\
{[0.0000]}\end{array}$ & $\begin{array}{l}0.2636 \\
{[0.0000]}\end{array}$ & $\begin{array}{r}-0.0937 \\
{[0.0546]}\end{array}$ & $\begin{array}{r}-0.3707 \\
{[0.0000]}\end{array}$ & $\begin{array}{r}232.11 \\
{[0.00]}\end{array}$ \\
\hline FT Straits Times & $03.02 .2000-23.01 .2015$ & $\begin{array}{r}-1.68 \\
{[0.00]}\end{array}$ & $\begin{array}{l}0.2461 \\
{[0.0000]}\end{array}$ & $\begin{array}{l}0.3781 \\
{[0.0000]}\end{array}$ & $\begin{array}{l}0.3073 \\
{[0.0000]}\end{array}$ & $\begin{array}{l}0.1974 \\
{[0.0004]}\end{array}$ & $\begin{array}{l}0.1301 \\
{[0.0000]}\end{array}$ & $\begin{array}{r}-0.0392 \\
{[0.0882]}\end{array}$ & $\begin{array}{r}-0.1324 \\
{[0.0000]}\end{array}$ & $\begin{array}{r}103.72 \\
{[0.00]}\end{array}$ \\
\hline FTSE MIB & 03.02.2000 - 23.01.2015 & $\begin{array}{c}-5.71 \\
{[0.00]}\end{array}$ & $\begin{array}{l}0.2280 \\
{[0.0000]}\end{array}$ & $\begin{array}{l}0.4085 \\
{[0.0000]}\end{array}$ & $\begin{array}{l}0.2387 \\
{[0.0000]}\end{array}$ & $\begin{array}{l}0.7813 \\
{[0.0000]}\end{array}$ & $\begin{array}{l}0.1393 \\
{[0.0000]}\end{array}$ & $\begin{array}{r}-0.0938 \\
{[0.0074]}\end{array}$ & $\begin{array}{r}-0.2753 \\
{[0.0000]}\end{array}$ & $\begin{array}{r}193.31 \\
{[0.00]}\end{array}$ \\
\hline
\end{tabular}

Notes: This table reports OLS regression estimates of the augmented HAR model parameters in (6) for each foreign equity index. Columns one and two show the equity indices and the corresponding full sample fitting periods. Columns 3 to 10 show the OLS parameter estimates, together with (2-sided) $p$-values computed with Heteroskedasticity and Autocorrelation (HAC) robust standard errors in brackets below the estimates. The last column shows the $\chi^{2}$-test values of a joint significance test with null hypothesis $\mathcal{H}_{0}: \boldsymbol{\beta}_{\mathrm{US}}=\mathbf{0}_{4 \times 1}$, with corresponding (HAC based) $p$-values in brackets below. 
Table 3: Augmented HAR model parameter estimates over the pre- and post Lehman Brothers collapse periods

\begin{tabular}{|c|c|c|c|c|c|c|c|c|c|c|}
\hline Equity Index & Sample Period & $\hat{\beta}_{0}$ & $\hat{\beta}^{(d)}$ & $\hat{\beta}^{(w)}$ & $\hat{\beta}^{(m)}$ & $\hat{\beta}_{\text {VIX }}$ & $\hat{\beta}_{\text {US }}^{(d)}$ & $\hat{\beta}_{\mathrm{US}}^{(w)}$ & $\hat{\beta}_{\mathrm{US}}^{(m)}$ & $\chi^{2}$-test \\
\hline \multicolumn{11}{|c|}{ Pre Lehman Brothers collapse $(t<$ September 15,2008$)$} \\
\hline FTSE 100 & $04.02 .2000-12.09 .2008$ & $\begin{array}{r}-6.95 \\
{[0.00]}\end{array}$ & $\begin{array}{l}0.1586 \\
{[0.0000]}\end{array}$ & $\begin{array}{l}0.3964 \\
{[0.0000]}\end{array}$ & $\begin{array}{l}0.2484 \\
{[0.0000]}\end{array}$ & $\begin{array}{l}0.9960 \\
{[0.0000]}\end{array}$ & $\begin{array}{l}0.1483 \\
{[0.0000]}\end{array}$ & $\begin{array}{r}-0.0704 \\
{[0.2298]}\end{array}$ & $\begin{array}{r}-0.2942 \\
{[0.0000]}\end{array}$ & $\begin{array}{r}131.89 \\
{[0.00]}\end{array}$ \\
\hline Nikkei 225 & 07.02.2000 - 12.09.2008 & $\begin{array}{r}-3.94 \\
{[0.00]}\end{array}$ & $\begin{array}{l}0.2815 \\
{[0.0000]}\end{array}$ & $\begin{array}{l}0.3245 \\
{[0.0000]}\end{array}$ & $\begin{array}{l}0.2557 \\
{[0.0000]}\end{array}$ & $\begin{array}{l}0.4993 \\
{[0.0000]}\end{array}$ & $\begin{array}{l}0.1669 \\
{[0.0000]}\end{array}$ & $\begin{array}{r}-0.0918 \\
{[0.0234]}\end{array}$ & $\begin{array}{r}-0.1982 \\
{[0.0000]}\end{array}$ & $\begin{array}{l}90.57 \\
{[0.00]}\end{array}$ \\
\hline DAX & 03.02.2000 - 12.09.2008 & $\begin{array}{r}-6.58 \\
{[0.00]}\end{array}$ & $\begin{array}{l}0.2004 \\
{[0.0000]}\end{array}$ & $\begin{array}{l}0.3599 \\
{[0.0000]}\end{array}$ & $\begin{array}{l}0.3022 \\
{[0.0000]}\end{array}$ & $\begin{array}{l}0.9503 \\
{[0.0000]}\end{array}$ & $\begin{array}{l}0.1872 \\
{[0.0000]}\end{array}$ & $\begin{array}{r}-0.1062 \\
{[0.0711]}\end{array}$ & $\begin{array}{r}-0.3444 \\
{[0.0000]}\end{array}$ & $\begin{array}{r}142.99 \\
{[0.00]}\end{array}$ \\
\hline All Ordinaries & $07.02 .2000-12.09 .2008$ & $\begin{array}{r}-2.81 \\
{[0.00]}\end{array}$ & $\begin{array}{l}0.0307 \\
{[0.2517]}\end{array}$ & $\begin{array}{l}0.3735 \\
{[0.0000]}\end{array}$ & $\begin{array}{l}0.5457 \\
{[0.0000]}\end{array}$ & $\begin{array}{l}0.3571 \\
{[0.0035]}\end{array}$ & $\begin{array}{l}0.3443 \\
{[0.0000]}\end{array}$ & $\begin{array}{c}0.0086 \\
{[0.8846]}\end{array}$ & $\begin{array}{r}-0.4809 \\
{[0.0000]}\end{array}$ & $\begin{array}{r}176.10 \\
{[0.00]}\end{array}$ \\
\hline $\mathrm{CAC} 40$ & $03.02 .2000-12.09 .2008$ & $\begin{array}{r}-6.99 \\
{[0.00]}\end{array}$ & $\begin{array}{l}0.1842 \\
{[0.0000]}\end{array}$ & $\begin{array}{l}0.3954 \\
{[0.0000]}\end{array}$ & $\begin{array}{l}0.2063 \\
{[0.0003]}\end{array}$ & $\begin{array}{c}1.0072 \\
{[0.0000]}\end{array}$ & $\begin{array}{l}0.1473 \\
{[0.0000]}\end{array}$ & $\begin{array}{r}-0.0913 \\
{[0.1112]}\end{array}$ & $\begin{array}{r}-0.2668 \\
{[0.0000]}\end{array}$ & $\begin{array}{r}154.54 \\
{[0.00]}\end{array}$ \\
\hline Hang Seng & $03.02 .2000-09.09 .2008$ & $\begin{array}{r}-3.44 \\
{[0.00]}\end{array}$ & $\begin{array}{l}0.1343 \\
{[0.0000]}\end{array}$ & $\begin{array}{l}0.3968 \\
{[0.0000]}\end{array}$ & $\begin{array}{l}0.3921 \\
{[0.0000]}\end{array}$ & $\begin{array}{l}0.4389 \\
{[0.0000]}\end{array}$ & $\begin{array}{l}0.0867 \\
{[0.0008]}\end{array}$ & $\begin{array}{r}-0.0123 \\
{[0.7932]}\end{array}$ & $\begin{array}{r}-0.2219 \\
{[0.0000]}\end{array}$ & $\begin{array}{r}47.46 \\
{[0.00]}\end{array}$ \\
\hline KOSPI & $07.02 .2000-12.09 .2008$ & $\begin{array}{r}-4.16 \\
{[0.00]}\end{array}$ & $\begin{array}{l}0.2816 \\
{[0.0000]}\end{array}$ & $\begin{array}{l}0.4253 \\
{[0.0000]}\end{array}$ & $\begin{array}{l}0.2001 \\
{[0.0000]}\end{array}$ & $\begin{array}{l}0.5357 \\
{[0.0000]}\end{array}$ & $\begin{array}{l}0.0478 \\
{[0.0506]}\end{array}$ & $\begin{array}{r}-0.0423 \\
{[0.2764]}\end{array}$ & $\begin{array}{r}-0.1877 \\
{[0.0000]}\end{array}$ & $\begin{array}{c}48.20 \\
{[0.00]}\end{array}$ \\
\hline $\mathrm{AEX}$ & 03.02.2000 - 12.09.2008 & $\begin{array}{r}-6.98 \\
{[0.00]}\end{array}$ & $\begin{array}{l}0.1894 \\
{[0.0000]}\end{array}$ & $\begin{array}{l}0.4182 \\
{[0.0000]}\end{array}$ & $\begin{array}{l}0.2360 \\
{[0.0000]}\end{array}$ & $\begin{array}{l}0.9968 \\
{[0.0000]}\end{array}$ & $\begin{array}{l}0.1902 \\
{[0.0000]}\end{array}$ & $\begin{array}{r}-0.1160 \\
{[0.0367]}\end{array}$ & $\begin{array}{r}-0.3408 \\
{[0.0000]}\end{array}$ & $\begin{array}{r}172.08 \\
{[0.00]}\end{array}$ \\
\hline Swiss Market Index & $04.02 .2000-12.09 .2008$ & $\begin{array}{r}-5.96 \\
{[0.00]}\end{array}$ & $\begin{array}{l}0.2111 \\
{[0.0000]}\end{array}$ & $\begin{array}{l}0.4417 \\
{[0.0000]}\end{array}$ & $\begin{array}{l}0.2565 \\
{[0.0000]}\end{array}$ & $\begin{array}{l}0.8152 \\
{[0.0000]}\end{array}$ & $\begin{array}{l}0.1071 \\
{[0.0000]}\end{array}$ & $\begin{array}{r}-0.0563 \\
{[0.2269]}\end{array}$ & $\begin{array}{r}-0.3290 \\
{[0.0000]}\end{array}$ & $\begin{array}{r}129.90 \\
{[0.00]}\end{array}$ \\
\hline IBEX 35 & $04.02 .2000-12.09 .2008$ & $\begin{array}{r}-7.00 \\
{[0.00]}\end{array}$ & $\begin{array}{l}0.1911 \\
{[0.0000]}\end{array}$ & $\begin{array}{l}0.4129 \\
{[0.0000]}\end{array}$ & $\begin{array}{l}0.1680 \\
{[0.0030]}\end{array}$ & $\begin{array}{c}1.0134 \\
{[0.0000]}\end{array}$ & $\begin{array}{l}0.1195 \\
{[0.0000]}\end{array}$ & $\begin{array}{r}-0.1080 \\
{[0.0244]}\end{array}$ & $\begin{array}{r}-0.2036 \\
{[0.0001]}\end{array}$ & $\begin{array}{r}133.66 \\
{[0.00]}\end{array}$ \\
\hline S\&P CNX Nifty & $07.08 .2002-12.09 .2008$ & $\begin{array}{c}-3.74 \\
{[0.00]}\end{array}$ & $\begin{array}{l}0.3399 \\
{[0.0000]}\end{array}$ & $\begin{array}{l}0.3370 \\
{[0.0000]}\end{array}$ & $\begin{array}{l}0.2253 \\
{[0.0000]}\end{array}$ & $\begin{array}{l}0.4093 \\
{[0.0031]}\end{array}$ & $\begin{array}{l}0.2133 \\
{[0.0000]}\end{array}$ & $\begin{array}{r}-0.1032 \\
{[0.1038]}\end{array}$ & $\begin{array}{r}-0.2822 \\
{[0.0000]}\end{array}$ & $\begin{array}{r}65.64 \\
{[0.00]}\end{array}$ \\
\hline IPC Mexico & $03.02 .2000-12.09 .2008$ & $\begin{array}{r}-5.87 \\
{[0.00]}\end{array}$ & $\begin{array}{l}0.2168 \\
{[0.0000]}\end{array}$ & $\begin{array}{l}0.2485 \\
{[0.0000]}\end{array}$ & $\begin{array}{l}0.5210 \\
{[0.0000]}\end{array}$ & $\begin{array}{l}0.7778 \\
{[0.0000]}\end{array}$ & $\begin{array}{l}0.0298 \\
{[0.4186]}\end{array}$ & $\begin{array}{l}0.0990 \\
{[0.0917]}\end{array}$ & $\begin{array}{r}-0.4871 \\
{[0.0000]}\end{array}$ & $\begin{array}{l}81.41 \\
{[0.00]}\end{array}$ \\
\hline Bovespa & $04.02 .2000-12.09 .2008$ & $\begin{array}{r}-5.26 \\
{[0.00]}\end{array}$ & $\begin{array}{l}0.3108 \\
{[0.0000]}\end{array}$ & $\begin{array}{l}0.3416 \\
{[0.0000]}\end{array}$ & $\begin{array}{l}0.1454 \\
{[0.0023]}\end{array}$ & $\begin{array}{l}0.5604 \\
{[0.0000]}\end{array}$ & $\begin{array}{l}0.0553 \\
{[0.0379]}\end{array}$ & $\begin{array}{r}-0.0322 \\
{[0.5335]}\end{array}$ & $\begin{array}{r}-0.2162 \\
{[0.0000]}\end{array}$ & $\begin{array}{l}51.29 \\
{[0.00]}\end{array}$ \\
\hline S\&P TSX & 05.06.2002 - 12.09.2008 & $\begin{array}{r}-6.29 \\
{[0.00]}\end{array}$ & $\begin{array}{l}0.2613 \\
{[0.0000]}\end{array}$ & $\begin{array}{l}0.3134 \\
{[0.0000]}\end{array}$ & $\begin{array}{l}0.4257 \\
{[0.0000]}\end{array}$ & $\begin{array}{l}0.8661 \\
{[0.0000]}\end{array}$ & $\begin{array}{l}0.0074 \\
{[0.7830]}\end{array}$ & $\begin{array}{l}0.0691 \\
{[0.2481]}\end{array}$ & $\begin{array}{r}-0.4674 \\
{[0.0000]}\end{array}$ & $\begin{array}{r}72.51 \\
{[0.00]}\end{array}$ \\
\hline Euro STOXX 50 & $03.02 .2000-12.09 .2008$ & $\begin{array}{r}-7.33 \\
{[0.00]}\end{array}$ & $\begin{array}{l}0.1056 \\
{[0.0012]}\end{array}$ & $\begin{array}{l}0.3936 \\
{[0.0000]}\end{array}$ & $\begin{array}{l}0.3274 \\
{[0.0000]}\end{array}$ & $\begin{array}{c}1.0413 \\
{[0.0000]}\end{array}$ & $\begin{array}{l}0.2925 \\
{[0.0000]}\end{array}$ & $\begin{array}{r}-0.1435 \\
{[0.0352]}\end{array}$ & $\begin{array}{r}-0.4260 \\
{[0.0000]}\end{array}$ & $\begin{array}{r}235.02 \\
{[0.00]}\end{array}$ \\
\hline FT Straits Times & 03.02.2000 - 12.09.2008 & $\begin{array}{r}-3.78 \\
{[0.00]}\end{array}$ & $\begin{array}{l}0.2465 \\
{[0.0000]}\end{array}$ & $\begin{array}{l}0.3587 \\
{[0.0000]}\end{array}$ & $\begin{array}{l}0.1972 \\
{[0.0003]}\end{array}$ & $\begin{array}{l}0.3589 \\
{[0.0001]}\end{array}$ & $\begin{array}{l}0.1312 \\
{[0.0000]}\end{array}$ & $\begin{array}{r}-0.0669 \\
{[0.0580]}\end{array}$ & $\begin{array}{r}-0.1461 \\
{[0.0002]}\end{array}$ & $\begin{array}{l}65.67 \\
{[0.00]}\end{array}$ \\
\hline FTSE MIB & $03.02 .2000-12.09 .2008$ & $\begin{array}{r}-7.39 \\
{[0.00]}\end{array}$ & $\begin{array}{l}0.1997 \\
{[0.0000]}\end{array}$ & $\begin{array}{l}0.3514 \\
{[0.0000]}\end{array}$ & $\begin{array}{l}0.2176 \\
{[0.0004]}\end{array}$ & $\begin{array}{l}1.0457 \\
{[0.0000]}\end{array}$ & $\begin{array}{l}0.1470 \\
{[0.0000]}\end{array}$ & $\begin{array}{r}-0.0846 \\
{[0.0824]}\end{array}$ & $\begin{array}{r}-0.2787 \\
{[0.0000]}\end{array}$ & $\begin{array}{r}151.67 \\
{[0.00]}\end{array}$ \\
\hline \multicolumn{11}{|c|}{ Post Lehman Brothers collapse $(t>$ September 15,2008$)$} \\
\hline FTSE 100 & 16.09.2008 - 23.01.2015 & $\begin{array}{r}-8.30 \\
{[0.00]}\end{array}$ & $\begin{array}{l}0.1952 \\
{[0.0000]}\end{array}$ & $\begin{array}{l}0.3411 \\
{[0.0000]}\end{array}$ & $\begin{array}{l}0.1475 \\
{[0.0887]}\end{array}$ & $\begin{array}{l}1.1195 \\
{[0.0000]}\end{array}$ & $\begin{array}{l}0.1170 \\
{[0.0000]}\end{array}$ & $\begin{array}{r}-0.0523 \\
{[0.3208]}\end{array}$ & $\begin{array}{r}-0.2496 \\
{[0.0001]}\end{array}$ & $\begin{array}{r}150.74 \\
{[0.00]}\end{array}$ \\
\hline Nikkei 225 & 17.09.2008 - 23.01.2015 & $\begin{array}{r}-3.80 \\
{[0.00]}\end{array}$ & $\begin{array}{l}0.3351 \\
{[0.0000]}\end{array}$ & $\begin{array}{l}0.3568 \\
{[0.0000]}\end{array}$ & $\begin{array}{l}0.2195 \\
{[0.0000]}\end{array}$ & $\begin{array}{l}0.4962 \\
{[0.0002]}\end{array}$ & $\begin{array}{l}0.1533 \\
{[0.0000]}\end{array}$ & $\begin{array}{r}-0.1379 \\
{[0.0016]}\end{array}$ & $\begin{array}{r}-0.1651 \\
{[0.0002]}\end{array}$ & $\begin{array}{c}72.44 \\
{[0.00]}\end{array}$ \\
\hline $\mathrm{DAX}$ & 16.09.2008 - 23.01.2015 & $\begin{array}{r}-6.45 \\
{[0.00]}\end{array}$ & $\begin{array}{l}0.2088 \\
{[0.0000]}\end{array}$ & $\begin{array}{l}0.4275 \\
{[0.0000]}\end{array}$ & $\begin{array}{l}0.1861 \\
{[0.0108]}\end{array}$ & $\begin{array}{l}0.8964 \\
{[0.0000]}\end{array}$ & $\begin{array}{l}0.1375 \\
{[0.0000]}\end{array}$ & $\begin{array}{r}-0.1117 \\
{[0.0413]}\end{array}$ & $\begin{array}{r}-0.2440 \\
{[0.0003]}\end{array}$ & $\begin{array}{r}122.97 \\
{[0.00]}\end{array}$ \\
\hline All Ordinaries & $16.09 .2008-23.01 .2015$ & $\begin{array}{c}-4.33 \\
{[0.00]}\end{array}$ & $\begin{array}{l}0.0536 \\
{[0.0592]}\end{array}$ & $\begin{array}{l}0.4416 \\
{[0.0000]}\end{array}$ & $\begin{array}{l}0.2902 \\
{[0.0000]}\end{array}$ & $\begin{array}{l}0.4988 \\
{[0.0000]}\end{array}$ & $\begin{array}{l}0.3013 \\
{[0.0000]}\end{array}$ & $\begin{array}{r}-0.1248 \\
{[0.0072]}\end{array}$ & $\begin{array}{r}-0.2416 \\
{[0.0000]}\end{array}$ & $\begin{array}{r}168.60 \\
{[0.00]}\end{array}$ \\
\hline CAC 40 & 16.09.2008 - 23.01.2015 & $\begin{array}{r}-6.43 \\
{[0.00]}\end{array}$ & $\begin{array}{l}0.1855 \\
{[0.0000]}\end{array}$ & $\begin{array}{l}0.4203 \\
{[0.0000]}\end{array}$ & $\begin{array}{l}0.1644 \\
{[0.0110]}\end{array}$ & $\begin{array}{l}0.8585 \\
{[0.0000]}\end{array}$ & $\begin{array}{l}0.1656 \\
{[0.0000]}\end{array}$ & $\begin{array}{r}-0.0806 \\
{[0.1048]}\end{array}$ & $\begin{array}{r}-0.2633 \\
{[0.0000]}\end{array}$ & $\begin{array}{r}107.11 \\
{[0.00]}\end{array}$ \\
\hline Hang Seng & 17.09.2008 - 23.01.2015 & $\begin{array}{r}-3.75 \\
{[0.00]}\end{array}$ & $\begin{array}{l}0.1128 \\
{[0.0031]}\end{array}$ & $\begin{array}{l}0.4265 \\
{[0.0000]}\end{array}$ & $\begin{array}{l}0.2747 \\
{[0.0000]}\end{array}$ & $\begin{array}{l}0.4185 \\
{[0.0004]}\end{array}$ & $\begin{array}{l}0.0893 \\
{[0.0028]}\end{array}$ & $\begin{array}{r}-0.0261 \\
{[0.4901]}\end{array}$ & $\begin{array}{r}-0.1321 \\
{[0.0143]}\end{array}$ & $\begin{array}{l}32.16 \\
{[0.00]}\end{array}$ \\
\hline KOSPI & 17.09.2008 - 23.01.2015 & $\begin{array}{r}-5.26 \\
{[0.00]}\end{array}$ & $\begin{array}{l}0.3468 \\
{[0.0000]}\end{array}$ & $\begin{array}{l}0.3197 \\
{[0.0000]}\end{array}$ & $\begin{array}{l}0.1158 \\
{[0.0566]}\end{array}$ & $\begin{array}{l}0.7079 \\
{[0.0000]}\end{array}$ & $\begin{array}{l}0.0686 \\
{[0.0034]}\end{array}$ & $\begin{array}{r}-0.0961 \\
{[0.0087]}\end{array}$ & $\begin{array}{r}-0.0729 \\
{[0.0879]}\end{array}$ & $\begin{array}{r}63.30 \\
{[0.00]}\end{array}$ \\
\hline AEX & $16.09 .2008-23.01 .2015$ & $\begin{array}{r}-6.85 \\
{[0.00]}\end{array}$ & $\begin{array}{l}0.1971 \\
{[0.0000]}\end{array}$ & $\begin{array}{l}0.4187 \\
{[0.0000]}\end{array}$ & $\begin{array}{l}0.1201 \\
{[0.1033]}\end{array}$ & $\begin{array}{l}0.9349 \\
{[0.0000]}\end{array}$ & $\begin{array}{l}0.1558 \\
{[0.0000]}\end{array}$ & $\begin{array}{r}-0.0750 \\
{[0.1556]}\end{array}$ & $\begin{array}{r}-0.2375 \\
{[0.0001]}\end{array}$ & $\begin{array}{r}120.78 \\
{[0.00]}\end{array}$ \\
\hline Swiss Market Index & 16.09.2008 - 23.01.2015 & $\begin{array}{r}-5.55 \\
{[0.00]}\end{array}$ & $\begin{array}{l}0.2462 \\
{[0.0000]}\end{array}$ & $\begin{array}{l}0.4092 \\
{[0.0000]}\end{array}$ & $\begin{array}{l}0.1918 \\
{[0.0014]}\end{array}$ & $\begin{array}{l}0.7450 \\
{[0.0000]}\end{array}$ & $\begin{array}{l}0.1157 \\
{[0.0000]}\end{array}$ & $\begin{array}{r}-0.0380 \\
{[0.3399]}\end{array}$ & $\begin{array}{r}-0.2637 \\
{[0.0000]}\end{array}$ & $\begin{array}{r}122.41 \\
{[0.00]}\end{array}$ \\
\hline IBEX 35 & 16.09.2008 - 23.01.2015 & $\begin{array}{r}-4.84 \\
{[0.00]}\end{array}$ & $\begin{array}{l}0.2739 \\
{[0.0000]}\end{array}$ & $\begin{array}{l}0.4172 \\
{[0.0000]}\end{array}$ & $\begin{array}{l}0.1872 \\
{[0.0001]}\end{array}$ & $\begin{array}{l}0.6116 \\
{[0.0000]}\end{array}$ & $\begin{array}{l}0.1448 \\
{[0.0000]}\end{array}$ & $\begin{array}{r}-0.0960 \\
{[0.0433]}\end{array}$ & $\begin{array}{r}-0.2474 \\
{[0.0000]}\end{array}$ & $\begin{array}{r}69.23 \\
{[0.00]}\end{array}$ \\
\hline S\&P CNX Nifty & 16.09.2008 - 23.01.2015 & $\begin{array}{r}-3.15 \\
{[0.00]}\end{array}$ & $\begin{array}{l}0.2269 \\
{[0.0000]}\end{array}$ & $\begin{array}{l}0.3623 \\
{[0.0000]}\end{array}$ & $\begin{array}{l}0.2974 \\
{[0.0000]}\end{array}$ & $\begin{array}{l}0.4059 \\
{[0.0020]}\end{array}$ & $\begin{array}{l}0.1723 \\
{[0.0000]}\end{array}$ & $\begin{array}{r}-0.0934 \\
{[0.0365]}\end{array}$ & $\begin{array}{r}-0.1671 \\
{[0.0004]}\end{array}$ & $\begin{array}{r}88.82 \\
{[0.00]}\end{array}$ \\
\hline IPC Mexico & 17.09.2008 - 23.01.2015 & $\begin{array}{r}-7.18 \\
{[0.00]}\end{array}$ & $\begin{array}{l}0.0516 \\
{[0.1072]}\end{array}$ & $\begin{array}{l}0.1725 \\
{[0.0342]}\end{array}$ & $\begin{array}{l}0.6425 \\
{[0.0000]}\end{array}$ & $\begin{array}{l}0.9732 \\
{[0.0000]}\end{array}$ & $\begin{array}{l}0.1187 \\
{[0.0046]}\end{array}$ & $\begin{array}{l}0.0926 \\
{[0.1832]}\end{array}$ & $\begin{array}{r}-0.5164 \\
{[0.0000]}\end{array}$ & $\begin{array}{r}115.01 \\
{[0.00]}\end{array}$ \\
\hline Bovespa & 16.09.2008 - 23.01.2015 & $\begin{array}{r}-4.37 \\
{[0.00]}\end{array}$ & $\begin{array}{l}0.1898 \\
{[0.0000]}\end{array}$ & $\begin{array}{l}0.4330 \\
{[0.0000]}\end{array}$ & $\begin{array}{l}0.3255 \\
{[0.0000]}\end{array}$ & $\begin{array}{l}0.5875 \\
{[0.0000]}\end{array}$ & $\begin{array}{l}0.0644 \\
{[0.0388]}\end{array}$ & $\begin{array}{r}-0.0522 \\
{[0.2724]}\end{array}$ & $\begin{array}{r}-0.2340 \\
{[0.0000]}\end{array}$ & $\begin{array}{r}51.85 \\
{[0.00]}\end{array}$ \\
\hline S\&P TSX & 16.09.2008 - 23.01.2015 & $\begin{array}{r}-8.77 \\
{[0.00]}\end{array}$ & $\begin{array}{l}0.1306 \\
{[0.0046]}\end{array}$ & $\begin{array}{l}0.3895 \\
{[0.0000]}\end{array}$ & $\begin{array}{l}0.2931 \\
{[0.0012]}\end{array}$ & $\begin{array}{l}1.2153 \\
{[0.0000]}\end{array}$ & $\begin{array}{l}0.0944 \\
{[0.0132]}\end{array}$ & $\begin{array}{r}-0.1329 \\
{[0.0439]}\end{array}$ & $\begin{array}{r}-0.2955 \\
{[0.0001]}\end{array}$ & $\begin{array}{l}95.54 \\
{[0.00]}\end{array}$ \\
\hline Euro STOXX 50 & 16.09.2008 - 23.01.2015 & $\begin{array}{r}-6.54 \\
{[0.00]}\end{array}$ & $\begin{array}{l}0.0915 \\
{[0.0848]}\end{array}$ & $\begin{array}{l}0.3903 \\
{[0.0000]}\end{array}$ & $\begin{array}{l}0.2546 \\
{[0.0053]}\end{array}$ & $\begin{array}{l}0.8678 \\
{[0.0000]}\end{array}$ & $\begin{array}{l}0.2355 \\
{[0.0000]}\end{array}$ & $\begin{array}{r}-0.0599 \\
{[0.4035]}\end{array}$ & $\begin{array}{r}-0.3333 \\
{[0.0001]}\end{array}$ & $\begin{array}{l}80.06 \\
{[0.00]}\end{array}$ \\
\hline FT Straits Times & 16.09.2008 - 23.01.2015 & $\begin{array}{r}-3.28 \\
{[0.00]}\end{array}$ & $\begin{array}{l}0.2222 \\
{[0.0000]}\end{array}$ & $\begin{array}{l}0.4050 \\
{[0.0000]}\end{array}$ & $\begin{array}{l}0.2074 \\
{[0.0002]}\end{array}$ & $\begin{array}{l}0.3993 \\
{[0.0000]}\end{array}$ & $\begin{array}{l}0.1079 \\
{[0.0000]}\end{array}$ & $\begin{array}{r}-0.0568 \\
{[0.0584]}\end{array}$ & $\begin{array}{r}-0.0884 \\
{[0.0067]}\end{array}$ & $\begin{array}{l}69.06 \\
{[0.00]}\end{array}$ \\
\hline FTSE MIB & 16.09.2008 - 23.01.2015 & $\begin{array}{r}-4.47 \\
{[0.00]}\end{array}$ & $\begin{array}{l}0.2510 \\
{[0.0000]}\end{array}$ & $\begin{array}{l}0.4327 \\
{[0.0000]}\end{array}$ & $\begin{array}{l}0.1872 \\
{[0.0014]}\end{array}$ & $\begin{array}{l}0.5788 \\
{[0.0000]}\end{array}$ & $\begin{array}{l}0.1365 \\
{[0.0000]}\end{array}$ & $\begin{array}{r}-0.0941 \\
{[0.0471]}\end{array}$ & $\begin{array}{r}-0.2039 \\
{[0.0003]}\end{array}$ & $\begin{array}{l}71.39 \\
{[0.00]}\end{array}$ \\
\hline
\end{tabular}

Notes: This table reports OLS regression estimates of the augmented HAR model parameters in (6) for each foreign equity index for the pre and post Lehman Brothers collapse, in the top and bottom panels, respectively. All column entries are the same as described in Table 2. 

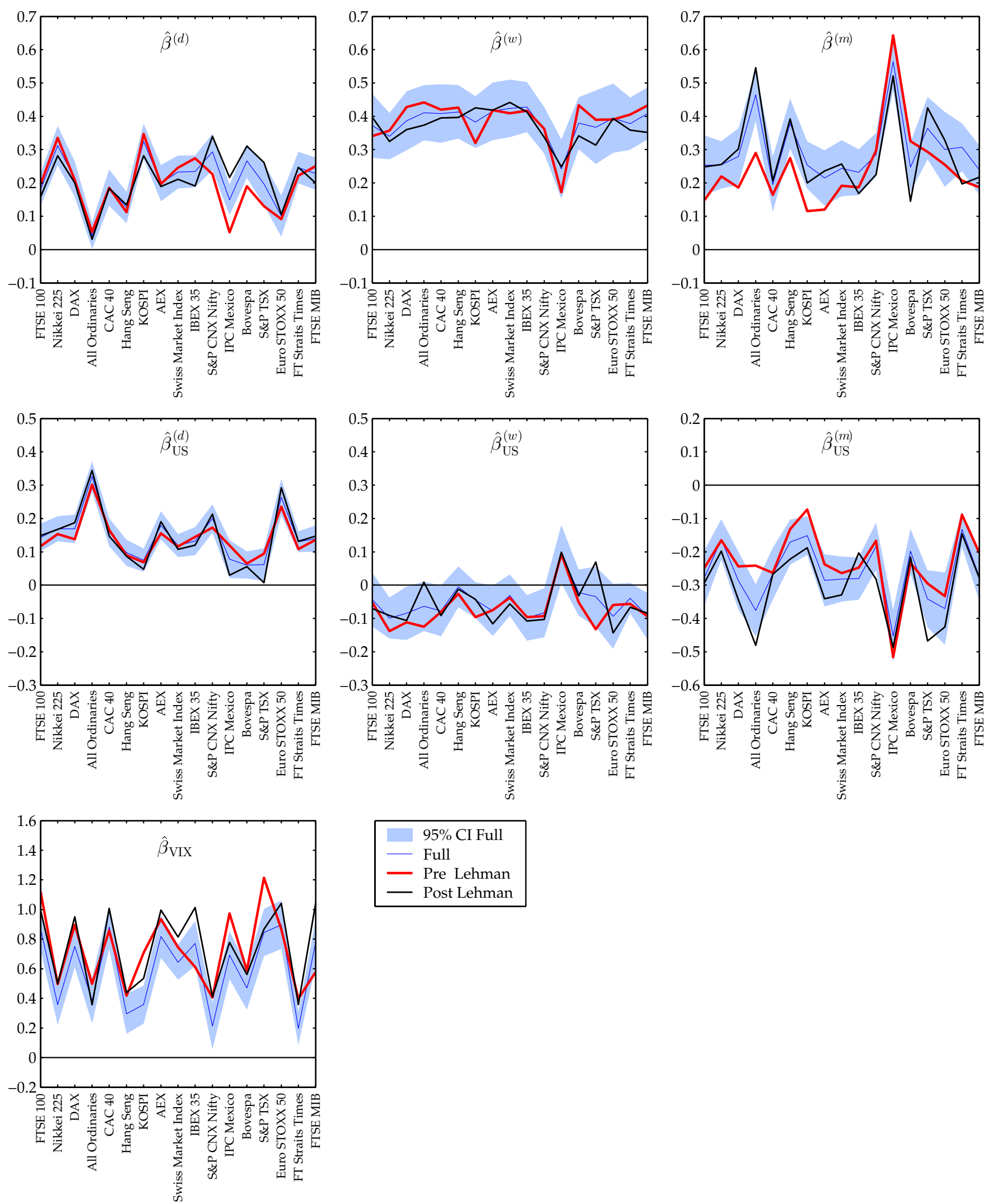

Figure 3: Plots of the parameter estimates from the augmented HAR model over the full, pre and post Lehman Brothers collapse periods. 
Table 4: One-step-ahead out-of-sample forecast evaluation results (expanding window, $T_{i s}=500$ )

\begin{tabular}{|c|c|c|c|c|c|c|c|c|c|c|}
\hline Equity Index & Country & Out-of-sample period & $T_{o s}$ & MSFE & Rel-MSFE & $R_{o s}^{2}$ & DM-stat & $p$-value & CW-stat & $p$-value \\
\hline FTSE 100 & United Kingdom & 14.03.2002 - 23.01.2015 & 3154 & 0.2321 & 0.9189 & 0.0811 & 6.9535 & 0.0000 & 14.4496 & 0.0000 \\
\hline Nikkei 225 & Japan & $22.04 .2002-23.01 .2015$ & 2977 & 0.2540 & 0.9487 & 0.0513 & 5.0642 & 0.0000 & 10.6069 & 0.0000 \\
\hline DAX & Germany & 12.03.2002 - 23.01.2015 & 3171 & 0.2432 & 0.9306 & 0.0694 & 5.7939 & 0.0000 & 13.7959 & 0.0000 \\
\hline All Ordinaries & Australia & 21.03.2002 - 23.01.2015 & 3113 & 0.3567 & 0.8717 & 0.1283 & 8.1859 & 0.0000 & 15.6020 & 0.0000 \\
\hline CAC 40 & France & 15.03.2002 - 23.01.2015 & 3186 & 0.2206 & 0.9059 & 0.0941 & 7.6917 & 0.0000 & 14.9231 & 0.0000 \\
\hline Hang Seng & Hong Kong & 19.04.2002 - 23.01.2015 & 2810 & 0.2396 & 0.9727 & 0.0273 & 3.0352 & 0.0012 & 7.4347 & 0.0000 \\
\hline KOSPI & South Korea & 25.04.2002 - 23.01.2015 & 3043 & 0.2142 & 0.9736 & 0.0264 & 4.3279 & 0.0000 & 8.5510 & 0.0000 \\
\hline AEX & The Netherlands & 18.03.2002 - 23.01.2015 & 3186 & 0.2235 & 0.9097 & 0.0903 & 6.8739 & 0.0000 & 14.8139 & 0.0000 \\
\hline Swiss Market Index & Switzerland & 22.03.2002 - 23.01.2015 & 3131 & 0.1746 & 0.9299 & 0.0701 & 6.0506 & 0.0000 & 13.4176 & 0.0000 \\
\hline IBEX 35 & Spain & 27.03.2002 - 23.01.2015 & 3154 & 0.2154 & 0.9314 & 0.0686 & 5.7927 & 0.0000 & 13.5312 & 0.0000 \\
\hline S\&P CNX Nifty & China & 15.09.2004 - 23.01.2015 & 2466 & 0.3237 & 0.9498 & 0.0502 & 4.6188 & 0.0000 & 9.6794 & 0.0000 \\
\hline IPC Mexico & Mexico & 19.03.2002 - 23.01.2015 & 3137 & 0.3655 & 0.9536 & 0.0464 & 6.1879 & 0.0000 & 11.4885 & 0.0000 \\
\hline Bovespa & Brazil & 17.04.2002 - 23.01.2015 & 3053 & 0.2505 & 0.9819 & 0.0181 & 2.5844 & 0.0049 & 7.8290 & 0.0000 \\
\hline S\&P TSX & Canada & $24.06 .2004-23.01 .2015$ & 2589 & 0.3223 & 0.9551 & 0.0449 & 5.6579 & 0.0000 & 10.3700 & 0.0000 \\
\hline Euro STOXX 50 & Euro Area & 11.03.2002 - 23.01.2015 & 3170 & 0.3322 & 0.8957 & 0.1043 & 6.0848 & 0.0000 & 12.0002 & 0.0000 \\
\hline FT Straits Times & Singapore & 01.04.2002 - 23.01.2015 & 3080 & 0.1515 & 0.9615 & 0.0385 & 3.4096 & 0.0003 & 10.0977 & 0.0000 \\
\hline FTSE MIB & Italy & 20.03.2002 - 23.01.2015 & 3154 & 0.2359 & 0.9357 & 0.0643 & 5.4411 & 0.0000 & 13.6648 & 0.0000 \\
\hline
\end{tabular}

Notes: This table reports the one-step-ahead out-of-sample forecast evaluation results for the 17 foreign equity markets that we consider. Columns one to four show the equity markets of interest, the corresponding country, the out-of-sample evaluation period and the number of out-of-sample observations $T_{o s}$. In columns five to seven we show the mean squared forecast errors (MSFEs) of the benchmark HAR model (without U.S. volatility information), the relative MSFE (Rel-MSFE) computed as MSFE(US)/MSFE where MSFE(US) and MSFE are from the augmented and benchmark HAR models respectively, and the Campbell and Thompson (2008) out-of-sample $R^{2}$ ( $R_{o S}^{2}$ ) computed as $R_{o s}^{2}=1-\operatorname{MSFE}(\mathrm{US}) / \mathrm{MSFE}$. The last four columns report standard (unadjusted) Diebold-Mariano (DM) and Clark-West (CW) test statistics, together with corresponding one-sided asymptotic $p$-values. Note here that because the augmented HAR model (with U.S. volatility information) nests the benchmark HAR, the $p$-values of the (unadjusted) DM statistic are invalid and are only provided as a 'reference' value. 
Table 5: Multiple-step-ahead out-of-sample forecast evaluation results (expanding window, $T_{i s}=500$ )

\begin{tabular}{|c|c|c|c|c|c|c|c|c|}
\hline Equity Index & Country & Out-of-sample period & $T_{o s}$ & MSFE & Rel-MSFE & $R_{o s}^{2}$ & CW-stat & $p$-value \\
\hline \multicolumn{9}{|c|}{ Forecast Horizon $h=5$} \\
\hline FTSE 100 & United Kingdom & 26.03.2002 - 23.01.2015 & 3146 & 0.1512 & 0.9077 & 0.0923 & 7.7667 & 0.0000 \\
\hline Nikkei 225 & Japan & 07.05.2002 - 23.01.2015 & 2969 & 0.1652 & 0.9613 & 0.0387 & 4.5852 & 0.0000 \\
\hline DAX & Germany & 22.03.2002 - 23.01.2015 & 3163 & 0.1632 & 0.9291 & 0.0709 & 7.5270 & 0.0000 \\
\hline All Ordinaries & Australia & 04.04 .2002 - 23.01.2015 & 3105 & 0.1549 & 0.8778 & 0.1222 & 8.0790 & 0.0000 \\
\hline CAC 40 & France & 27.03.2002 - 23.01.2015 & 3178 & 0.1502 & 0.8962 & 0.1038 & 8.6266 & 0.0000 \\
\hline Hang Seng & Hong Kong & 02.05.2002 - 23.01.2015 & 2802 & 0.1159 & 0.9638 & 0.0362 & 3.0938 & 0.0010 \\
\hline KOSPI & South Korea & 08.05.2002 - 23.01.2015 & 3035 & 0.1401 & 0.9818 & 0.0182 & 2.8132 & 0.0025 \\
\hline AEX & The Netherlands & 28.03.2002 - 23.01.2015 & 3178 & 0.1587 & 0.9029 & 0.0971 & 8.9068 & 0.0000 \\
\hline Swiss Market Index & Switzerland & 05.04.2002 - 23.01.2015 & 3123 & 0.1233 & 0.9347 & 0.0653 & 7.9367 & 0.0000 \\
\hline IBEX 35 & Spain & 10.04.2002 - 23.01.2015 & 3146 & 0.1486 & 0.9290 & 0.0710 & 7.1463 & 0.0000 \\
\hline S\&P CNX Nifty & China & $27.09 .2004-23.01 .2015$ & 2458 & 0.1914 & 0.9707 & 0.0293 & 5.1372 & 0.0000 \\
\hline IPC Mexico & Mexico & 03.04.2002 - 23.01.2015 & 3129 & 0.1797 & 0.9145 & 0.0855 & 6.9220 & 0.0000 \\
\hline Bovespa & Brazil & 29.04.2002 - 23.01.2015 & 3045 & 0.1527 & 0.9880 & 0.0120 & 3.1301 & 0.0009 \\
\hline S\&P TSX & Canada & 08.07.2004 - 23.01.2015 & 2581 & 0.1877 & 0.9443 & 0.0557 & 5.0478 & 0.0000 \\
\hline Euro STOXX 50 & Euro Area & $21.03 .2002-23.01 .2015$ & 3162 & 0.1966 & 0.8852 & 0.1148 & 8.3857 & 0.0000 \\
\hline FT Straits Times & Singapore & 11.04.2002 - 23.01.2015 & 3072 & 0.0848 & 0.9597 & 0.0403 & 5.2582 & 0.0000 \\
\hline FTSE MIB & Italy & 03.04.2002 - 23.01.2015 & 3146 & 0.1528 & 0.9421 & 0.0579 & 6.9360 & 0.0000 \\
\hline \multicolumn{9}{|c|}{ Forecast Horizon $h=10$} \\
\hline FTSE 100 & United Kingdom & 11.04.2002 - 23.01.2015 & 3136 & 0.1562 & 0.9288 & 0.0712 & 5.7869 & 0.0000 \\
\hline Nikkei 225 & Japan & 21.05.2002 - 23.01.2015 & 2959 & 0.1638 & 0.9726 & 0.0274 & 2.8447 & 0.0022 \\
\hline DAX & Germany & 09.04 .2002 - 23.01.2015 & 3153 & 0.1679 & 0.9403 & 0.0597 & 5.4737 & 0.0000 \\
\hline All Ordinaries & Australia & 18.04.2002 - 23.01.2015 & 3095 & 0.1506 & 0.9052 & 0.0948 & 5.3674 & 0.0000 \\
\hline CAC 40 & France & 12.04.2002 - 23.01.2015 & 3168 & 0.1591 & 0.9112 & 0.0888 & 6.2324 & 0.0000 \\
\hline Hang Seng & Hong Kong & 16.05.2002 - 23.01.2015 & 2792 & 0.1067 & 0.9690 & 0.0310 & 2.5219 & 0.0058 \\
\hline KOSPI & South Korea & $22.05 .2002-23.01 .2015$ & 3025 & 0.1405 & 0.9868 & 0.0132 & 1.9692 & 0.0245 \\
\hline AEX & The Netherlands & 15.04.2002 - 23.01.2015 & 3168 & 0.1710 & 0.9147 & 0.0853 & 6.4819 & 0.0000 \\
\hline Swiss Market Index & Switzerland & 19.04.2002 - 23.01.2015 & 3113 & 0.1332 & 0.9588 & 0.0412 & 6.0843 & 0.0000 \\
\hline IBEX 35 & Spain & 24.04.2002 - 23.01.2015 & 3136 & 0.1544 & 0.9486 & 0.0514 & 5.1068 & 0.0000 \\
\hline S\&P CNX Nifty & China & $11.10 .2004-23.01 .2015$ & 2448 & 0.1842 & 1.0091 & -0.0091 & 2.2363 & 0.0127 \\
\hline IPC Mexico & Mexico & 17.04.2002 - 23.01.2015 & 3119 & 0.1639 & 0.9285 & 0.0715 & 5.4598 & 0.0000 \\
\hline Bovespa & Brazil & 14.05.2002 - 23.01.2015 & 3035 & 0.1499 & 1.0026 & -0.0026 & 2.0764 & 0.0189 \\
\hline S\&P TSX & Canada & 22.07.2004 - 23.01.2015 & 2571 & 0.1848 & 0.9453 & 0.0547 & 4.1092 & 0.0000 \\
\hline Euro STOXX 50 & Euro Area & 08.04.2002 - 23.01.2015 & 3152 & 0.1969 & 0.9095 & 0.0905 & 6.1753 & 0.0000 \\
\hline FT Straits Times & Singapore & 25.04.2002 - 23.01.2015 & 3062 & 0.0820 & 0.9841 & 0.0159 & 3.7404 & 0.0001 \\
\hline FTSE MIB & Italy & 17.04.2002 - 23.01.2015 & 3136 & 0.1597 & 0.9571 & 0.0429 & 4.9490 & 0.0000 \\
\hline \multicolumn{9}{|c|}{ Forecast Horizon $h=22$} \\
\hline FTSE 100 & United Kingdom & $16.05 .2002-23.01 .2015$ & 3112 & 0.1847 & 0.9482 & 0.0518 & 4.3139 & 0.0000 \\
\hline Nikkei 225 & Japan & $25.06 .2002-23.01 .2015$ & 2935 & 0.1854 & 0.9849 & 0.0151 & 1.9721 & 0.0243 \\
\hline DAX & Germany & 14.05.2002 - 23.01.2015 & 3129 & 0.1986 & 0.9606 & 0.0394 & 3.8820 & 0.0001 \\
\hline All Ordinaries & Australia & 23.05.2002 - 23.01.2015 & 3071 & 0.1638 & 0.9437 & 0.0563 & 3.6152 & 0.0002 \\
\hline CAC 40 & France & 17.05.2002 - 23.01.2015 & 3144 & 0.1864 & 0.9263 & 0.0737 & 4.5518 & 0.0000 \\
\hline Hang Seng & Hong Kong & 21.06.2002 - 23.01.2015 & 2768 & 0.1070 & 1.0035 & -0.0035 & 1.9948 & 0.0230 \\
\hline KOSPI & South Korea & 28.06.2002 - 23.01.2015 & 3001 & 0.1589 & 1.0174 & -0.0174 & 0.6811 & 0.2479 \\
\hline AEX & The Netherlands & 20.05 .2002 - 23.01.2015 & 3144 & 0.2055 & 0.9317 & 0.0683 & 4.5003 & 0.0000 \\
\hline Swiss Market Index & Switzerland & 24.05.2002 - 23.01.2015 & 3089 & 0.1677 & 1.0068 & -0.0068 & 2.6603 & 0.0039 \\
\hline IBEX 35 & Spain & $30.05 .2002-23.01 .2015$ & 3112 & 0.1723 & 0.9612 & 0.0388 & 4.1209 & 0.0000 \\
\hline S\&P CNX Nifty & China & 22.11.2004 - 23.01.2015 & 2424 & 0.2022 & 1.0498 & -0.0498 & -0.6123 & 0.7298 \\
\hline IPC Mexico & Mexico & 22.05.2002 - 23.01.2015 & 3095 & 0.1666 & 0.9722 & 0.0278 & 3.4133 & 0.0003 \\
\hline Bovespa & Brazil & 19.06.2002 - 23.01.2015 & 3011 & 0.1667 & 1.0153 & -0.0153 & 1.4433 & 0.0745 \\
\hline S\&P TSX & Canada & $26.08 .2004-23.01 .2015$ & 2547 & 0.2010 & 0.9637 & 0.0363 & 3.6196 & 0.0001 \\
\hline Euro STOXX 50 & Euro Area & 13.05.2002 - 23.01.2015 & 3128 & 0.2176 & 0.9301 & 0.0699 & 4.6450 & 0.0000 \\
\hline FT Straits Times & Singapore & 31.05.2002 - 23.01.2015 & 3038 & 0.0980 & 1.0110 & -0.0110 & 2.3937 & 0.0083 \\
\hline FTSE MIB & Italy & 22.05.2002 - 23.01.2015 & 3112 & 0.1810 & 0.9646 & 0.0354 & 3.2616 & 0.0006 \\
\hline
\end{tabular}

Notes: This table reports the multiple-steps-ahead out-of-sample forecast evaluation results for the 17 international equity markets that we consider. Forecasts for horizons $h=5,10$ and 22 are shown in the top, middle and bottom panels, respectively. The target variable is (normalised) multi-period log RV, as defined in (13). All column entries are the same as described in Table 4. The $p$-values corresponding to the CW - statistic are computed from HAC robust standard errors, where we use a pre-whitening step using an $\operatorname{ARMA}(1,1)$ model for the $\mathrm{CW}_{t+h}$ sequence to reduce the initial autocorrelation in the series, and then apply a Quadratic Spectral (QS) kernel based non-parametric HAC estimator on the ARMA $(1,1)$ residuals. We follow Andrews and Monahan (1992) and choose the bandwidth optimally with an AR(1) as the approximating model, and then re-colour to obtain the HAC standard errors of the $\mathrm{CW}_{t+h}$ sequence. 

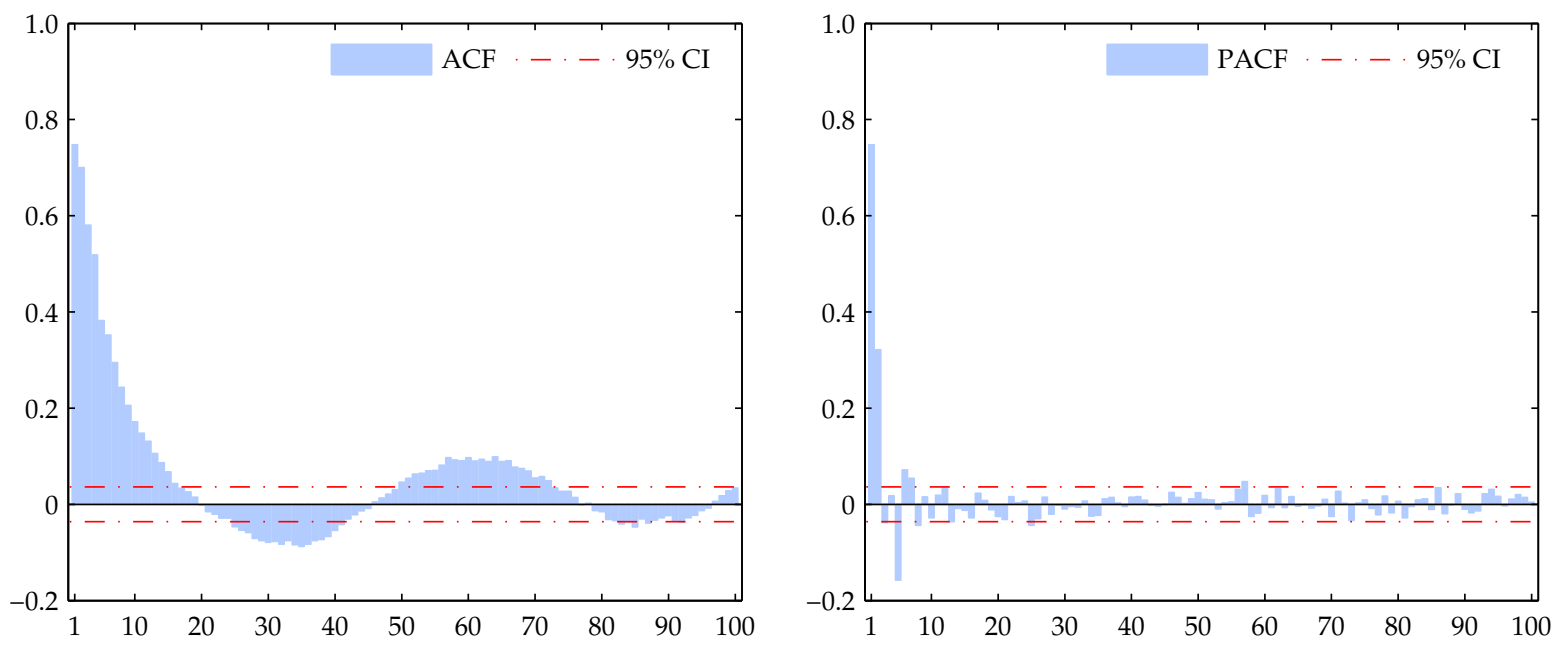

(a) $\mathrm{CW}_{t+22}$ sequence
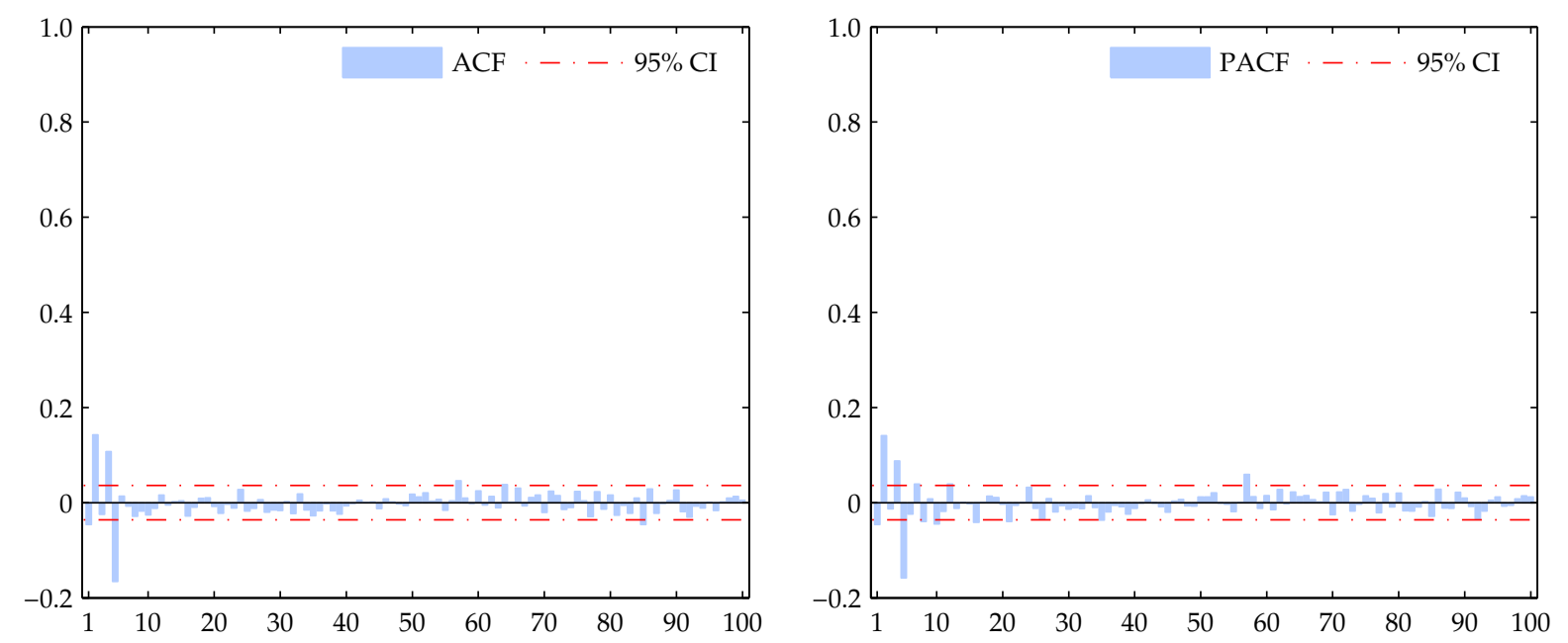

(b) Residuals from $\operatorname{ARMA}(1,1)$ fitted $\mathrm{CW}_{t+22}$

Figure 5: $A C F$ and PACF plots of the (22-day-ahead) $\mathrm{CW}_{t+22}$ sequence and the residuals from an $\operatorname{ARMA}(1,1)$ fit. 


\section{Appendix for: \\ 'Global Equity Market Volatility Spillovers: \\ A Broader Role for the United States'}

\section{A.1. Robustness checks}

This appendix provides tables and figures for a number of robustness checks that we discuss in Section 5 of the paper. In particular, we address robustness concerns related to questions about:

(a) varying the size of the in-sample period,

(b) the choice of U.S. headline index used, and

(c) whether most of the out-of-sample forecasting power comes from the log VIX series alone.

We address each one of these concerns separately, taking the results we obtained in Table 4, Figure 4 and Table 5 as reference values to which to compare them to. The format of the tables and figures that we present below is the same as for Table 4, Figure 4 and Table 5. Due to this, we do not provide any further explanations here, but delegate all the discussions of the robustness check to Section 5 of the paper. 


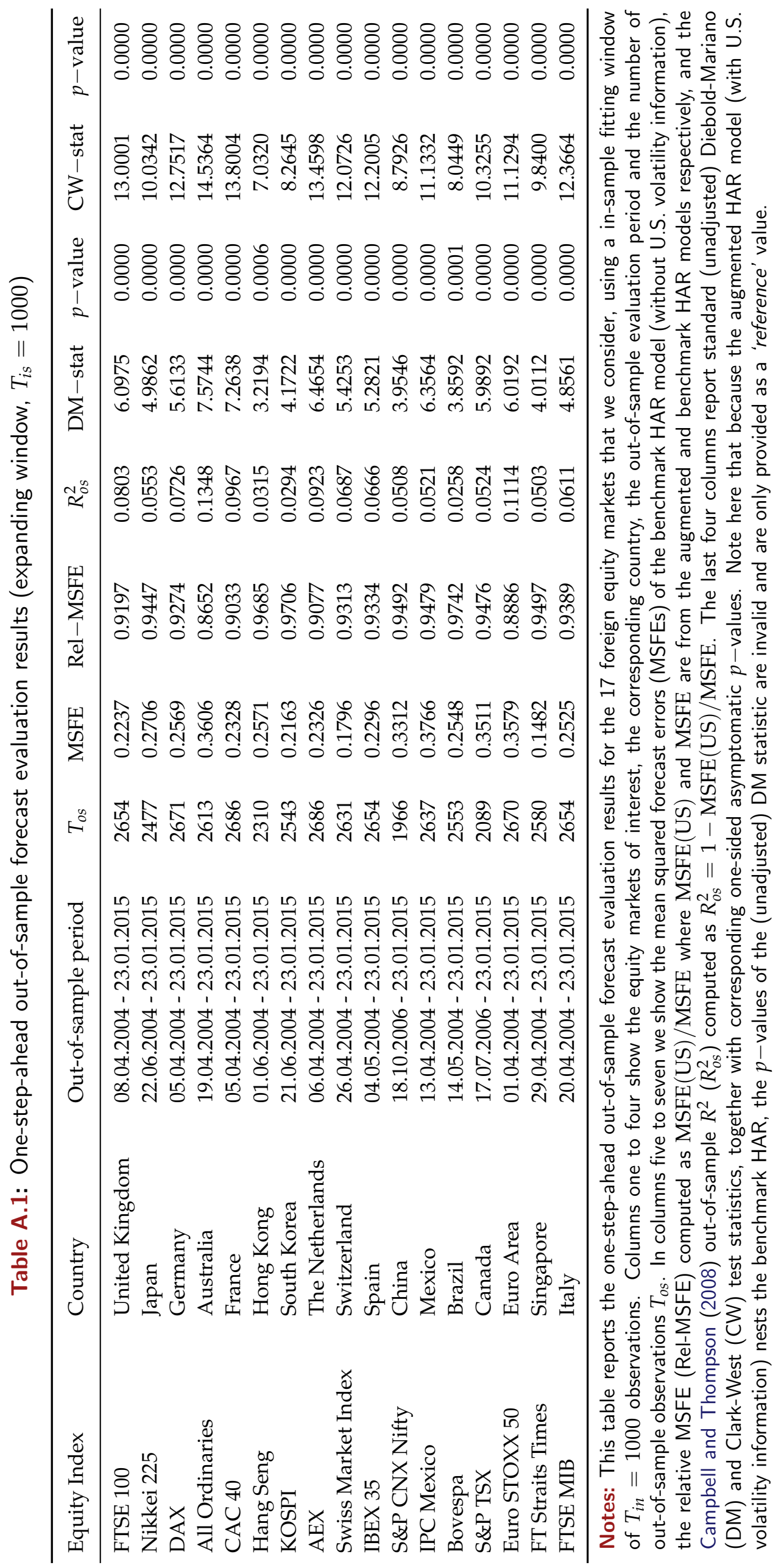


Table A.2: Multiple-step-ahead out-of-sample forecast evaluation results (expanding window, $T_{i s}=1000$ )

\begin{tabular}{|c|c|c|c|c|c|c|c|c|}
\hline Equity Index & Country & Out-of-sample period & $T_{o s}$ & MSFE & Rel-MSFE & $R_{o s}^{2}$ & CW-stat & $p$-value \\
\hline \multicolumn{9}{|c|}{ Forecast Horizon $h=5$} \\
\hline FTSE 100 & United Kingdom & 22.04.2004 - 23.01.2015 & 2646 & 0.1488 & 0.9190 & 0.0810 & 6.6817 & 0.0000 \\
\hline Nikkei 225 & Japan & $02.07 .2004-23.01 .2015$ & 2469 & 0.1804 & 0.9627 & 0.0373 & 4.2379 & 0.0000 \\
\hline DAX & Germany & 19.04.2004 - 23.01.2015 & 2663 & 0.1731 & 0.9323 & 0.0677 & 6.7052 & 0.0000 \\
\hline All Ordinaries & Australia & $29.04 .2004-23.01 .2015$ & 2605 & 0.1607 & 0.8980 & 0.1020 & 7.1018 & 0.0000 \\
\hline CAC 40 & France & $19.04 .2004-23.01 .2015$ & 2678 & 0.1573 & 0.8984 & 0.1016 & 7.7795 & 0.0000 \\
\hline Hang Seng & Hong Kong & 14.06.2004 - 23.01.2015 & 2302 & 0.1266 & 0.9589 & 0.0411 & 2.7916 & 0.0026 \\
\hline KOSPI & South Korea & $01.07 .2004-23.01 .2015$ & 2535 & 0.1432 & 0.9777 & 0.0223 & 3.0622 & 0.0011 \\
\hline AEX & The Netherlands & 20.04.2004 - 23.01.2015 & 2678 & 0.1639 & 0.9098 & 0.0902 & 7.8792 & 0.0000 \\
\hline Swiss Market Index & Switzerland & $06.05 .2004-23.01 .2015$ & 2623 & 0.1258 & 0.9394 & 0.0606 & 7.4248 & 0.0000 \\
\hline IBEX 35 & Spain & 14.05.2004 - 23.01.2015 & 2646 & 0.1597 & 0.9357 & 0.0643 & 6.2964 & 0.0000 \\
\hline S\&P CNX Nifty & China & $01.11 .2006-23.01 .2015$ & 1958 & 0.1928 & 0.9702 & 0.0298 & 4.6329 & 0.0000 \\
\hline IPC Mexico & Mexico & 23.04.2004 - 23.01.2015 & 2629 & 0.1902 & 0.9088 & 0.0912 & 6.6267 & 0.0000 \\
\hline Bovespa & Brazil & $26.05 .2004-23.01 .2015$ & 2545 & 0.1591 & 0.9703 & 0.0297 & 4.3208 & 0.0000 \\
\hline S\&P TSX & Canada & $27.07 .2006-23.01 .2015$ & 2081 & 0.2084 & 0.9321 & 0.0679 & 5.1382 & 0.0000 \\
\hline Euro STOXX 50 & Euro Area & 15.04.2004 - 23.01.2015 & 2662 & 0.2091 & 0.8805 & 0.1195 & 7.7688 & 0.0000 \\
\hline FT Straits Times & Singapore & 11.05.2004 - 23.01.2015 & 2572 & 0.0858 & 0.9512 & 0.0488 & 4.7718 & 0.0000 \\
\hline FTSE MIB & Italy & $30.04 .2004-23.01 .2015$ & 2646 & 0.1643 & 0.9531 & 0.0469 & 5.9357 & 0.0000 \\
\hline \multicolumn{9}{|c|}{ Forecast Horizon $h=10$} \\
\hline FTSE 100 & United Kingdom & 07.05.2004 - 23.01.2015 & 2636 & 0.1520 & 0.9415 & 0.0585 & 4.8078 & 0.0000 \\
\hline Nikkei 225 & Japan & $20.07 .2004-23.01 .2015$ & 2459 & 0.1796 & 0.9761 & 0.0239 & 2.5112 & 0.0060 \\
\hline DAX & Germany & 03.05.2004 - 23.01.2015 & 2653 & 0.1750 & 0.9393 & 0.0607 & 4.9850 & 0.0000 \\
\hline All Ordinaries & Australia & 13.05.2004 - 23.01.2015 & 2595 & 0.1567 & 0.9283 & 0.0717 & 4.6065 & 0.0000 \\
\hline CAC 40 & France & 03.05.2004 - 23.01.2015 & 2668 & 0.1644 & 0.9112 & 0.0888 & 5.6382 & 0.0000 \\
\hline Hang Seng & Hong Kong & $29.06 .2004-23.01 .2015$ & 2292 & 0.1187 & 0.9636 & 0.0364 & 2.2451 & 0.0124 \\
\hline KOSPI & South Korea & 16.07.2004 - 23.01.2015 & 2525 & 0.1422 & 0.9795 & 0.0205 & 2.0910 & 0.0183 \\
\hline AEX & The Netherlands & 04.05.2004 - 23.01.2015 & 2668 & 0.1743 & 0.9194 & 0.0806 & 5.6694 & 0.0000 \\
\hline Swiss Market Index & Switzerland & 21.05.2004 - 23.01.2015 & 2613 & 0.1323 & 0.9560 & 0.0440 & 5.4769 & 0.0000 \\
\hline IBEX 35 & Spain & $28.05 .2004-23.01 .2015$ & 2636 & 0.1639 & 0.9533 & 0.0467 & 4.4353 & 0.0000 \\
\hline S\&P CNX Nifty & China & 15.11.2006 - 23.01.2015 & 1948 & 0.1856 & 1.0002 & -0.0002 & 2.3118 & 0.0104 \\
\hline IPC Mexico & Mexico & 07.05.2004 - 23.01.2015 & 2619 & 0.1765 & 0.9226 & 0.0774 & 5.2041 & 0.0000 \\
\hline Bovespa & Brazil & 14.06.2004 - 23.01.2015 & 2535 & 0.1574 & 0.9763 & 0.0237 & 3.1812 & 0.0007 \\
\hline S\&P TSX & Canada & 15.08.2006 - 23.01.2015 & 2071 & 0.2059 & 0.9269 & 0.0731 & 4.1643 & 0.0000 \\
\hline Euro STOXX 50 & Euro Area & 29.04.2004 - 23.01.2015 & 2652 & 0.2053 & 0.8992 & 0.1008 & 5.8437 & 0.0000 \\
\hline FT Straits Times & Singapore & $25.05 .2004-23.01 .2015$ & 2562 & 0.0855 & 0.9745 & 0.0255 & 3.2750 & 0.0005 \\
\hline FTSE MIB & Italy & $14.05 .2004-23.01 .2015$ & 2636 & 0.1699 & 0.9643 & 0.0357 & 4.2060 & 0.0000 \\
\hline \multicolumn{9}{|c|}{ Forecast Horizon $h=22$} \\
\hline FTSE 100 & United Kingdom & 14.06.2004 - 23.01.2015 & 2612 & 0.1735 & 0.9578 & 0.0422 & 3.6281 & 0.0001 \\
\hline Nikkei 225 & Japan & $23.08 .2004-23.01 .2015$ & 2435 & 0.2042 & 0.9897 & 0.0103 & 1.7297 & 0.0418 \\
\hline DAX & Germany & 07.06.2004 - 23.01.2015 & 2629 & 0.1982 & 0.9538 & 0.0462 & 3.7262 & 0.0001 \\
\hline All Ordinaries & Australia & $21.06 .2004-23.01 .2015$ & 2571 & 0.1737 & 0.9599 & 0.0401 & 3.0508 & 0.0011 \\
\hline CAC 40 & France & $07.06 .2004-23.01 .2015$ & 2644 & 0.1838 & 0.9189 & 0.0811 & 4.2887 & 0.0000 \\
\hline Hang Seng & Hong Kong & 04.08.2004 - 23.01.2015 & 2268 & 0.1177 & 0.9970 & 0.0030 & 1.7121 & 0.0434 \\
\hline KOSPI & South Korea & $19.08 .2004-23.01 .2015$ & 2501 & 0.1606 & 1.0032 & -0.0032 & 1.0889 & 0.1381 \\
\hline AEX & The Netherlands & 08.06.2004 - 23.01.2015 & 2644 & 0.2008 & 0.9221 & 0.0779 & 4.3126 & 0.0000 \\
\hline Swiss Market Index & Switzerland & $28.06 .2004-23.01 .2015$ & 2589 & 0.1564 & 0.9765 & 0.0235 & 3.3712 & 0.0004 \\
\hline IBEX 35 & Spain & 06.07.2004 - 23.01.2015 & 2612 & 0.1762 & 0.9584 & 0.0416 & 3.7555 & 0.0001 \\
\hline S\&P CNX Nifty & China & $20.12 .2006-23.01 .2015$ & 1924 & 0.2060 & 1.0417 & -0.0417 & -0.7100 & 0.7612 \\
\hline IPC Mexico & Mexico & 14.06.2004 - 23.01.2015 & 2595 & 0.1798 & 0.9698 & 0.0302 & 3.1998 & 0.0007 \\
\hline Bovespa & Brazil & 20.07.2004 - 23.01.2015 & 2511 & 0.1775 & 0.9827 & 0.0173 & 2.2781 & 0.0114 \\
\hline S\&P TSX & Canada & 19.09.2006 - 23.01.2015 & 2047 & 0.2238 & 0.9380 & 0.0620 & 4.3679 & 0.0000 \\
\hline Euro STOXX 50 & Euro Area & 03.06.2004 - 23.01.2015 & 2628 & 0.2156 & 0.9091 & 0.0909 & 4.6602 & 0.0000 \\
\hline FT Straits Times & Singapore & 01.07.2004 - 23.01.2015 & 2538 & 0.1074 & 0.9985 & 0.0015 & 2.0138 & 0.0220 \\
\hline FTSE MIB & Italy & $21.06 .2004-23.01 .2015$ & 2612 & 0.1866 & 0.9593 & 0.0407 & 3.0379 & 0.0012 \\
\hline
\end{tabular}

Notes: This table reports the multiple-steps-ahead out-of-sample forecast evaluation results for the 17 international equity markets that we consider, using an in-sample fitting window of $T_{i n}=1000$ observations. Forecasts for horizons $h=5,10$ and 22 are shown in the top, middle and bottom panels, respectively. The target variable is (normalised) multi-period log RV, as defined in (13). All column entries are the same as described in Table 4. The $p$-values corresponding to the CW - statistic are computed from HAC robust standard errors, where we use a pre-whitening step using an ARMA $(1,1)$ model for the $\mathrm{CW}_{t+h}$ sequence to reduce the initial autocorrelation in the series, and then apply a Quadratic Spectral (QS) kernel based non-parametric $H A C$ estimator on the $\operatorname{ARMA}(1,1)$ residuals. We follow Andrews and Monahan (1992) and choose the bandwidth optimally with an $\mathrm{AR}(1)$ as the approximating model, and then re-colour to obtain the HAC standard errors of the $\mathrm{CW}_{t+h}$ sequence. 


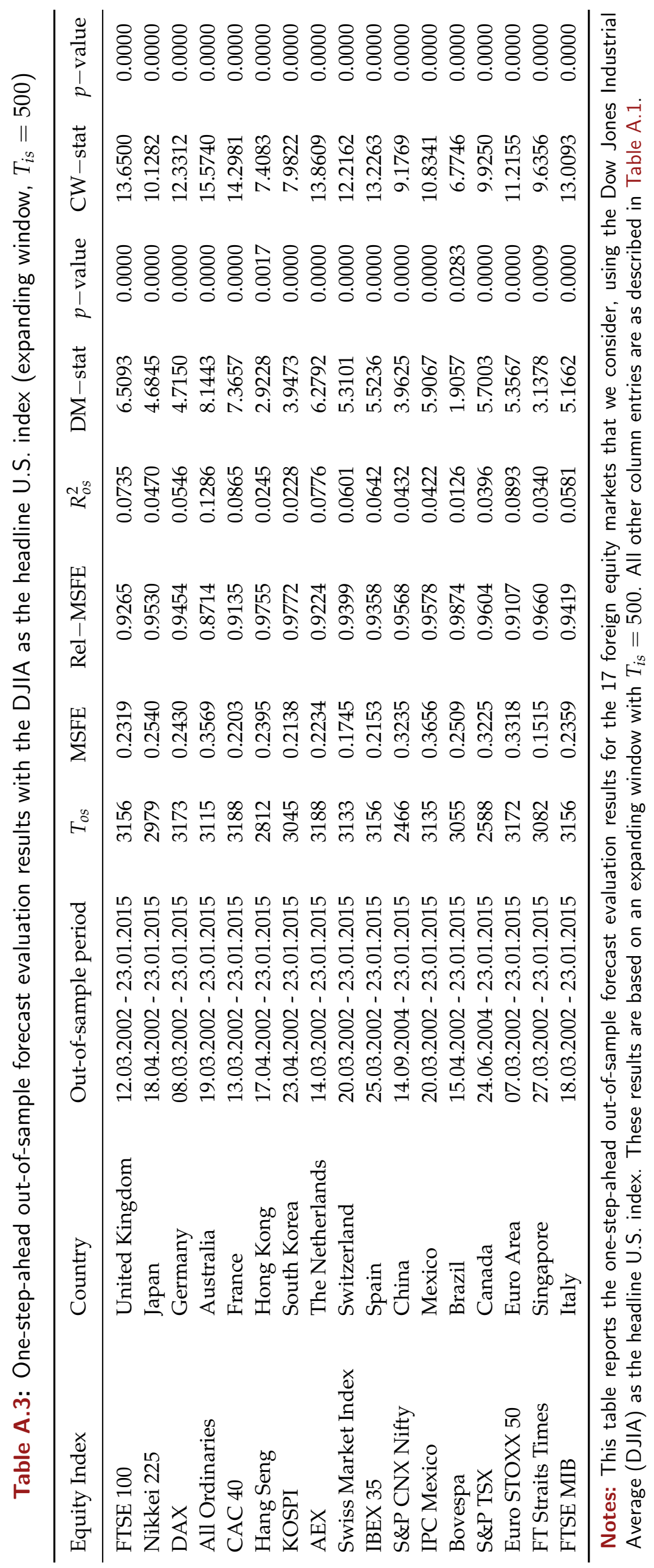



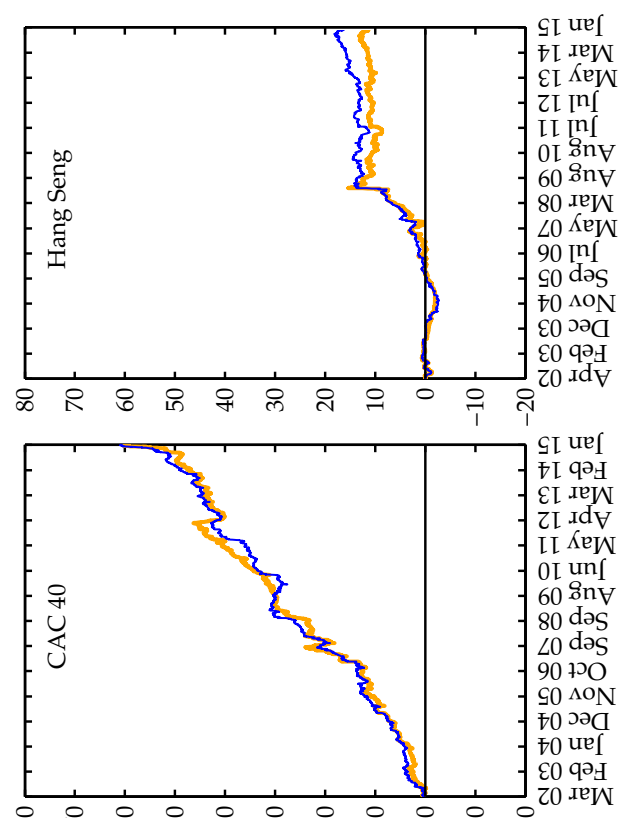

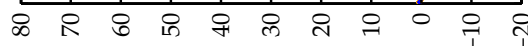

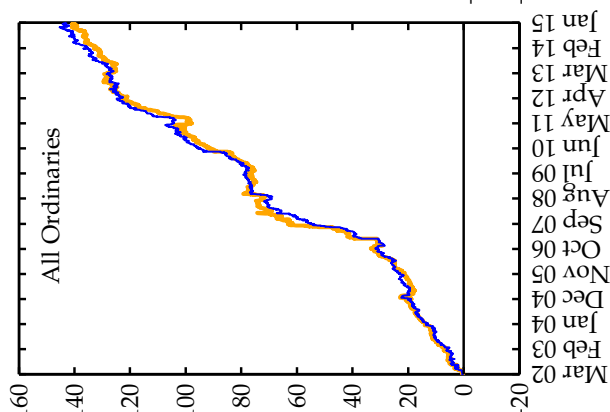

:

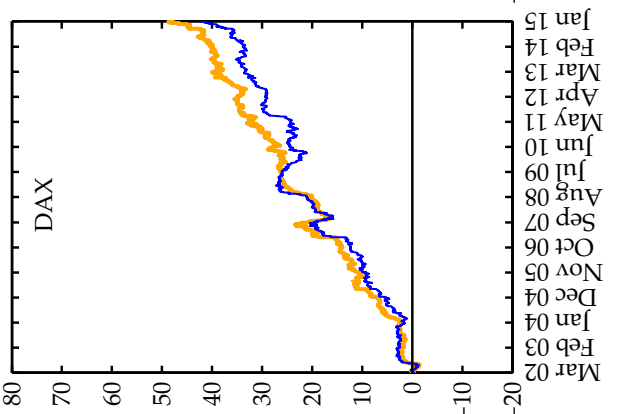

.

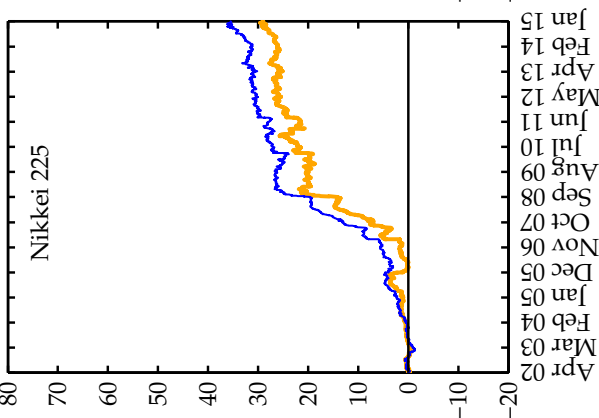

.

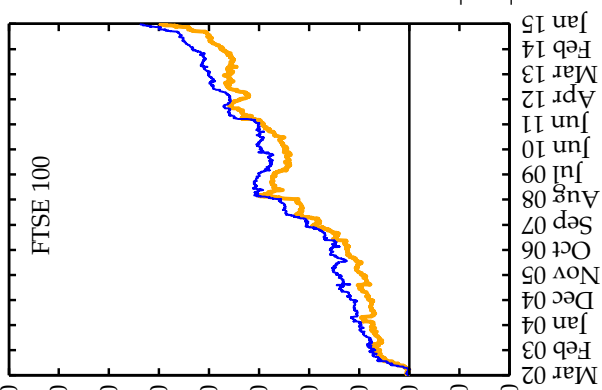

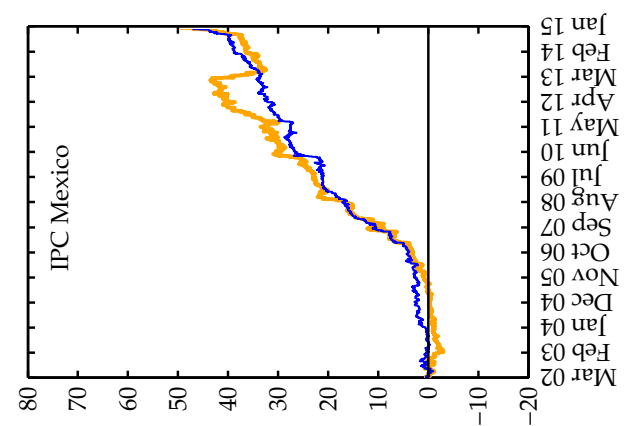
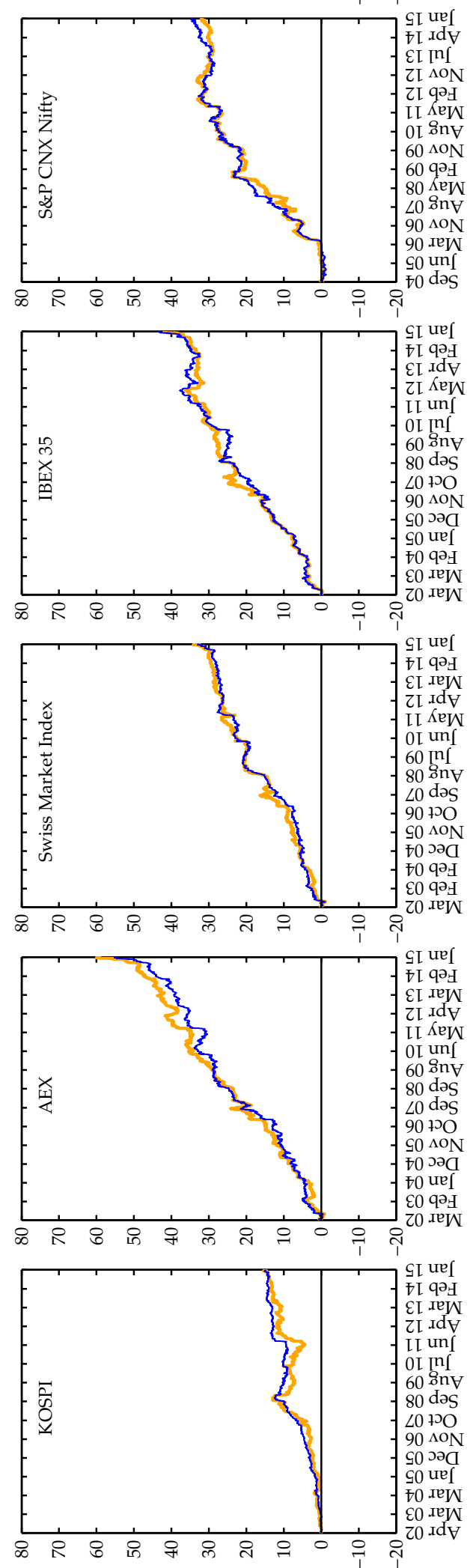
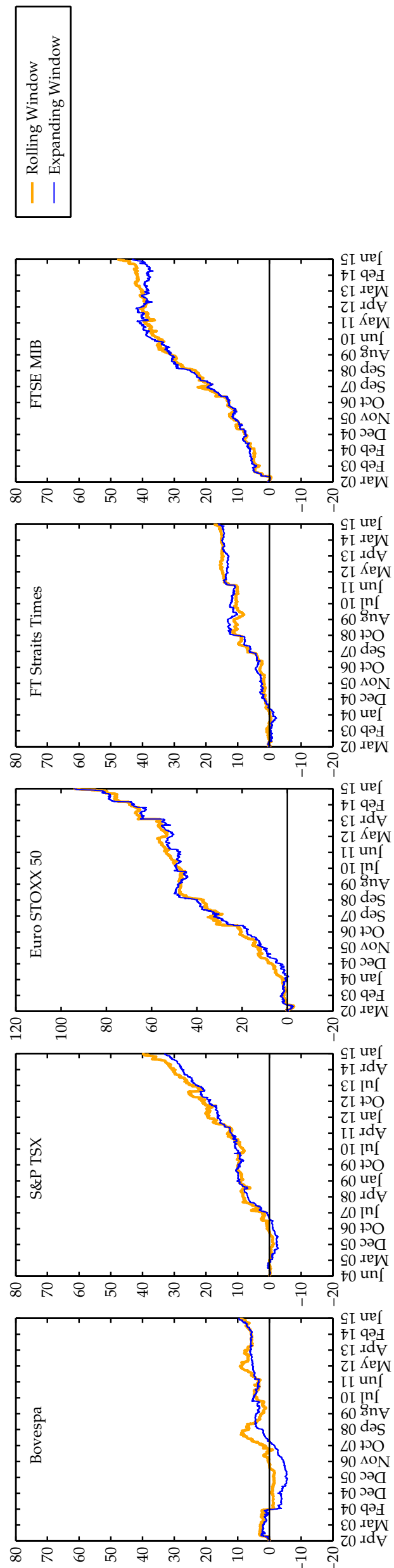
Table A.4: Multiple-step-ahead out-of-sample forecast evaluation results with the DJIA as the headline U.S. index (expanding window, $T_{i s}=500$ )

\begin{tabular}{|c|c|c|c|c|c|c|c|c|}
\hline Equity Index & Country & Out-of-sample period & $T_{o s}$ & MSFE & Rel-MSFE & $R_{o s}^{2}$ & CW-stat & $p$-value \\
\hline \multicolumn{9}{|c|}{ Forecast Horizon $h=5$} \\
\hline FTSE 100 & United Kingdom & 22.03.2002 - 23.01.2015 & 3148 & 0.1512 & 0.9134 & 0.0866 & 7.7024 & 0.0000 \\
\hline Nikkei 225 & Japan & $01.05 .2002-23.01 .2015$ & 2971 & 0.1652 & 0.9628 & 0.0372 & 4.6250 & 0.0000 \\
\hline DAX & Germany & 20.03.2002 - 23.01.2015 & 3165 & 0.1631 & 0.9370 & 0.0630 & 7.1405 & 0.0000 \\
\hline All Ordinaries & Australia & $02.04 .2002-23.01 .2015$ & 3107 & 0.1550 & 0.8846 & 0.1154 & 7.8421 & 0.0000 \\
\hline CAC 40 & France & 25.03.2002 - 23.01.2015 & 3180 & 0.1501 & 0.9010 & 0.0990 & 8.5092 & 0.0000 \\
\hline Hang Seng & Hong Kong & $29.04 .2002-23.01 .2015$ & 2804 & 0.1159 & 0.9667 & 0.0333 & 3.3887 & 0.0004 \\
\hline KOSPI & South Korea & 06.05.2002 - 23.01.2015 & 3037 & 0.1397 & 0.9831 & 0.0169 & 3.2560 & 0.0006 \\
\hline AEX & The Netherlands & 26.03.2002 - 23.01.2015 & 3180 & 0.1587 & 0.9143 & 0.0857 & 8.5884 & 0.0000 \\
\hline Swiss Market & Switzerland & 03.04.2002 - 23.01.2015 & 3125 & 0.1232 & 0.9424 & 0.0576 & 7.1517 & 0.0000 \\
\hline IBEX 35 & Spain & 08.04.2002 - 23.01.2015 & 3148 & 0.1485 & 0.9293 & 0.0707 & 7.3319 & 0.0000 \\
\hline S\&P CNX Nifty & China & 24.09.2004 - 23.01.2015 & 2458 & 0.1915 & 0.9770 & 0.0230 & 4.6423 & 0.0000 \\
\hline IPC Mexico & Mexico & $04.04 .2002-23.01 .2015$ & 3127 & 0.1797 & 0.9219 & 0.0781 & 6.5740 & 0.0000 \\
\hline Bovespa & Brazil & 25.04.2002 - 23.01.2015 & 3047 & 0.1527 & 0.9985 & 0.0015 & 2.6412 & 0.0041 \\
\hline S\&P TSX & Canada & 08.07.2004 - 23.01.2015 & 2580 & 0.1878 & 0.9508 & 0.0492 & 4.7674 & 0.0000 \\
\hline Euro STOXX 50 & Euro Area & 19.03.2002 - 23.01.2015 & 3164 & 0.1965 & 0.8951 & 0.1049 & 8.2864 & 0.0000 \\
\hline FT Straits Times & Singapore & 09.04.2002 - 23.01.2015 & 3074 & 0.0848 & 0.9632 & 0.0368 & 5.1794 & 0.0000 \\
\hline FTSE MIB & Italy & 28.03.2002 - 23.01.2015 & 3148 & 0.1527 & 0.9440 & 0.0560 & 6.9509 & 0.0000 \\
\hline \multicolumn{9}{|c|}{ Forecast Horizon $h=10$} \\
\hline FTSE 100 & United Kingdom & $09.04 .2002-23.01 .2015$ & 3138 & 0.1561 & 0.9325 & 0.0675 & 5.7978 & 0.0000 \\
\hline Nikkei 225 & Japan & 17.05.2002 - 23.01.2015 & 2961 & 0.1636 & 0.9731 & 0.0269 & 2.9923 & 0.0014 \\
\hline DAX & Germany & 05.04.2002 - 23.01.2015 & 3155 & 0.1677 & 0.9455 & 0.0545 & 5.2444 & 0.0000 \\
\hline All Ordinaries & Australia & $16.04 .2002-23.01 .2015$ & 3097 & 0.1506 & 0.9090 & 0.0910 & 5.3433 & 0.0000 \\
\hline CAC 40 & France & 10.04.2002 - 23.01.2015 & 3170 & 0.1589 & 0.9151 & 0.0849 & 6.1221 & 0.0000 \\
\hline Hang Seng & Hong Kong & 14.05.2002 - 23.01.2015 & 2794 & 0.1066 & 0.9727 & 0.0273 & 3.1015 & 0.0010 \\
\hline KOSPI & South Korea & 20.05.2002 - 23.01.2015 & 3027 & 0.1403 & 0.9883 & 0.0117 & 2.6254 & 0.0043 \\
\hline AEX & The Netherlands & 11.04.2002 - 23.01.2015 & 3170 & 0.1710 & 0.9253 & 0.0747 & 6.1551 & 0.0000 \\
\hline Swiss Market & Switzerland & 17.04.2002 - 23.01.2015 & 3115 & 0.1330 & 0.9641 & 0.0359 & 4.9431 & 0.0000 \\
\hline IBEX 35 & Spain & 22.04.2002 - 23.01.2015 & 3138 & 0.1544 & 0.9474 & 0.0526 & 5.2380 & 0.0000 \\
\hline S\&P CNX Nifty & China & 08.10.2004 - 23.01.2015 & 2448 & 0.1843 & 1.0140 & -0.0140 & 2.0704 & 0.0192 \\
\hline IPC Mexico & Mexico & 18.04.2002 - 23.01.2015 & 3117 & 0.1639 & 0.9341 & 0.0659 & 5.0547 & 0.0000 \\
\hline Bovespa & Brazil & 10.05.2002 - 23.01.2015 & 3037 & 0.1500 & 1.0157 & -0.0157 & 1.6341 & 0.0511 \\
\hline S\&P TSX & Canada & 22.07.2004 - 23.01.2015 & 2570 & 0.1849 & 0.9525 & 0.0475 & 3.7030 & 0.0001 \\
\hline Euro STOXX 50 & Euro Area & $04.04 .2002-23.01 .2015$ & 3154 & 0.1968 & 0.9130 & 0.0870 & 6.0757 & 0.0000 \\
\hline FT Straits Times & Singapore & 23.04.2002 - 23.01.2015 & 3064 & 0.0819 & 0.9865 & 0.0135 & 3.7626 & 0.0001 \\
\hline FTSE MIB & Italy & 15.04.2002 - 23.01.2015 & 3138 & 0.1596 & 0.9565 & 0.0435 & 4.8612 & 0.0000 \\
\hline \multicolumn{9}{|c|}{ Forecast Horizon $h=22$} \\
\hline FTSE 100 & United Kingdom & 14.05.2002 - 23.01.2015 & 3114 & 0.1846 & 0.9507 & 0.0493 & 4.1991 & 0.0000 \\
\hline Nikkei 225 & Japan & 21.06.2002 - 23.01.2015 & 2937 & 0.1851 & 0.9854 & 0.0146 & 2.0930 & 0.0182 \\
\hline DAX & Germany & 10.05.2002 - 23.01.2015 & 3131 & 0.1982 & 0.9674 & 0.0326 & 3.6080 & 0.0002 \\
\hline All Ordinaries & Australia & 21.05.2002 - 23.01.2015 & 3073 & 0.1637 & 0.9455 & 0.0545 & 3.7986 & 0.0001 \\
\hline CAC 40 & France & 15.05.2002 - 23.01.2015 & 3146 & 0.1861 & 0.9338 & 0.0662 & 4.3669 & 0.0000 \\
\hline Hang Seng & Hong Kong & 19.06.2002 - 23.01.2015 & 2770 & 0.1070 & 1.0076 & -0.0076 & 1.9688 & 0.0245 \\
\hline KOSPI & South Korea & $26.06 .2002-23.01 .2015$ & 3003 & 0.1588 & 1.0232 & -0.0232 & 0.4935 & 0.3108 \\
\hline AEX & The Netherlands & 16.05.2002 - 23.01.2015 & 3146 & 0.2053 & 0.9432 & 0.0568 & 4.1057 & 0.0000 \\
\hline Swiss Market & Switzerland & $22.05 .2002-23.01 .2015$ & 3091 & 0.1673 & 1.0073 & -0.0073 & 2.4817 & 0.0065 \\
\hline IBEX 35 & Spain & 28.05.2002 - 23.01.2015 & 3114 & 0.1723 & 0.9584 & 0.0416 & 4.2116 & 0.0000 \\
\hline S\&P CNX Nifty & China & 19.11.2004 - 23.01.2015 & 2424 & 0.2024 & 1.0580 & -0.0580 & -0.5556 & 0.7108 \\
\hline IPC Mexico & Mexico & 23.05.2002 - 23.01.2015 & 3093 & 0.1667 & 0.9753 & 0.0247 & 2.5722 & 0.0051 \\
\hline Bovespa & Brazil & 17.06.2002 - 23.01.2015 & 3013 & 0.1666 & 1.0329 & -0.0329 & 1.0865 & 0.1386 \\
\hline S\&P TSX & Canada & $26.08 .2004-23.01 .2015$ & 2546 & 0.2010 & 0.9737 & 0.0263 & 2.9856 & 0.0014 \\
\hline Euro STOXX 50 & Euro Area & 09.05.2002 - 23.01.2015 & 3130 & 0.2173 & 0.9338 & 0.0662 & 4.5721 & 0.0000 \\
\hline FT Straits Times & Singapore & 29.05.2002 - 23.01.2015 & 3040 & 0.0979 & 1.0162 & -0.0162 & 2.3942 & 0.0083 \\
\hline FTSE MIB & Italy & 20.05.2002 - 23.01.2015 & 3114 & 0.1808 & 0.9656 & 0.0344 & 3.0554 & 0.0011 \\
\hline
\end{tabular}

Notes: This table reports the multiple-steps-ahead out-of-sample forecast evaluation results for the 17 international equity markets that we consider, using the Dow Jones Industrial Average (DJIA) as the headline U.S. index. These results are based on an expanding window with $T_{i s}=500$. All other column entries are as described in Table A. 2 . 


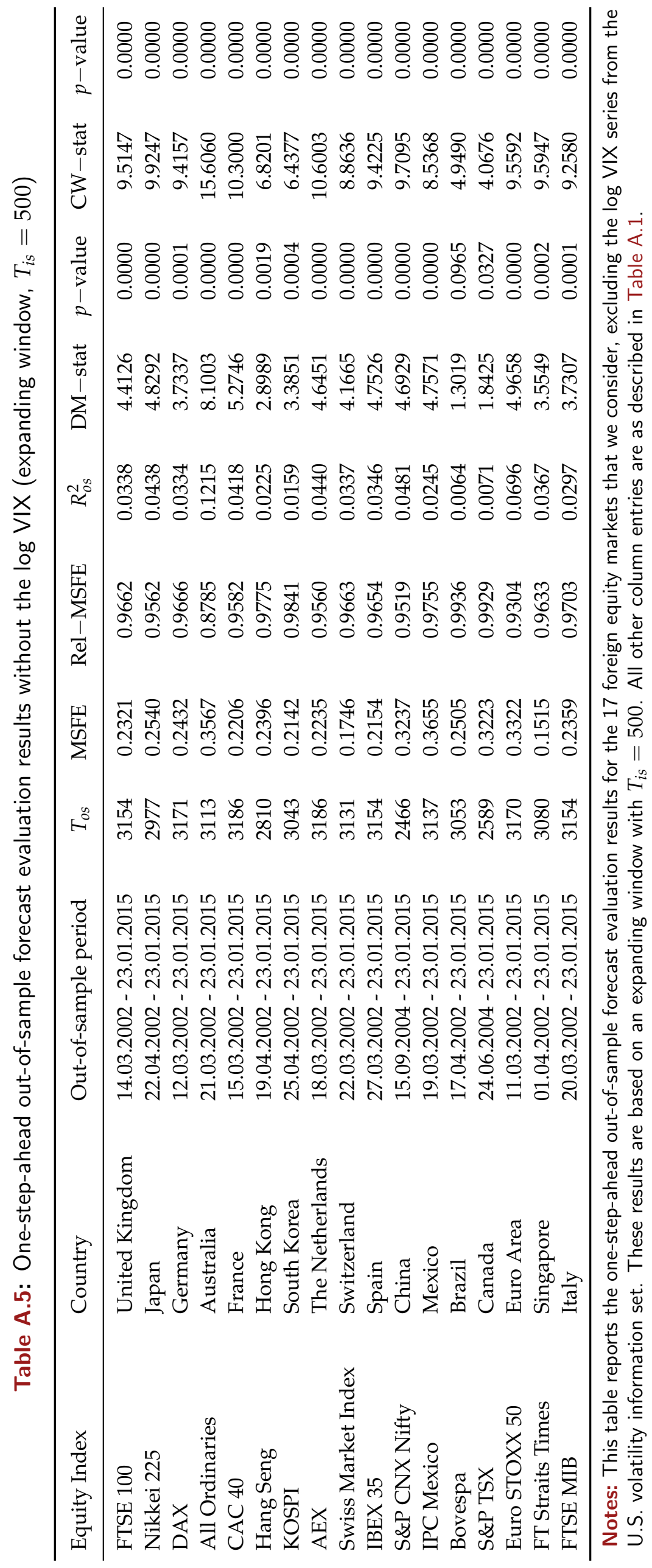



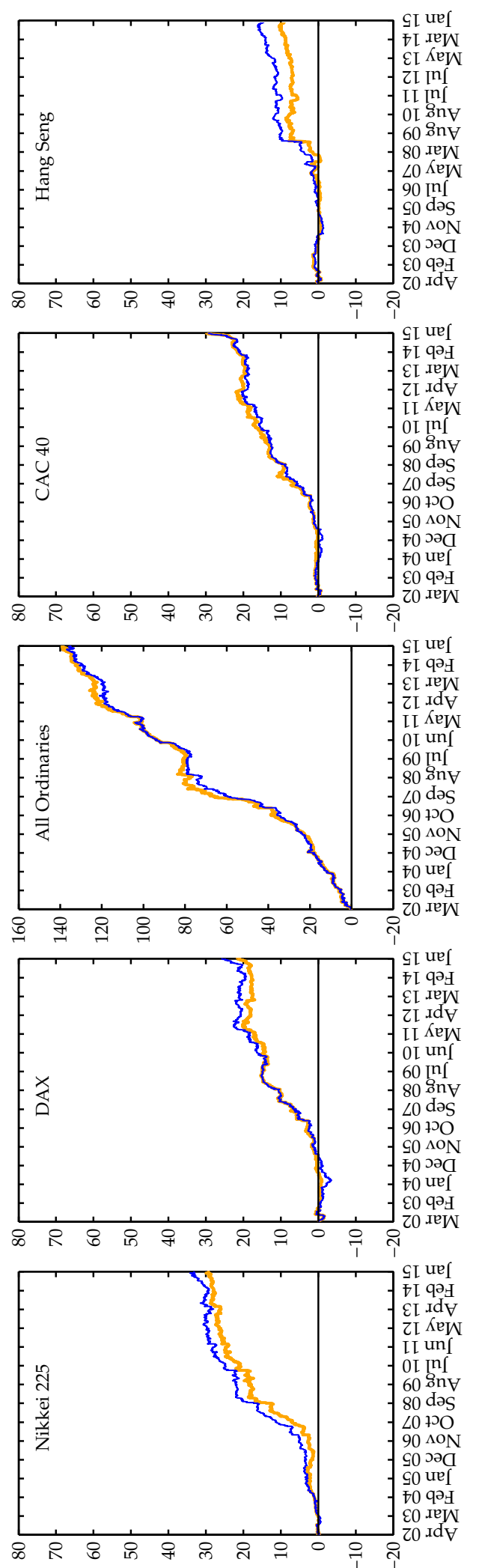

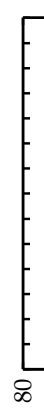

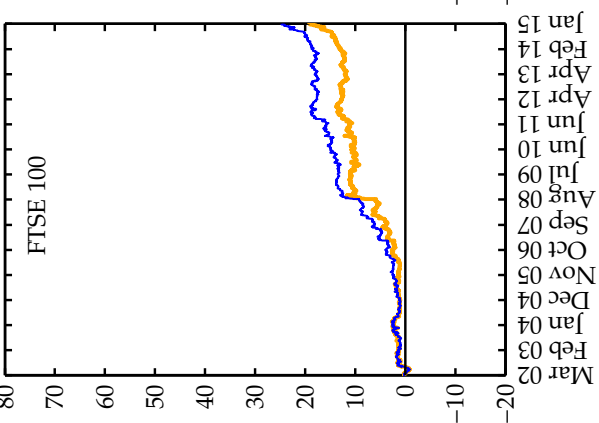

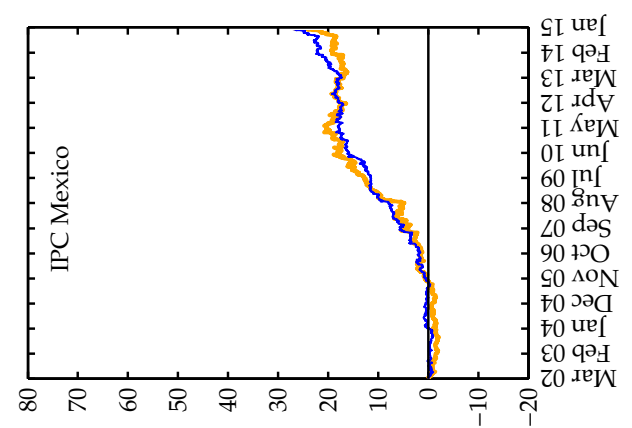
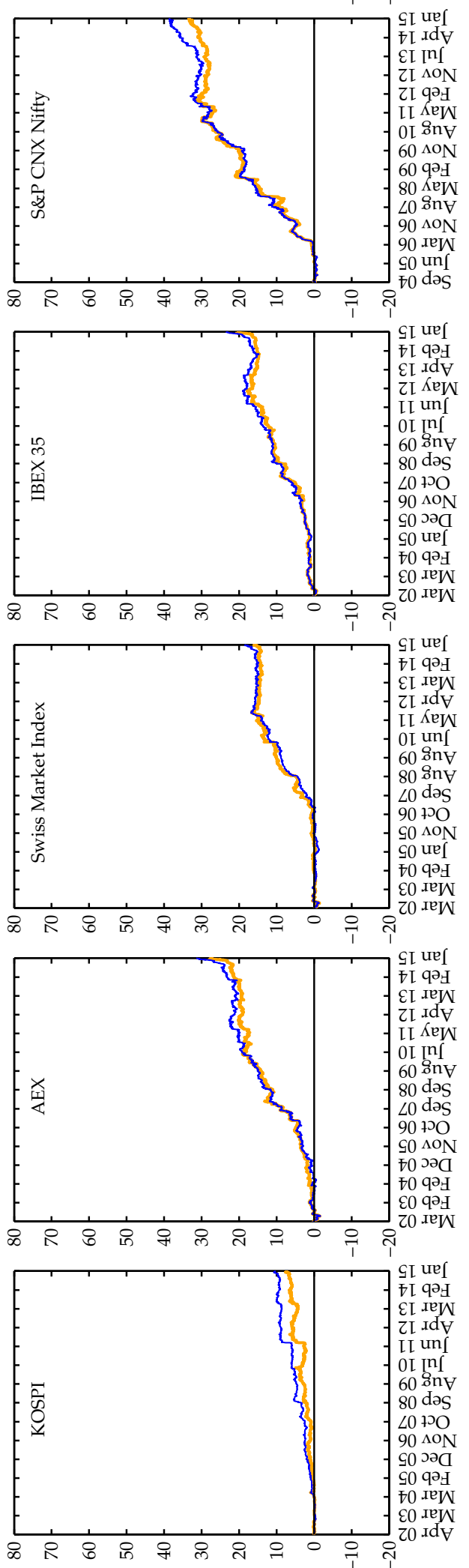
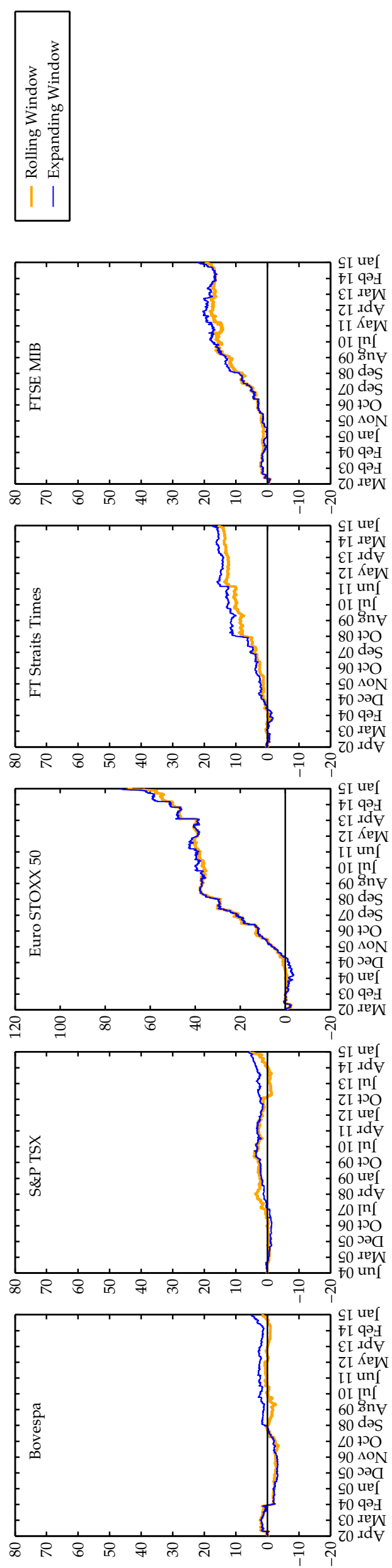
Table A.6: Multiple-step-ahead out-of-sample forecast evaluation results without the log VIX (expanding window, $\left.T_{\text {is }}=500\right)$

\begin{tabular}{|c|c|c|c|c|c|c|c|c|}
\hline Equity Index & Country & Out-of-sample period & $T_{o s}$ & MSFE & Rel-MSFE & $R_{o s}^{2}$ & CW-stat & $p$-value \\
\hline \multicolumn{9}{|c|}{ Forecast Horizon $h=5$} \\
\hline FTSE 100 & United Kingdom & 26.03.2002 - 23.01.2015 & 3146 & 0.1512 & 0.9760 & 0.0240 & 4.2863 & 0.0000 \\
\hline Nikkei 225 & Japan & 07.05.2002 - 23.01.2015 & 2969 & 0.1652 & 0.9667 & 0.0333 & 4.3560 & 0.0000 \\
\hline DAX & Germany & $22.03 .2002-23.01 .2015$ & 3163 & 0.1632 & 0.9806 & 0.0194 & 4.9447 & 0.0000 \\
\hline All Ordinaries & Australia & 04.04.2002 - 23.01.2015 & 3105 & 0.1549 & 0.9075 & 0.0925 & 7.5466 & 0.0000 \\
\hline CAC 40 & France & 27.03.2002 - 23.01.2015 & 3178 & 0.1502 & 0.9718 & 0.0282 & 5.4893 & 0.0000 \\
\hline Hang Seng & Hong Kong & 02.05.2002 - 23.01.2015 & 2802 & 0.1159 & 0.9717 & 0.0283 & 3.1169 & 0.0009 \\
\hline KOSPI & South Korea & 08.05.2002 - 23.01.2015 & 3035 & 0.1401 & 0.9846 & 0.0154 & 2.4863 & 0.0065 \\
\hline AEX & The Netherlands & 28.03.2002 - 23.01.2015 & 3178 & 0.1587 & 0.9709 & 0.0291 & 6.1102 & 0.0000 \\
\hline Swiss Market & Switzerland & 05.04.2002 - 23.01.2015 & 3123 & 0.1233 & 0.9783 & 0.0217 & 5.0180 & 0.0000 \\
\hline IBEX 35 & Spain & $10.04 .2002-23.01 .2015$ & 3146 & 0.1486 & 0.9774 & 0.0226 & 4.9584 & 0.0000 \\
\hline S\&P CNX Nifty & China & 27.09.2004 - 23.01.2015 & 2458 & 0.1914 & 0.9754 & 0.0246 & 4.8448 & 0.0000 \\
\hline IPC Mexico & Mexico & $03.04 .2002-23.01 .2015$ & 3129 & 0.1797 & 0.9532 & 0.0468 & 6.1290 & 0.0000 \\
\hline Bovespa & Brazil & $29.04 .2002-23.01 .2015$ & 3045 & 0.1527 & 0.9993 & 0.0007 & 2.0725 & 0.0191 \\
\hline S\&P TSX & Canada & $08.07 .2004-23.01 .2015$ & 2581 & 0.1877 & 0.9966 & 0.0034 & 2.0157 & 0.0219 \\
\hline Euro STOXX 50 & Euro Area & 21.03.2002 - 23.01.2015 & 3162 & 0.1966 & 0.9539 & 0.0461 & 5.7474 & 0.0000 \\
\hline FT Straits Times & Singapore & $11.04 .2002-23.01 .2015$ & 3072 & 0.0848 & 0.9601 & 0.0399 & 4.7579 & 0.0000 \\
\hline FTSE MIB & Italy & $03.04 .2002-23.01 .2015$ & 3146 & 0.1528 & 0.9826 & 0.0174 & 4.6106 & 0.0000 \\
\hline \multicolumn{9}{|c|}{ Forecast Horizon $h=10$} \\
\hline FTSE 100 & United Kingdom & 11.04.2002 - 23.01.2015 & 3136 & 0.1562 & 0.9905 & 0.0095 & 2.5394 & 0.0056 \\
\hline Nikkei 225 & Japan & $21.05 .2002-23.01 .2015$ & 2959 & 0.1638 & 0.9719 & 0.0281 & 2.6953 & 0.0035 \\
\hline DAX & Germany & 09.04.2002 - 23.01.2015 & 3153 & 0.1679 & 0.9906 & 0.0094 & 2.9690 & 0.0015 \\
\hline All Ordinaries & Australia & $18.04 .2002-23.01 .2015$ & 3095 & 0.1506 & 0.9308 & 0.0692 & 4.9894 & 0.0000 \\
\hline CAC 40 & France & $12.04 .2002-23.01 .2015$ & 3168 & 0.1591 & 0.9844 & 0.0156 & 3.0802 & 0.0010 \\
\hline Hang Seng & Hong Kong & 16.05.2002 - 23.01.2015 & 2792 & 0.1067 & 0.9769 & 0.0231 & 2.4508 & 0.0071 \\
\hline KOSPI & South Korea & $22.05 .2002-23.01 .2015$ & 3025 & 0.1405 & 0.9867 & 0.0133 & 1.6680 & 0.0477 \\
\hline AEX & The Netherlands & 15.04.2002 - 23.01.2015 & 3168 & 0.1710 & 0.9851 & 0.0149 & 3.2083 & 0.0007 \\
\hline Swiss Market & Switzerland & $19.04 .2002-23.01 .2015$ & 3113 & 0.1332 & 1.0015 & -0.0015 & 2.3612 & 0.0091 \\
\hline IBEX 35 & Spain & $24.04 .2002-23.01 .2015$ & 3136 & 0.1544 & 0.9924 & 0.0076 & 2.6852 & 0.0036 \\
\hline S\&P CNX Nifty & China & $11.10 .2004-23.01 .2015$ & 2448 & 0.1842 & 1.0070 & -0.0070 & 1.9569 & 0.0252 \\
\hline IPC Mexico & Mexico & 17.04.2002 - 23.01.2015 & 3119 & 0.1639 & 0.9658 & 0.0342 & 4.2577 & 0.0000 \\
\hline Bovespa & Brazil & $14.05 .2002-23.01 .2015$ & 3035 & 0.1499 & 1.0077 & -0.0077 & 1.4367 & 0.0754 \\
\hline S\&P TSX & Canada & $22.07 .2004-23.01 .2015$ & 2571 & 0.1848 & 0.9978 & 0.0022 & 1.5415 & 0.0616 \\
\hline Euro STOXX 50 & Euro Area & $08.04 .2002-23.01 .2015$ & 3152 & 0.1969 & 0.9799 & 0.0201 & 3.2804 & 0.0005 \\
\hline FT Straits Times & Singapore & 25.04.2002 - 23.01.2015 & 3062 & 0.0820 & 0.9761 & 0.0239 & 3.0838 & 0.0010 \\
\hline FTSE MIB & Italy & 17.04.2002 - 23.01.2015 & 3136 & 0.1597 & 0.9953 & 0.0047 & 2.2742 & 0.0115 \\
\hline \multicolumn{9}{|c|}{ Forecast Horizon $h=22$} \\
\hline FTSE 100 & United Kingdom & $16.05 .2002-23.01 .2015$ & 3112 & 0.1847 & 0.9916 & 0.0084 & 1.8369 & 0.0331 \\
\hline Nikkei 225 & Japan & $25.06 .2002-23.01 .2015$ & 2935 & 0.1854 & 0.9730 & 0.0270 & 1.8152 & 0.0347 \\
\hline DAX & Germany & $14.05 .2002-23.01 .2015$ & 3129 & 0.1986 & 1.0022 & -0.0022 & 1.5986 & 0.0550 \\
\hline All Ordinaries & Australia & 23.05.2002 - 23.01.2015 & 3071 & 0.1638 & 0.9555 & 0.0445 & 3.4952 & 0.0002 \\
\hline CAC 40 & France & $17.05 .2002-23.01 .2015$ & 3144 & 0.1864 & 0.9855 & 0.0145 & 2.3000 & 0.0107 \\
\hline Hang Seng & Hong Kong & 21.06.2002 - 23.01.2015 & 2768 & 0.1070 & 1.0083 & -0.0083 & 1.4263 & 0.0769 \\
\hline KOSPI & South Korea & $28.06 .2002-23.01 .2015$ & 3001 & 0.1589 & 1.0091 & -0.0091 & 0.5089 & 0.3054 \\
\hline AEX & The Netherlands & 20.05.2002 - 23.01.2015 & 3144 & 0.2055 & 0.9935 & 0.0065 & 1.7521 & 0.0399 \\
\hline Swiss Market & Switzerland & $24.05 .2002-23.01 .2015$ & 3089 & 0.1677 & 1.0332 & -0.0332 & 0.0742 & 0.4704 \\
\hline IBEX 35 & Spain & 30.05.2002 - 23.01.2015 & 3112 & 0.1723 & 0.9924 & 0.0076 & 2.2931 & 0.0109 \\
\hline S\&P CNX Nifty & China & $22.11 .2004-23.01 .2015$ & 2424 & 0.2022 & 1.0380 & -0.0380 & -0.4001 & 0.6555 \\
\hline IPC Mexico & Mexico & $22.05 .2002-23.01 .2015$ & 3095 & 0.1666 & 0.9943 & 0.0057 & 2.3144 & 0.0103 \\
\hline Bovespa & Brazil & 19.06.2002 - 23.01.2015 & 3011 & 0.1667 & 1.0128 & -0.0128 & 1.0761 & 0.1409 \\
\hline S\&P TSX & Canada & 26.08.2004 - 23.01.2015 & 2547 & 0.2010 & 0.9971 & 0.0029 & 1.2454 & 0.1065 \\
\hline Euro STOXX 50 & Euro Area & 13.05.2002 - 23.01.2015 & 3128 & 0.2176 & 0.9947 & 0.0053 & 2.0417 & 0.0206 \\
\hline FT Straits Times & Singapore & $31.05 .2002-23.01 .2015$ & 3038 & 0.0980 & 0.9911 & 0.0089 & 1.8962 & 0.0290 \\
\hline FTSE MIB & Italy & $22.05 .2002-23.01 .2015$ & 3112 & 0.1810 & 1.0011 & -0.0011 & 1.1960 & 0.1159 \\
\hline
\end{tabular}

Notes: This table reports the multiple-steps-ahead out-of-sample forecast evaluation results for the 17 international equity markets that we consider, excluding the log VIX series from the U.S. volatility information set. These results are based on an expanding window with $T_{i s}=500$. All other column entries are as described in Table A.2. 